\title{
Structural Fire Design of Thin Walled Steel Sections
}

\author{
by \\ Anders Ranby
}




\section{STRUCTURAL FIRE DESIGN OF THIN WALLED STEEL SECTIONS}

ANDERS RANBY

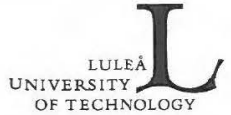

Department of Civil and Mining Engineering Division of Steel Structures

LTU - LIC - 99/05

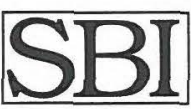

STÅLBYGGNADSINSTITUTET

Swedish Institute of Steel Construction Report 188:5, 1999 


\section{PREFACE}

The work described in this thesis has been carried out at the Swedish Institute of Steel Construction and the Division of Steel Structures, Luleå University of Technology during the period January 1995 - December 1998.

The thesis deals with two different topics, first to get an idea of the temperature development in light steel framed walls and second to describe the different phenomena governing the failure of thin walled steel sections at elevated temperature. With this knowledge a design model of the load bearing resistance of thin walled steel sections at elevated temperature is proposed.

The work was financially supported by the Swedish Fire Research Board, SSAB Tunnplåt $\mathrm{AB}$, Plannja $\mathrm{AB}$, Gasell Profil $\mathrm{AB}$, Lindab Profil AB, Gyproc Group $\mathrm{AB}$ and Knauf Danogips A/S.

I would like to thank my supervisor professor Bernt Johansson for his supportive guidance and M.Sc. Patrik Jansson for helping me with the software of Ansys. I would also like to thank Ph.D. Milan Veljkovic for his most excellent and encouraging guidance with the analyses of Abaqus. His dedicated commitment, his skills and his ability to always solve my problems have been of greatest importance to me.

Further, I would like to thank the Directors Mikael Nyquist and Johan Anderson at the Institute during the period, giving me the opportunity to get the licentiate exam and lastly many thanks to my dear wife Annika.

Stockholm, February 1999

Anders Ranby 


\section{ABSTRACT}

New design solutions have to be developed that can fulfil higher requirements to building quality, environment and total economy. A load bearing structure of thin walled steel sections has the possibility to fulfil these requirements and therefore, there is a growing interest in using such structures in both apartment blocks and residential houses. New design methods and products have resulted in environmental steel frame buildings with high U-values and good sound insulation.

The aim of this thesis is to study the structural fire behaviour of thin walled steel sections; to find the actual steel temperature; how it varies across the steel sections and the phenomena of local buckling at elevated steel temperatures. The flexural buckling and torsional-flexural buckling load bearing resistances have also been studied. By using this information a method to design thin walled steel columns at elevated temperature has been developed.

When calculating the load bearing resistance of thin walled steel columns at elevated temperatures, it is necessary to know the actual distribution of steel temperatures. This has been solved by using the software of Super-Tasef. The temperature calculation results have been verified by comparison to different tests. Results show that the agreement is quite acceptable.

The phenomena of initial deflections and local plate buckling resistance at elevated steel temperatures are described and estimated by a theory of Nylander. Different empirical estimates show that the results are fairly consistent. The resistance is numerically estimated by an $\mathrm{FE}$ analysis, using a non-linear solution procedure. The numerical analysis shows results rather in accordance with the empirical solutions. These results have also been verified by comparisons to tests.

The load bearing resistance of thin walled steel columns depends on local and global buckling, including flexural and torsional-flexural buckling. Calculations have been done according to StBK-N5, Swedish Code for Light-Gauge Metal Structures and Eurocode 3, part 1-3. Equivalent numerical calculations have then been done using FE analysis. These results have been verified by tests as well. 
The effects of a temperature gradient across the section and different kind of bracing have been studied as well, modelling that the bracing gypsum layer is lost after the calcination process. The deflection due to uneven temperature has to be calculated and introduced into the verification of global buckling.

Since the yield strength and modulus of elasticity decrease with the temperature, the load bearing resistance decreases too. The axial deformations increase with the temperature. In both the empirical estimations and the numerical analysis the yield point and modulus of elasticity have been reduced with regard to the temperature. The reduced values were taken from Eurocode 3, part 1-2. However, the yield strength is defined as the stress at a plastic strain of 0,2 per cent. The results show that the resistance can be calculated with the same methods under both normal room temperatures and at elevated temperatures in case of fire. Calculations of the ultimate load agree fairly well with both computer FE analyses and tests.

The conclusion is that the yield point can be taken as the conventional 0,2 per cent proof stress, and empirical expressions in codes can be used, when designing the load resistance of thin walled steel columns in case of fire.

The proposed model presented in this thesis is the result of an analysis of the different phenomena, determining the load bearing resistance of thin walled steel columns at elevated temperature verified by numerical FE analyses. The work is completed with a comparison to two earlier design models, Gerlich 1995 and Klippstein 1978. These two models are only taking the flexural buckling into account, but show partly a good similarity to the proposed model for flexural buckling.

There are advantages by using a structural design fire model both in the daily structural analysis work and for developing new products of thin walled steel columns. The model can easily be accepted and used in the daily design work as the well known equations of Eurocode, part 1-3 are used. In the work of developing new products, a model can be used instead of fire tests, saving a lot of time and costs. 


\section{NOTATIONS AND SYMBOLS}

\section{Roman upper case letters}

$A \quad$ surface steel area per unit length

$A_{e f} \quad$ effective cross sectional area

$A_{g r} \quad$ gross cross sectional area

$A_{5} \quad \varepsilon_{\mathrm{u} 5}$ according to ISO 3898

$B_{y} \quad=E I_{y}$ bending stiffness with respect to $y$ - axis

$C=G K_{v}$ torsion stiffness

$C_{w} \quad=E K_{w}$ warping stiffness

$D \quad$ plate bending stiffness, $=E t^{3} /\left(12\left(1-v^{2}\right)\right)$

$D_{0} \quad$ plate bending stiffness with respect to an initial plane plate

$E \quad$ modulus of elasticity

$E_{T} \quad$ modulus of elasticity at temperature $T$

$G \quad$ modulus of shear

$I_{e f} \quad$ second moment of area of an effective cross sectional area

$I_{g r} \quad$ second moment of area of a gross cross sectional area

$I_{x} \quad$ second moment of area with respect to the $x$ axis

$I_{y} \quad$ second moment of area with respect to the $y$ axis

$K_{v} \quad$ torsion constant

$K_{w} \quad$ warping constant

$M \quad$ moment

$M_{c r} \quad$ critical moment

$N \quad$ axial load

$N_{0} \quad$ axial load for an initially plane plate

$N_{\text {ocr }} \quad$ critical load for an initially plane plate

$N_{c r} \quad$ critical load

$N_{p 20}$ resistance load without reduction for buckling at $20^{\circ} \mathrm{C}$, $=f_{y} A_{g r}$

$N_{u} \quad$ ultimate axial load

$N_{u 20}$ axial load resistance with reduction for local buckling at $20^{\circ} \mathrm{C}$

$Q \quad$ internally generated heat

$Q \quad$ strength reduction factor

$Q_{T} \quad$ strength reduction factor at temperature $T$

$T$ temperature 
$T_{0} \quad$ temperature at time $t=0$

$T_{c r} \quad$ critical temperature

$T_{f i} \quad$ temperature of inner flange

$T_{f o} \quad$ temperature of outer flange

$T_{g} \quad$ absolute surrounding gas temperature, fire temperature

$T_{s} \quad$ absolute surface temperature, steel temperature

$T_{w} \quad$ temperature of web

$V \quad$ steel volume per unit length

$W \quad$ initial deflection

$W_{g r} \quad$ section modulus of gross cross sectional area

$W_{e f}$ section modulus of effective cross sectional area

$W_{\max }$ maximum initial deflection

$W_{x x} \quad$ initial deflection in $x-x$ direction

$W_{x y} \quad$ initial deflection in $x-y$ direction

$W_{y y} \quad$ initial deflection in $y-y$ direction

\section{Roman lower case letters}

a length of panel

$b \quad$ width of panel, distance between support and centre of gravity

$b_{c} \quad$ width of flange stiffener

$b_{e f} \quad$ effective width

$b_{e f, c} \quad$ effective width of flange stiffener

$b_{e f f} \quad$ effective width of flange

$b_{e f, w} \quad$ effective width of web

$b_{f} \quad$ width of flange

$b_{p} \quad$ notional flat width of plane element

$b_{w} \quad$ width of web

c specific heat capacity

$e \quad$ enthalpy

$e \quad$ eccentricity

$e(\Delta T)$ thermal eccentricity

$f_{y} \quad$ yield strength

$f_{y T} \quad$ yield strength at temperature $T$

$f_{u} \quad$ ultimate strength

$i \quad$ radius of gyration

$i_{\text {ef }} \quad$ radius of gyration for an effective cross sectional area

$i_{g r} \quad$ radius of gyration for a gross cross sectional area 
$i_{p} \quad$ polar radius of gyration with respect to the centre of cravity

$k \quad$ constant

$k \quad$ thermal conductivity

$k_{y, T} \quad$ steel strength reduction factor

$k_{E, T} \quad$ steel elastic modulus reduction factor

$k_{\sigma} \quad$ buckling factor

$k_{\sigma l} \quad$ buckling factor of flange

$k_{\sigma^{2}} \quad$ buckling factor of flange stiffener

$l$ buckling length

$q \quad$ intensity of distributed load

$q_{0} \quad$ intensity of distributed load for an initially plane plate

$q_{c} \quad$ convection heat flux

$q_{r} \quad$ radiation heat flux

$q_{\text {tot }}$ total net heat flux

$t$ thickness

$t$ time

$t^{*} \quad$ modified time

$t_{d}{ }^{*} \quad$ modified heating phase time

$t_{0} \quad$ thickness of an initially plane plate

$t_{e f, c} \quad$ effective thickness of the flange stiffener

$w$ deflection

$w_{\max }$ maximum deflection

$w_{0} \quad$ deflection of an initially plane plate

$w_{0 \max }$ maximum deflection of an initially plane plate

$w_{0 x x} \quad$ deflection in $x-x$ direction of an initially plane plate

$w_{0 x y} \quad$ deflection in $x-y$ direction of an initially plane plate

$w_{0 y y}$ deflection in $y-y$ direction of an initially plane plate

$w_{x x} \quad$ deflection in $x-x$ direction

$w_{x y} \quad$ deflection in $x-y$ direction

$w_{y y} \quad$ deflection in $y-y$ direction

$w_{z} \quad$ out of plane deflection, $z$ direction

\section{Greek upper case letters}

$\Delta l \quad$ length difference

$\Delta T \quad$ temperature difference

$\Gamma \quad$ factor of fire compartment type 


\section{Greek lower case letters}

$\alpha \quad$ imperfection factor corresponding to an appropriate buckling curve

$\alpha \quad$ relative initial deflection $=w / t$

$\alpha_{T} \quad$ coefficient of thermal expansion at temperature $T$

$\beta \quad$ convective heat transfer coefficient

$\beta_{A}=A_{e} f A_{g r}$ reduction factor of gross area

$\beta_{c} \quad$ coefficient for effective thickness of a flange edge

$\chi \quad$ reduction factor for buckling resistance

$\chi_{L T} \quad$ reduction factor for lateral-torsional buckling resistance

$\chi_{x} \quad$ reduction factor for flexural buckling resistance

$\delta \quad$ difference

$\varepsilon \quad$ unit normal strain

$\varepsilon_{f} \quad$ emission of the flames

$\varepsilon_{m} \quad$ emission of the material surface

$\varepsilon_{r} \quad$ resultant emission

$\phi \quad$ calculation parameter of buckling resistance, angle of twist

$\phi_{L T} \quad$ calculation parameter for lateral-torsional buckling resistance

$\phi_{x} \quad$ calculation parameter for flexural buckling resistance

$\gamma \quad$ convective heat transfer power

$\kappa \quad$ constant describing warping restraint

$\kappa_{L T}$ reduction factor for lateral-torsional buckling resistance

$\kappa_{x} \quad$ reduction factor for flexural buckling resistance

$\lambda$ slenderness

$\bar{\lambda} \quad$ relative slenderness

$\lambda_{p} \quad$ slenderness for plate element

$\lambda_{L T} \quad$ slenderness for lateral-torsional buckling

$\lambda_{x} \quad$ slenderness for flexural buckling resistance

$\mu \quad$ load ratio

$\mu_{L T} \quad$ parameter for lateral-torsional buckling

$\mu_{x} \quad$ parameter for lateral-flexural buckling

$\rho \quad$ reduction factor of effective width

$\rho$ density 


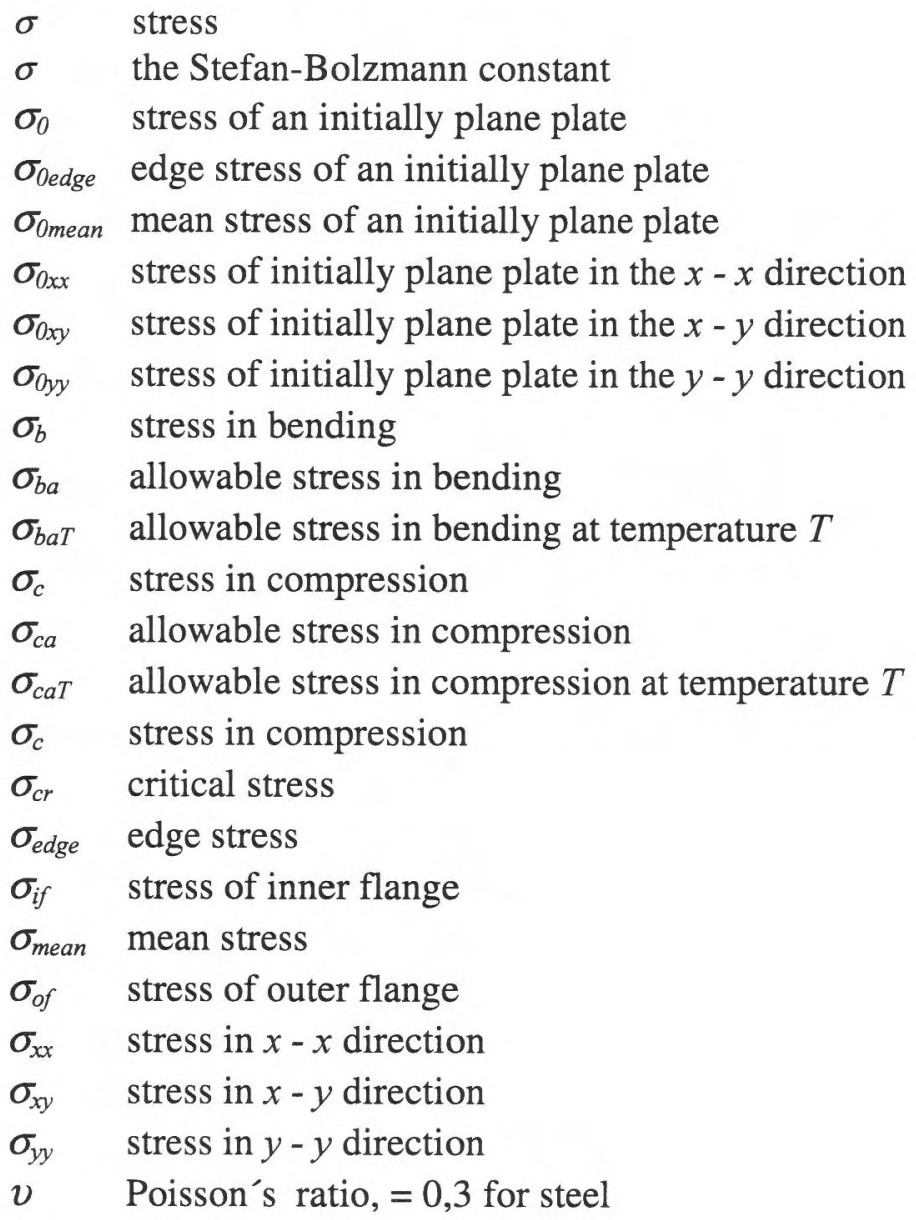




\section{TABLE OF CONTENTS}

PREFACE

I

ABSTRACT III

NOTATIONS AND SYMBOLS

$\mathbf{V}$

TABLE OF CONTENTS XI

1. INTRODUCTION 1

1.1 Background 1

1.2 Scope and limitations 2

1.3 Structural steel strength and deformation properties 3

1.4 Critical load 5

1.4.1 Plate buckling 5

1.4.2 Restrained torsional-flexural buckling $\quad 7$

1.5 Critical steel temperature 11

2. TEMPERATURE MODELLING AND

CALCULATION

2.1 General 13

2.2 Thermal model 15

$\begin{array}{ll}2.3 \text { Material properties } & 17\end{array}$

$\begin{array}{ll}2.3 .1 \text { Steel } & 18\end{array}$

2.3.2 Rock fibre wool $\quad 18$

2.3.3 Glass fibre wool $\quad 19$

2.3.4 Gypsum board 19

2.4 Temperature FE model 21

2.5 Verification of the FE analysis model 22

2.6 Conclusions 23 
3. LOCAL BUCKLING OF THIN WALLED STEEL PLATES AND COLUMNS

3.1 General 25

3.2 Structural model of a thin plane plate 25

3.3 Analytical solution for an initially deflected plate 26

3.4 Empirical estimation of plate resistance 30

3.5 Resistance of plates estimated by FE analyses 32

3.6 Summary of results from the plate calculations 32

3.7 Structural model of thin walled columns 35

3.8 Empirical estimation of the resistance of columns 36 3.8.1 StBK-N5 36

3.8.2 Eurocode $\quad 38$

3.9 Resistance of columns estimated by FE analyses $\quad 39$

3.10 Summary of results from the calculations of columns 41

3.11 Verification of the FE analysis model 42

3.12 Conclusions 43

4. FLEXURAL BUCKLING OF

THIN WALLED STEEL COLUMNS

4.1 General 45

4.2 Structural model $\quad 45$

4.3 Empirical estimation of the resistance 46 4.3.1 StBK-N5 46

4.3.2 Eurocode $\quad 48$

4.4 Resistance estimated by FE analyses $\quad 50$

4.5 Verification of the FE analysis model 51

4.6 Summary of results from calculations 54

4.7 Conclusions 55

5. TORSIONAL-FLEXURAL BUCKLING OF THIN WALLED STEEL COLUMNS 57

5.1 General $\quad 57$

5.2 Structural model $\quad 58$

5.3 Empirical estimation of the resistance 59

5.4 Resistance estimated by FE analyses 66

5.5 Verification of the FE analysis model $\quad 70$

5.6 Summary of results from calculations $\quad 73$

5.7 Conclusions $\quad 75$ 
6.

A MODEL FOR LOAD BEARING FIRE RESISTANCE OF

THIN WALLED STEEL COLUMNS

6.1 General 77

6.2 Structural design model 78

6.2.1 Flexural buckling design model $\quad 79$

6.2.2 Torsional-flexural buckling design model $\quad 80$

6.3 Model presented by Gerlich $\quad 82$

6.4 Model presented by Klippstein $\quad 85$

6.5 Summary of results from calculations 88

7. DISCUSSION AND CONCLUSIONS 91

7.1 Discussion $\quad 91$

$\begin{array}{lll}7.2 \text { Conclusions } & 92\end{array}$

$\begin{array}{lll}7.3 & \text { Future work } & 94\end{array}$

$\begin{array}{ll}\text { 8. REFERENCES } & 97\end{array}$

\section{$\begin{array}{ll}\text { APPENDIX A } & 101\end{array}$}

Temperature development in different wall constructions.

\section{APPENDIX B}

Relationship of load - axial deformation due to local buckling.

Relationship of ultimate load - temperature due to local buckling.

\section{APPENDIX C}

Relationship of load - axial deformation due to flexural buckling.

Relationship of ultimate load - temperature due to flexural buckling.

\section{APPENDIX D}

Relationship of ultimate load - temperature due to torsional-flexural buckling.

\section{APPENDIX E}

Relationship of ultimate load - temperature due to flexural buckling by different design models. 
Input files used in non-linear analysis with Abaqus v. 5.6 to v. 5.8 . 


\subsection{Background}

In the Eurocode ENV 1993, part 1-3, [1] design models for cold formed thin walled steel members are given, but only at room temperature. In the Eurocode ENV 1993, part 1-2, [2] simple design models are given by which the load bearing resistance can be found for different steel sections at elevated temperatures. However, these models are restricted to steel sections where the first order theory in a plastic analysis may be used. Thin walled steel sections of class 4 do not fulfil this requirement and the models can not normally be used. The alternative is then to use design models for the mechanical response taking into account the change in effective cross section for local buckling and change of the yield strength.

Such design models have to be verified by relevant test results. Very few attempts have been made to develop and verify design models for load bearing thin walled steel sections at elevated temperature, however two different models are described in Chapter 6, [3, 4]. Another alternative according to Eurocode, if no relevant design model is available, is to take the critical temperature equal to $350{ }^{\circ} \mathrm{C}$. This temperature could be used as a conservative value without any further proof. The third alternative to determine the load bearing resistance is to use an ordinary standard fire test. The drawback with this alternative is the relatively high cost of the test and the result is limited to the structure tested. A change of the structure concerning span, load and section can require further tests. Finally a combination of calculation and testing is possible.

Structures of thin walled steel sections in apartment blocks and residential buildings are almost always part of a wall or floor structure. These structures are built up of different layers of gypsum board and mineral wool to meet the requirements of insulation and integrity in case of fire, airborne and impact sound insulation. These materials also give the structure good qualities concerning load bearing resistance at elevated temperature. The temperature increase in a load bearing thin walled steel section can thereby be limited and meet the required fire resistance time. 
The temperature increase in a thin walled steel section built into a wall can not be determined through an ordinary $A / V$-value. The $A / V$-value namely implies that the temperature is the same all over the steel cross section and that the heat is kept within the section. This is normally not true because the structure is not heated from all sides and a heat transfer also takes place from the steel structure to other parts of the wall. The steel temperature can be determined by computer analysis or by testing.

The advantage of calculating the fire resistance of a structure instead of doing standard fire tests is above all the time and the cost. Especially during the development phase of a new product calculations of different alternatives are of very great help.

Consequently, there is a need for a simple design model of thin walled steel sections at elevated temperature. A design model should take into account different phenomena of thin walled steel sections such as the reduced effective area for local buckling as well as the temperature effect of the yield strength and elastic modulus. Such a design model is needed both for the daily structural analysis work and for developing new products of thin walled steel sections.

\subsection{Scope and limitations}

The scope of this study is:

- To find out the actual steel temperatures in a wall structure of gypsum boards, mineral wool insulation and thin walled steel sections. How the steel temperature varies across the steel section and how the steel temperature differs between different types of wall structures is of great interest.

- To calculate the load bearing resistance of thin walled steel columns at elevated temperatures considering local buckling, flexural buckling and torsional-flexural buckling both empirical and numerical and to verify the results by comparison to tests.

- To propose a design model for load bearing thin walled steel columns at elevated temperatures. 
The study describes the axial load bearing resistance only. As concerns load bearing walls, it is important to distinguish between walls which are designed for vertical loads only and walls which also are used to stabilise the building against horizontal loads. In the latter case the gypsum boards may be used to obtain the stabilising effect. If, in a fire the gypsum board or its fixing to the thin walled steel columns are becoming too weak or the board starts to disintegrate at an early stage the stabilising effect can be endangered even if the steel sections themselves have enough load bearing resistance.

The notion of empirical estimation is used when the result is based on empirical formulas as those in codes. A set of representative files of the different FE analysis models used are available on $\mathrm{CD}$, [5].

\subsection{Structural steel strength and deformation properties}

Steel begins to lose strength at temperatures above $100{ }^{\circ} \mathrm{C}$ and the decrease in strength is approximately at a steady rate with increasing temperature until about $800{ }^{\circ} \mathrm{C}$. The residual strength of steel, although small, then reduces more gradually until reaching its melting temperature at approximately $1500{ }^{\circ} \mathrm{C}$. Importantly, the greatest rate of loss of strength is in the region of 400 to $600{ }^{\circ} \mathrm{C}$. Data on physical properties of steel are given in Eurocode 3, part 1-2.

The choice of strain limit is very important. In Sweden, the 0,2 per cent proof stress has normally been used but now Eurocode 3, part 1-2 defines the yield point as the stress at 2,0 per cent total strain. The former ECCS Recommendations, [6] used a yield criterion of 0,5 per cent total strain. The two latter definitions may be relevant where no instability influences the behaviour of the structure, but it is clearly too optimistic when instability governs. The effective yield strength relative to the yield strength at $20^{\circ} \mathrm{C}$ is presented as the strength reduction factor, $k_{y, T}$. In this study the reduction factor is defined as the effective yield strength at 0,2 per cent plastic strain relative to the yield strength at $20^{\circ} \mathrm{C}$. In the study of initial deflection and local buckling of thin walled plates the effective strength at 0,1 per cent plastic strain is also used as a comparison, Table 3.1 - 3.4. The elastic modulus will be reduced too at elevated temperature. The reductions of the yield strength and elastic modulus in Table 1.1, are from Eurocode 3, part 1-2. 
Table 1.1 Strength reduction factors and reduction factors for the elastic modulus at elevated temperature used in empirical estimations.

\begin{tabular}{|c||c|c|c|c|c|c|c|}
\hline Temp. ${ }^{\circ} \mathrm{C}$ & 20 & 100 & 200 & 300 & 400 & 500 & 600 \\
\hline \hline$k_{\gamma, T} / 0,1 \%$ & 1,00 & 1,00 & 0,878 & 0,761 & 0,646 & 0,526 & 0,293 \\
\hline$k_{\gamma, T} / 0,2 \%$ & 1,00 & 1,00 & 0,900 & 0,800 & 0,680 & 0,550 & 0,310 \\
\hline$k_{E, T}$ & 1,00 & 1,00 & 0,900 & 0,800 & 0,700 & 0,600 & 0,310 \\
\hline
\end{tabular}

The FE analysis are done by using a stress-strain relationship according to BSK, [7], $f_{y}=355 \mathrm{MPa}$ and $f_{u}=470 \mathrm{MPa}$, Figure 1.1, when the steel temperature is $20^{\circ} \mathrm{C}$. The stress-strain relationship at higher temperatures is taken as defined in Eurocode 3, part 1-2, Table 1.2.

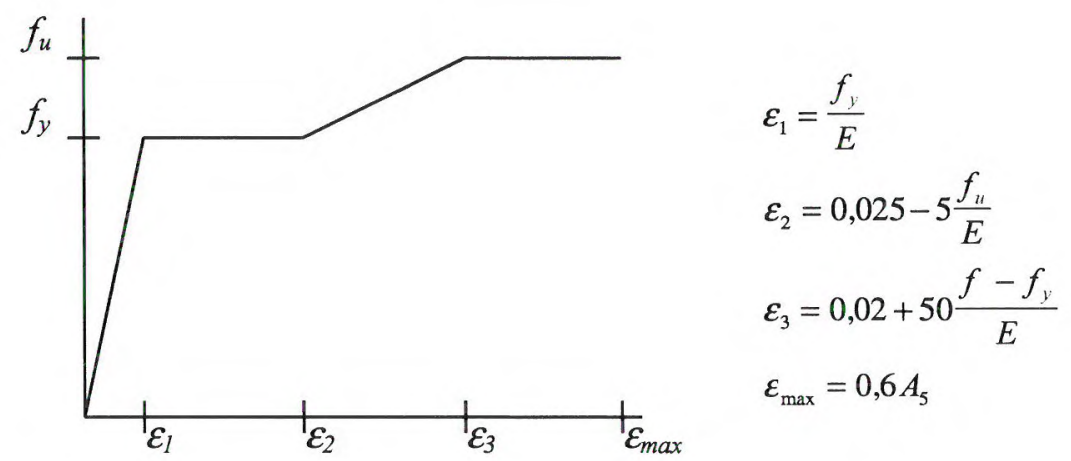

Figure 1.1 The stress-strain relation at room temperature according to $B S K,[7]$.

Table 1.2 Strength reduction factors and reduction factors for the elastic modulus at elevated temperature for grade S 355 steel used in numerical estimations, strain hardening not included.

\begin{tabular}{|c||c||c||c|c||c||c|}
\hline \multicolumn{1}{|c|}{$\begin{array}{c}\text { Total } \\
\text { strain }\end{array}$} & 100 & 200 & 300 & 400 & 500 & 600 \\
\hline \hline$\varepsilon=0,001$ & 0,592 & 0,532 & 0,473 & 0,414 & 0,355 & 0,183 \\
\hline$\varepsilon=0,002$ & 1,000 & 0,848 & 0,706 & 0,576 & 0,476 & 0,258 \\
\hline$\varepsilon=0,005$ & 1,000 & 0,918 & 0,837 & 0,758 & 0,607 & 0,348 \\
\hline$\varepsilon=0,010$ & 1,000 & 0,969 & 0,937 & 0,906 & 0,713 & 0,428 \\
\hline \hline$E$ & 1,00 & 0,900 & 0,800 & 0,700 & 0,600 & 0,310 \\
\hline
\end{tabular}


Poisson's ratio for steel may be taken as $v=0,3$ in the elastic state and the density of steel may be taken as $7850 \mathrm{~kg} / \mathrm{m}^{3}$. Both values are assumed temperature independent. The coefficient of thermal elongation of steel, valid for all structural steels, may be determined from the following:

$$
\begin{array}{ll}
\Delta l / l=-2,4166 \times 10^{-4}+1,2 \times 10^{-5} T_{s}+0,4 \times 10^{-8} T_{s}^{2} & \text { for } 20 C \leq T_{s} \leq 750 C \\
\Delta l / l=11 \times 10^{-3} & \text { for } 750 C<T_{s} \leq 860 C \\
\Delta l / l=-6,2 \times 10^{-3}+2 \times 10^{-5} T_{s} & \text { for } 860 C<T_{s} \leq 1200 C
\end{array}
$$

Properties such as the specific heat and thermal conductivity of steel are defined in section 2.3.

\subsection{Critical load}

\subsubsection{Plate buckling}

A first check of the correspondence between the theory of stability and the numerical model can be done by studying the critical load, $N_{c r}$ for uniform compression. In the theoretical solution the critical load can be written as a function of the first critical stress. Since the whole steel section has the same thickness and the geometry is such that the width of the web is larger than the width of the flanges, the critical stress in the web is the determining factor.

A thin walled steel C-section prevented from global bending will undergo plate buckling. The critical buckling load $N_{c r}$ can be written:

$$
\begin{aligned}
& N_{c r}=A_{g r} \sigma_{c r, \min } \\
& \sigma_{c r, \text { min }}=k_{\sigma} \frac{\pi^{2} E}{12\left(1-v^{2}\right)} \frac{t^{2}}{b_{w}{ }^{2}}
\end{aligned}
$$

where $k_{\sigma}$ is the buckling factor varying with the geometry and boundaries of the considered part, web or flanges. 
From solutions in literature $k_{\sigma}=6,2$ when $b_{w}=100 \mathrm{~mm}$ and $k_{\sigma}=5,5$ when $b_{w}=200 \mathrm{~mm}$ for the C-section in Table 1.3, [8]. The results of equations 1.1 and 1.2 and the value from the finite element analysis, FEA, shown in Table 1.3 are in rather good agreement .

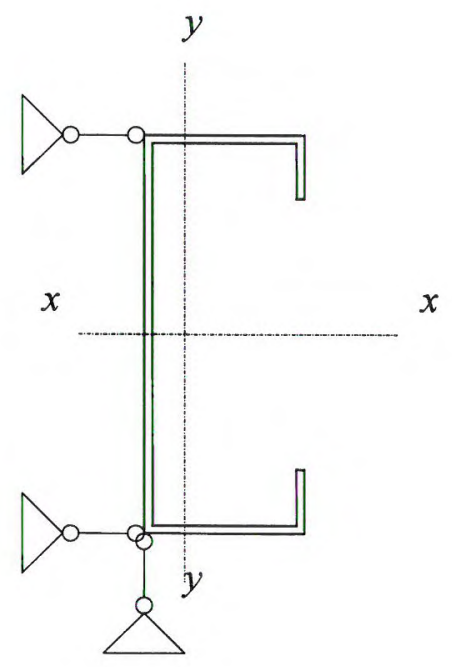

Figure 1.2 Model for plate buckling. The C-section is prevented from global buckling.

Table 1.3 The critical plate buckling load $N_{c r}(\mathrm{kN})$ and $\sigma_{c r},(\mathrm{MPa})$ for the different steel $\mathbf{C}$-sections studied in this thesis.

\begin{tabular}{|c|c||c|c|c|c|}
\hline \multicolumn{1}{|c||}{ C-section } & \multicolumn{1}{|c||}{ Thickness } & \multicolumn{4}{c|}{ Model } \\
$b_{w} \times b_{f} \times b_{c}$ & $t$ & \multicolumn{2}{c|}{ Theory } & \multicolumn{2}{c|}{ Numerical model } \\
& & $N_{c r}$ & $\sigma_{c r}$ & $N_{c r}$ & $\sigma_{c r}$ \\
\hline \hline $100 \times 40 \times 15$ & 1,0 & 24,6 & 120 & 22,4 & 108 \\
$k_{\sigma}=6,2$ & 1,5 & 84,7 & 268 & 75,4 & 242 \\
\hline $200 \times 40 \times 15$ & 1,0 & 8,1 & 26,1 & 9,0 & 29,2 \\
$k_{\sigma}=5,5$ & 1,5 & 27,3 & 59,2 & 30,2 & 65,5 \\
\hline
\end{tabular}




\subsubsection{Restrained torsional-flexural buckling}

A thin walled steel C-section, supported sideways along only one flange will experience restrained torsional-flexural buckling, Figure 1.3. The critical torsional-flexural buckling for a centrically loaded column without bending or warping restraint the ends may according to StBK-K2, [9] be written as:

$$
\begin{aligned}
& N_{c r, 0}=\frac{1}{b^{2}+i_{p}^{2}}\left[\left(B_{y} b^{2}+C_{w}\right) \frac{\pi^{2}}{l^{2}}+C\right] \\
& b=b_{w} / 2 \\
& B_{y}=E I_{y} \\
& C_{w}=E K_{w} \\
& C=G K_{v} \\
& i_{p}=\sqrt{\frac{I_{y}+I}{A_{r}}}
\end{aligned}
$$

In the case where a simply supported C-section is exposed to a temperature gradient over the gross section area, an additional deformation in the plane of the web will occur, Figure 1.3. This deformation will cause a moment equal to the axial load times the deflection. According to StBK-K2, [9] the critical torsional-flexural buckling moment, $M_{c r}$ for a constant moment can be written:

$$
M_{c r, 0}=\frac{1}{2 b}\left[\left(B_{y} b^{2}+C_{w}\right) \frac{\pi^{2}}{l^{2}}+C\right]
$$

The bending moment in this equation is assumed to be positive when the flange in tension is supported. For a bending moment and axial load the interactive equation is:

$$
\frac{N}{N_{c r, 0}}+\frac{M}{M_{c r, 0}}=1,0
$$


In this case $M=-N e$ and equation 1.5 becomes:

$$
\frac{N}{N_{c r, 0}}-\frac{N e}{M_{c r, 0}}=1,0
$$

The moment is negative because it causes tension in the unsupported flange.

This gives the relationship of:

$$
N_{c r}=\frac{1}{\frac{1}{N_{c r, 0}}-\frac{e}{M_{c r, 0}}}=\frac{N_{c r, 0}}{1-\frac{e N_{c r, 0}}{M_{c r, 0}}}=\frac{N_{c r, 0}}{1-\frac{e 2 b}{b^{2}+i_{p}{ }^{2}}}
$$

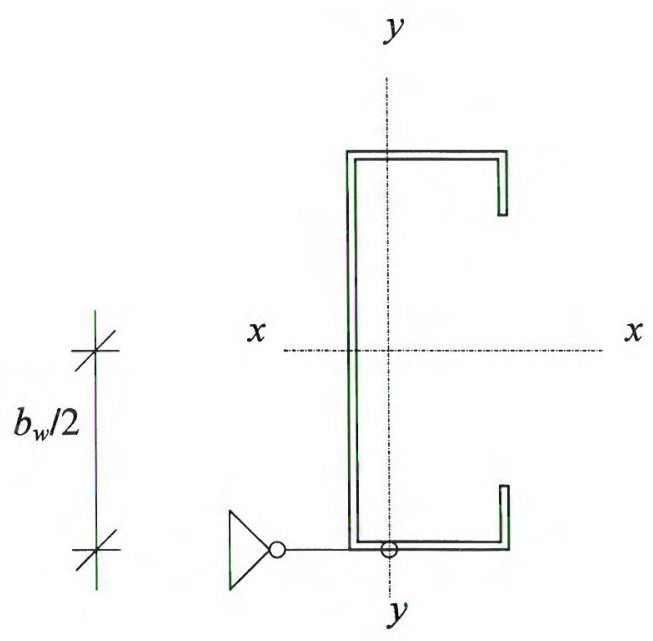

Figure 1.3 Model for torsional-flexural buckling. The C-section is supported laterally at only one flange. 
If then:

$$
e>\frac{b^{2}+i_{p}^{2}}{2 b}
$$

the section is stable and not influenced by torsional-flexural buckling. However, the assumption of constant moment is not conservative in this case as it helps reducing the risk of flexural-torsional buckling. The actual bending moment has a parabolic distribution, which for simplicity is approximated by half a sine wave in the following deduction of a more accurate solution.

In the StBK-K2, [9] where the equations 1.3 and 1.4 were found, these where derived by the energy method. The change in total potential when the section undergoes a small change in twist can be written:

$$
\begin{aligned}
& \Pi=\frac{1}{2} \int_{0}\left(C_{w}+B_{y} b^{2}\right) \phi^{\prime \prime 2} d z+\frac{1}{2} \int_{0}^{h} C \phi^{\prime 2} d z-\frac{1}{2} \int_{0}^{h} N\left(i_{p}{ }^{2}+b^{2}\right) \phi^{\prime 2} d z+\int_{0} M b \phi \phi^{\prime \prime} d z \\
& M=-N e \sin \frac{\pi z}{l}
\end{aligned}
$$

The Rayleigh-Ritz method is applied for finding the critical load with an assumed angle of twist. Generally the angle of twist can be written:

$$
\phi=\sum_{n=1}^{\infty} A_{n} \sin \frac{n \pi z}{l}
$$

In this thesis equation 1.11 is simplified to:

$$
\phi=A \sin \frac{\pi z}{l}
$$

This simplification is possible with regard to the different $\mathrm{C}$-sections described and will not affect the result very much. The explicit solution can then be written:

$$
N_{c r}=\frac{1}{b^{2}+i_{p}{ }^{2}-e \frac{8 b_{w}}{3 \pi}}\left[\left(B_{y} b^{2}+C_{w}\right) \frac{\pi^{2}}{l^{2}}+C\right]
$$


A comparison solution for a constant moment according to StBK-K2 is:

$$
N_{c r, e=c o n s t .}=\frac{1}{b^{2}+i_{p}^{2}-e b_{w}}\left[\left(B_{y} b^{2}+C_{w}\right) \frac{\pi^{2}}{l^{2}}+C\right]
$$

Table 1.4 The critical torsional-flexural buckling load, $N_{c r},(\mathrm{kN})$ and $\sigma_{c r}(\mathrm{MPa})$ for C-sections determined by StBK-K2, $e=0$.

\begin{tabular}{|c|c|c|c|c|c|}
\hline \multirow{3}{*}{$\begin{array}{c}\text { C-section } \\
b_{w} \times b_{f} \times b_{c}\end{array}$} & \multirow{3}{*}{$\begin{array}{c}\text { Thickness } \\
t\end{array}$} & \multicolumn{4}{|c|}{ Profile length, $m$} \\
\hline & & \multicolumn{2}{|c|}{0,8} & \multicolumn{2}{|c|}{2,5} \\
\hline & & $N_{c r}$ & $\sigma_{c r}$ & $N_{c r}$ & $\sigma_{c r}$ \\
\hline \multirow[t]{2}{*}{$100 \times 40 \times 15$} & 1,0 & 188 & 910 & 19,2 & 93,0 \\
\hline & 1,5 & 279 & 897 & 28,5 & 91,6 \\
\hline \multirow[t]{2}{*}{$200 \times 40 \times 15$} & 1,0 & 236 & 766 & 24,1 & 78,2 \\
\hline & 1,5 & 348 & 755 & 35,6 & 77,2 \\
\hline
\end{tabular}

Table 1.5 The critical torsional buckling load, $N_{c r},(\mathrm{kN})$ for C-sections determined by $\mathrm{StBK}-\mathrm{K} 2$, considering constant eccentricities. Profile length $=2,5 \mathrm{~m}$.

\begin{tabular}{|c|c||c|c|c|c|}
\hline C-section & \multicolumn{1}{|c||}{ Thickness } & \multicolumn{4}{|c|}{$e$} \\
$b_{w} \times b_{f} \times b_{c}$ & $t$ & 0,00 & 0,01 & 0,02 & 0,03 \\
\hline \hline $100 \times 40 \times 15$ & 1,0 & 19,2 & 25,0 & 35,9 & 63,6 \\
& 1,5 & 28,5 & 37,3 & 53,7 & 92,2 \\
\hline $200 \times 40 \times 15$ & 1,0 & 24,1 & 27,7 & 32,4 & 39,1 \\
& 1,5 & 35,6 & 40,9 & 48,0 & 58,0 \\
\hline
\end{tabular}

Table 1.6 The critical torsional buckling load, $N_{c r}$, $(\mathrm{kN})$ for $\mathrm{C}$-sections determined by StBK-K2, considering sinus formed eccentricities. Profile length $=2,5 \mathrm{~m}$.

\begin{tabular}{|c|c||c|c|c|c|}
\hline C-section & \multicolumn{1}{|c||}{ Thickness } & \multicolumn{4}{|c|}{$e$} \\
$b_{w} \times b_{f} \times b_{c}$ & $t$ & 0,00 & 0,01 & 0,02 & 0,03 \\
\hline \hline $100 \times 40 \times 15$ & 1,0 & 19,2 & 23,9 & 31,7 & 47,1 \\
& 1,5 & 28,5 & 35,6 & 47,4 & 70,7 \\
\hline $200 \times 40 \times 15$ & 1,0 & 24,1 & 27,1 & 30,8 & 35,8 \\
& 1,5 & 35,6 & 40,0 & 45,6 & 53,0 \\
\hline
\end{tabular}




\subsection{Critical steel temperature}

In section 1.3, the way in which steel loses strength with increasing temperature was described. All steel members lose strength in a similar manner, but because of aspects such as temperature gradients and instability effects at elevated temperatures, it is not necessarily appropriate to apply the same strength reductions to structural members as to the material strength itself.

The temperature $T_{c r}$ at which the member would fail under load is known as the critical temperature. In principle, the critical temperature is only a function of load level and the type of member. The designer has to calculate how much fire protection is required in order to reach the critical temperature of the member at a time which is equal to, or greater than the specified fire resistance period. The higher the critical temperature of the member, the smaller the amount of fire protection that is required to achieve a given fire resistance.

Therefore, low load levels and hence higher critical temperatures of members can be used to achieve some reduction in protection thickness, leading to more economical constructions. Also, different partial safety factors and live loads are used to determine the load level at the fire limit state.

Eurocode 3, part 1-2 proposes a single critical temperature of $350{ }^{\circ} \mathrm{C}$ for Class 4 , thin walled steel sections. Clearly, this value is very conservative and could be improved. The Steel Construction Institute adopts critical temperatures of $450{ }^{\circ} \mathrm{C}$ for columns and $500{ }^{\circ} \mathrm{C}$ for beams of thin walled steel sections, [10]. 


\section{TEMPERATURE MODELLING AND CALCULATION}

\subsection{General}

The dominant consideration when assessing the performance of load bearing thin walled steel sections under fire is the effect of elevated temperature, as a function of time in the fire compartment. There are a lot of different ways to determine this time-temperature curve function, simple and more sophisticated models. For testing and design the ISO 834, Standard Fire Curve, [11] is used in most cases.

The ISO 834, Standard Fire Curve is described in Eurocode ENV 1991, part 22 , [12] together with some alternative time-temperature curves. These alternative curves can be used in different specific circumstances as in case of fire outside a facade, the External Fire Curve is relevant. The Hydro Carbon Curve, representing a fire of hydrocarbon, which is a pool fire with a rapid growth, short duration and a rapid decay phase. In Annex B of Eurocode 1, part 2-2 the Parametric Fire Curve is described. It is principally a numerical function of time-temperature depending on the opening factor, [13], which is commonly used in Sweden. The Parametric Fire Curve gives the possibility to adapt the actual time temperature curve with regard to the building system, e.g. timber framed, light weight steel framed or in situ concrete. The size of the fire load density related to the surface area of the enclosure and the size of the openings. Fire testing against standard time-temperature furnace conditions and computer FE analysis will give good comparative data for structures tested or analysed under identical conditions. However, standard fire resistance tests do not accurately model the performance of a building element when exposed to a real fire. The standard fire resistance test just classifies the building element.

In case of fire, the temperature in the thin walled steel section will increase. At the beginning rather slowly, but when the gypsum board is calcinated and the hydration water has vanished the steel temperature will grow more rapidly. The process results in a loss of strength and shrinkage of the gypsum layer. Normally, a wall is exposed to fire from one side. This means that the temperature will vary across the steel section. The steel temperature and its variation will determine the load bearing resistance of the thin walled steel column. 
The ISO 834, Standard Fire Curve is defined by the relationship:

$$
T_{g}=20+345 \log _{10}(8 t+1)
$$

During the heating phase the Parametric Fire Curve is defined by the relationship:

$$
\begin{aligned}
& T_{g}=1325\left(1-0,324 e^{-0,2 t^{*}}-0,204 e^{-1,7 t^{*}}-0,472 e^{-19 t^{*}}\right) \\
& t^{*}=t \times \Gamma
\end{aligned}
$$

where $\Gamma$ is the factor of fire compartment type. It depends of the opening area and total area of surrounding walls, ceiling and floor of the fire compartment and density, specific heat and thermal conductivity of the boundary of the enclosure. $\Gamma$ together with the fire load density describes the maximum temperature during the heating phase. The temperature during the cooling phase is given by:

$$
\begin{array}{ll}
T_{g}=T_{\max }-625\left(t^{*}-t_{d}{ }^{*}\right) & \text { for } t_{d}{ }^{*} \leq 0,5 \\
T_{g}=T_{\max }-250\left(3-t_{d}{ }^{*}\right)\left(t^{*}-t_{d}{ }^{*}\right) & \text { for } 0,5<t_{d}{ }^{*}<2 \\
T_{g}=T_{\max }-250\left(t^{*}-t_{d}{ }^{*}\right) & \text { for } t_{d}{ }^{*} \geq 2,0
\end{array}
$$

where $T_{\max }$ is the maximum temperature during the heating phase for $t^{*}=t_{d}{ }^{*}$. $t_{d}{ }^{*}$ is the modified heating phase time.

As the yield strength and elastic modulus will be reduced because of the high temperatures, it is necessary to know the temperature in the thin walled steel section to calculate the load bearing resistance. The Super-Tasef computer finite element analysis program model, [14] was used to predict the heat transfer and temperature in the steel sections. This software is described in section 2.4. The steel temperature model used has been verified against eight fire tests of walls. Different kinds of insulation material, types of steel sections and number of gypsum layers and their thickness have been analysed. 


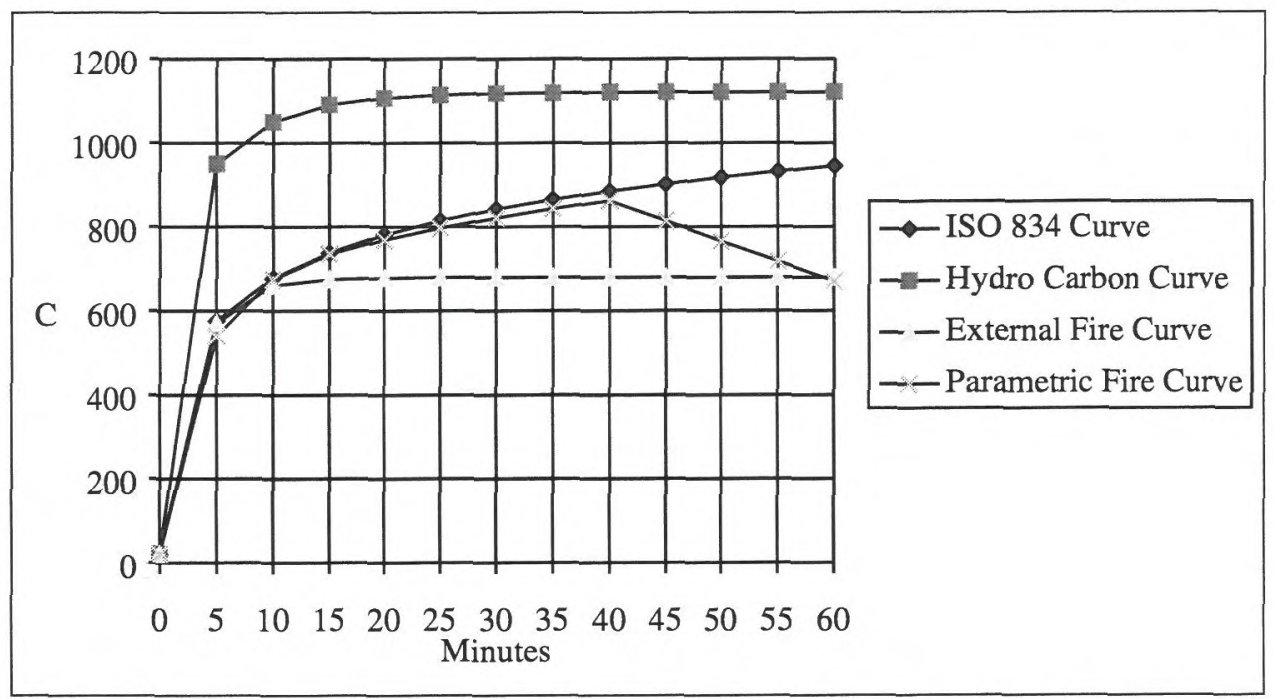

Figure 2.1 Comparison of different time-temperature curves, the Parametric fire curve has been design with $\Gamma=1$.

The results show that it is difficult to find thermal properties of the different materials in order to find a numerical model that always agrees with tests. Both the thermal properties in the literature and the test results varies. But, a numerical model can give a good assessment of temperatures in thin walled steel sections. The results also show that thermal properties of the gypsum layer and insulation, if any, have a lot more influence on the temperature than the geometry of the load bearing steel section.

\section{$2.2 \quad$ Thermal model}

The net heat flux from the fire compartment to the boundary is transferred through thermal radiation and convection. The radiation heat flux component is usually the largest part and it also varies the most with the temperature. The net heat flux to boundaries may be described as:

$$
q_{t o t}=q_{r}+q_{c}
$$


The radiation heat flux component per unit surface area is determined by:

$$
q_{r}=\varepsilon_{r} \sigma\left(T_{g}^{4}-T_{s}^{4}\right)
$$

where $\sigma$ is the Stefan-Bolzmann constant. The resultant emissivity, $\varepsilon_{r}$ for building materials when exposed to fire is in the range $0,6-1,0$ and should be introduced as the sum:

$$
\varepsilon_{r}=\varepsilon_{m}+\varepsilon_{f}
$$

The convective heat flux component per unit surface area should be determined by:

$$
q_{c}=\beta\left(T_{g}-T_{s}\right)^{\gamma}
$$

The coefficient of heat transfer by convection is $25 \mathrm{~W} / \mathrm{m}^{2}{ }^{\circ} \mathrm{C}$ for the Standard Fire Curve. The total heat flux can consequently be written:

$$
q_{t o t}=\varepsilon_{r} \sigma\left(T_{g}^{4}-T_{s}^{4}\right)+\beta\left(T_{g}-T_{s}\right)^{\gamma}
$$

The values chosen for the resultant emission, $\varepsilon_{r}$, convection coefficient, $\beta$, and convector heat transfer power, $\gamma$, are shown in Table 2.1, see also Figure 2.2.

Table 2.1 Heat transfer coefficients used in the Super-Tasef model.

\begin{tabular}{|l||c|c|c|}
\hline Position & $\mathcal{E}_{r}$ & $\beta$ & $\gamma$ \\
\hline \hline Fire side of the wall & 0,8 & 1,00 & 1,33 \\
\hline Lining, fire side of the cavity & 0,6 & - & - \\
\hline Thin walled steel section, in the cavity & 0,8 & - & - \\
\hline Lining, ambient side of the cavity & 0,6 & - & - \\
\hline Ambient side of the wall & 0,6 & 2,20 & 1,33 \\
\hline
\end{tabular}

The calculation of the development of temperature fields over the cross section of a structural member exposed to fire, requires solving a Fourier's differential equation, the transient two-dimensional heat transfer equation: 


$$
\begin{aligned}
& \frac{\delta}{\delta x}\left(k \frac{\delta T}{\delta x}\right)+\frac{\delta}{\delta y}\left(k \frac{\delta T}{\delta y}\right)-\frac{\delta e}{\delta t}+Q=0 \\
& T=\text { temperature } \\
& k=\text { thermal conductivity } \\
& e=\text { specific volumetric enthalpy } \\
& Q=\text { internally generated heat }
\end{aligned}
$$

The equation is solved by using the finite element method. The body to be analysed is divided into elements and the internal temperature is approximated from the nodal temperatures. In general several small elements yield high levels of accuracy but require more computational efforts. Small elements are needed where large temperature gradients are expected, e.g. near boundaries. Each node is designated a number and co-ordinates in the plane. The elements are given certain thermal properties depending on material type and average temperature.

The thermal conductivity of materials is specified at a number of temperature levels and are assumed to vary linearly in between. The heat capacity is indirectly input by the specific volumetric enthalpy defined as:

$$
e=\int_{T_{0}}^{T} c \rho \delta T
$$

\subsection{Material Properties}

The material properties used are relevant values found in the literature, usually with large differences among themselves. Therefore, the material properties have been adjusted to find a good agreement between the calculations and the furnace tests. In particular for the thermal properties of gypsum, a lot of calculations were done to find an acceptable agreement. In Table $2.2-2.6$ the thermal properties used are shown. These give a good result together with the Super-Tasef analysis program. 


\subsubsection{Steel}

The density, the thermal conductivity and specific heat capacity of steel are well known, [6]. The density is $7850 \mathrm{~kg} / \mathrm{m}^{3}$ and the differences in thermal properties data between different references are small.

Table 2.2 Conductivity and Specific heat of steel.

\begin{tabular}{|c||c|c|c|c|c|c|c|c|}
\hline \multicolumn{1}{|c||}{ Steel } & \multicolumn{8}{c|}{ Temperature, ${ }^{\circ} \mathrm{c}$} \\
$\rho=7850 \mathrm{~kg} / \mathrm{m}^{3}$ & 0 & 200 & 400 & 500 & 600 & 700 & 800 & 1200 \\
\hline \hline $\begin{array}{c}\text { Conductivity, } k \\
\text { W/m } / \mathrm{m}^{\circ} \mathrm{C}\end{array}$ & 60 & 51,8 & 43,5 & 39,4 & 35,3 & 31,1 & 27,0 & 27,0 \\
\hline $\begin{array}{c}\text { Specific heat, } c \\
\text { MJ } / \mathrm{kg}^{\circ} \mathrm{C}\end{array}$ & 469 & 525 & 611 & 665 & 727 & 796 & 873 & 873 \\
\hline
\end{tabular}

\subsubsection{Rock fibre wool}

The properties of different kinds of mineral wool insulation material have been tested and can be found in the literature, [15]. For rock fibre wool with a density of 30 to $50 \mathrm{~kg} / \mathrm{m}^{3}$ the thermal properties in Table 2.3 were used. The variations in material properties data presented in the literature are too small to influence results of the computer analyses.

Table 2.3 Conductivity and Specific heat of rock fibre wool, density $30-50 \mathrm{~kg} / \mathrm{m}^{3}$.

\begin{tabular}{|c|c|c|c|c|c|c|c|c|}
\hline \multirow{2}{*}{$\begin{array}{l}\text { Rock fibre wool } \\
\rho=30-50 \mathrm{~kg} / \mathrm{m}^{3}\end{array}$} & \multicolumn{8}{|c|}{ Temperature, ${ }^{\circ} \mathrm{C}$} \\
\hline & 0 & 100 & 200 & 300 & 400 & 700 & 900 & 1200 \\
\hline $\begin{array}{c}\text { Conductivity, } k \\
\mathrm{~W} / \mathrm{m}^{\circ} \mathrm{C}\end{array}$ & 0,034 & 0,046 & 0,061 & 0,078 & 0,098 & 0,50 & 0,75 & 0,75 \\
\hline $\begin{array}{c}\text { Specific heat, } c \\
\mathrm{MJ} / \mathrm{kg}^{\circ} \mathrm{C}\end{array}$ & 900 & 900 & 900 & 900 & 900 & 900 & 900 & 900 \\
\hline
\end{tabular}




\subsubsection{Glass fibre wool}

The thermal properties of light glass fibre wool insulation, with a density between 15 and $30 \mathrm{~kg} / \mathrm{m}^{3}$ were chosen as shown in Table 2.4 . The variations in property data presented are limited and too small to influence results of the computer analyses.

Table 2.4 Conductivity and Specific heat of glass fibre wool, density $15-30 \mathrm{~kg} / \mathrm{m}^{3}$.

\begin{tabular}{|c|c|c|c|c|c|c|c|c|}
\hline Glass fibre wool & \multicolumn{8}{|c|}{ Temperature, ${ }^{\circ} \mathrm{C}$} \\
\hline$\rho=15-30 \mathrm{~kg} / \mathrm{m}^{3}$ & 0 & 100 & 200 & 300 & 400 & 600 & 650 & 1200 \\
\hline $\begin{array}{c}\text { Conductivity, } k \\
\mathrm{~W} / \mathrm{m}^{\circ} \mathrm{C}\end{array}$ & 0,034 & 0,058 & 0,096 & 0,150 & 0,233 & 0,444 & 1,50 & 1,50 \\
\hline $\begin{array}{c}\text { Specific heat, } c \\
\mathrm{MJ} / \mathrm{kg}^{\circ} \mathrm{C}\end{array}$ & 900 & 900 & 900 & 900 & 900 & 900 & 900 & 900 \\
\hline
\end{tabular}

\subsubsection{Gypsum board}

The thermal properties of gypsum are complicated to describe, [16]. This depends of course on the large content of water, approximately 21 per cent hydration water of crystallisation, but also on the calcination process which results in a loss of strength, shrinkage and cracks. The density for gypsum changes when the water calcinates and vanishes. Therefore, the thermal properties shown in Table 2.5 and used in calculations have been modified to make it possible to use a constant density in the computer analysis model. The density was determined to $700 \mathrm{~kg} / \mathrm{m}^{3}$.

Both the density and the contents of water vary a lot. They influence the thermal properties, which in the literature differ relatively much. If the steel temperature is calculated for different values of the conductivity and enthalpy of gypsum found in the literature, $[13,17,18]$ the steel temperature approximately will vary about $50{ }^{\circ} \mathrm{C}$ in the inner flange of the thin walled steel section after a 45 minutes ISO 834 fire exposure. 
The corresponding steel temperature variation as a function of the variation of the gypsum density, $670-700 \mathrm{~kg} / \mathrm{m}^{3}$ is $100{ }^{\circ} \mathrm{C}$. It shall be noted that a difference in the steel temperature of $50-100{ }^{\circ} \mathrm{C}$ after 45 minutes of fire exposure is equivalent to just a few minutes of the steel temperature development.

Table 2.5 Conductivity and Specific heat of gypsum boards, density $700 \mathrm{~kg} / \mathrm{m}^{3}$.

\begin{tabular}{|c||c|c|c|c|c|c|c|c|}
\hline \multicolumn{1}{|c||}{ Gypsum } & \multicolumn{8}{c|}{ Temperature, ${ }^{\circ} \mathrm{C}$} \\
$\rho=700 \mathrm{~kg} / \mathrm{m}^{3}$ & 0 & 80 & 140 & 220 & 250 & 800 & 900 & 1200 \\
\hline \hline $\begin{array}{c}\text { Conductivity, } k \\
\mathrm{~W} / \mathrm{m}^{\circ} \mathrm{C}\end{array}$ & 0,25 & 0,22 & 0,14 & 0,12 & 0,13 & 0,27 & 60 & 60 \\
\hline $\begin{array}{c}\text { Specific heat, } c \\
\mathrm{MJ} / \mathrm{kg}^{\circ} \mathrm{C}\end{array}$ & 1,4 & 1,4 & 4,0 & 2,4 & 1,7 & 2,8 & 3,0 & 3,4 \\
\hline
\end{tabular}

There are different types of fire resistant gypsum boards. These boards are glass fibre reinforced and have significantly better qualities in fire as they do not shrink or crack during and after the calcination process. For these fire resistant gypsum boards the following values were chosen.

Table 2.6 Conductivity and Specific heat of fire resistant gypsum boards, density $700 \mathrm{~kg} / \mathrm{m}^{3}$.

\begin{tabular}{|c||c|c|c|c|c|c|c|c|}
\hline \multicolumn{1}{|c||}{ Gypsum } & \multicolumn{9}{c|}{ Temperature, ${ }^{\circ} \mathrm{C}$} \\
$\rho=700 \mathrm{~kg} / \mathrm{m}^{3}$ & 0 & 80 & 140 & 220 & 250 & 800 & 900 & 1200 \\
\hline \hline $\begin{array}{c}\text { Conductivity, } k \\
\text { W/m } \mathrm{m}^{\circ} \mathrm{C}\end{array}$ & 0,25 & 0,25 & 0,12 & 0,12 & 0,12 & 0,30 & 5 & 10 \\
\hline $\begin{array}{c}\text { Specific heat, } c \\
\text { MJ } / \mathrm{kg}^{\circ} \mathrm{C}\end{array}$ & 1,4 & 1,4 & 4,0 & 2,4 & 1,7 & 2,6 & 3,0 & 3,4 \\
\hline
\end{tabular}

The temperature when the gypsum is falling down from the thin walled steel column is very important. This temperature has, in the model, been set to $550{ }^{\circ} \mathrm{C}$ for ordinary boards and it refers to the side towards the cavity. This temperature is reached when the fire temperature in the compartment is approximately $800^{\circ} \mathrm{C}$. 


\subsection{Temperature FE model}

The software Super-Tasef is a set of computer programs for the calculation of temperatures in structures exposed to fire. They are specifically designed to model heat transfer through materials and composite construction elements. The program uses a forward difference time integration scheme. The program package contains a pre-processor, used for defining the geometry, boundary conditions, control parameters and material data. A post-processor is also available. This program can plot the geometry, nodes, elements, contour lines for important variables and produce time histories. The thermal analysis code is based on the finite element method, FEM. Two dimensional and axisymmetrical structures can be analysed. Another tool in the package is the material database. Also, problems involving conduction in a solid coupled with radiation in enclosures within the solid can be solved. A fine mesh will produce more accurate results, but at the expense of more computing time. In this study a model of 1110 elements and 1178 nodes were used.

Ambient side

Gypsum, $2 \times 12,5 \mathrm{~mm}$

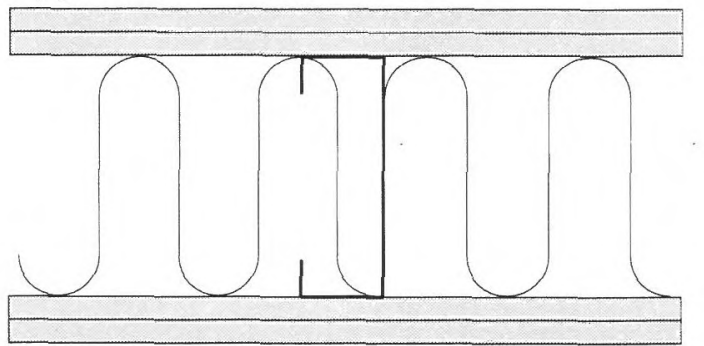

$b_{w}=150 \mathrm{~mm}$

$b_{f}=40 \mathrm{~mm}$

$t=0,8 \mathrm{~mm}$

Gypsum, $2 \times 12,5 \mathrm{~mm}$

Fire side

Figure 2.2 Model of a wall section for temperature calculation. 


\subsection{Verification of the FE analysis model}

Eight different structures of steel framed walls were modelled to calculate the development of temperature in the gypsum boards and the steel $\mathrm{C}$-sections. These calculations were used to verify the temperature FEA model against real furnace tests. The calculations were also done, to help to choose such thermal properties of gypsum boards that the FEA calculations and furnace tests gave a good agreement. Of course, the same properties were used for all the different comparisons. For two similar thermocouples placed at the same position in the same test, the temperature development in the steel section can differ up to about $100{ }^{\circ} \mathrm{C}$. It is, therefore not easy to verify the thermal properties.

Another problem is that two exactly similar structures are never tested. This should have given an idea of the variation in the test result. In Table 2.7 the mean value and the standard deviation of the difference between tests and calculations in minutes to reach a certain temperature are presented. The test results were received from different gypsum board manufacturers and are confidential. Wall tests in furnace are in Sweden done according to NT FIRE 005, ISO 834-1975, [19].

Table 2.7 Mean value and standard deviation of the difference between the tests and calculations in minutes to reach the indicate temperature.

\begin{tabular}{|c||c|c|c|c|c|c|}
\hline Temperature & $200{ }^{\circ} \mathrm{C}$ & $300{ }^{\circ} \mathrm{C}$ & $400{ }^{\circ} \mathrm{C}$ & $500{ }^{\circ} \mathrm{C}$ & $600{ }^{\circ} \mathrm{C}$ & $700{ }^{\circ} \mathrm{C}$ \\
\hline \hline $\begin{array}{c}\text { Mean } \\
\text { value }\end{array}$ & 0,860 & 0,614 & $-0,982 *)$ & $-2,890 *)$ & $-3,160 *)$ & $-1,830 *)$ \\
\hline $\begin{array}{c}\text { Standard } \\
\text { deviation }\end{array}$ & 5,597 & 3,799 & 3,319 & 4,528 & 5,000 & 5,260 \\
\hline $\begin{array}{c}\text { Number of } \\
\text { measurements }\end{array}$ & 15 & 14 & 11 & 10 & 10 & 9 \\
\hline
\end{tabular}

*) Negative values show that the differences are such that the test results give less time to the actual temperature in comparison to the time calculated using numerical analysis. 


\subsection{Conclusions}

The steel temperature in different kinds of wall structures, presented in Appendix A, shows a rather slow development during the first 45 minutes, the hot inner flange reaches approximately $300{ }^{\circ} \mathrm{C}$ and the cold outer flange about $100{ }^{\circ} \mathrm{C}$. After the first 45 minutes the steel temperature rises faster since the gypsum boards have been calcinated. During the last 15 minutes of a 60 minutes ISO 834 temperature development the steel temperature in structures not insulated, for the inner flange reaches nearly $900^{\circ} \mathrm{C}$ and for the outer flange $700{ }^{\circ} \mathrm{C}$. In insulated structures the steel temperature, for the outer flange depending on the type and density of the insulation, only reaches $100-300{ }^{\circ} \mathrm{C}$.

The thickness of the gypsum board is very important for the resulting steel temperature. If two layers of $15 \mathrm{~mm}$ gypsum are used instead of two layers of $12,5 \mathrm{~mm}$, the steel temperature decreases about $50-100{ }^{\circ} \mathrm{C}, 40$ to 50 minutes after ignition. This is equivalent to approximately 6 minutes of fire development. Two layers of glass fibre reinforced gypsum will protect the steel section very well. The steel temperature then does not exceed $270{ }^{\circ} \mathrm{C}$ after a 60 minutes ISO 834 standard fire development.

The mineral wool insulation gives a larger gradient of temperature across the steel $\mathrm{C}$-section, the heavier insulation the larger gradient. As the hot inner flange always has nearly the same temperature, the outer flange is less heated when the density of the mineral wool increases.

The geometry of the steel $\mathrm{C}$-section affects the temperature gradient only to a small extend. If the thickness is $3,0 \mathrm{~mm}$ instead of $0,6 \mathrm{~mm}$, or the web width is $200 \mathrm{~mm}$ instead of $100 \mathrm{~mm}$, or the flanges are $30 \mathrm{~mm}$ width instead of $50 \mathrm{~mm}$, the differences in temperature will be very small, about $0-50{ }^{\circ} \mathrm{C}$, which approximately is equivalent to only one or two minutes of fire development, ISO 834.

The results presented in [20] show that the agreement is quite acceptable. A typical steel temperature developing scenario of a wall with double gypsum layers on both sides and a fire according to ISO 834 is shown in Figure 2.3. Other kinds of walls are shown in Appendix A. 


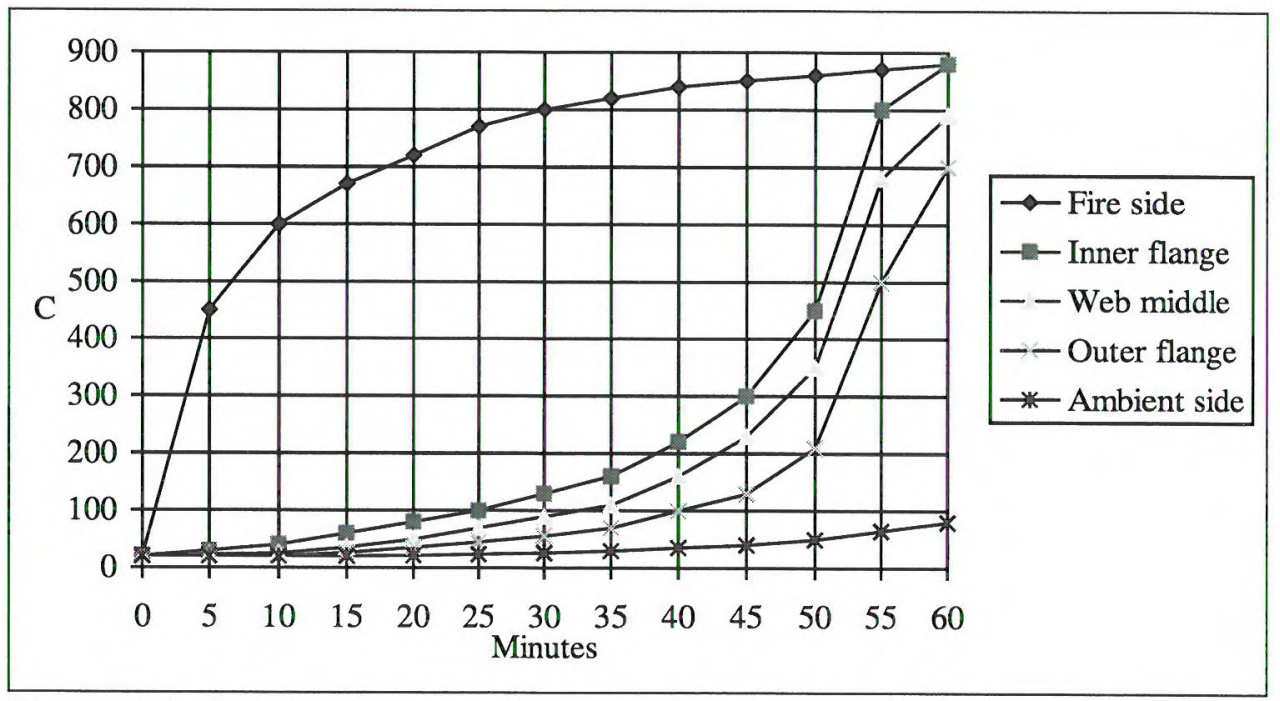

Figure 2.3 The development of temperatures in different parts of a typical thin walled C-section, $b_{w}=150 \mathrm{~mm}, b_{f}=40 \mathrm{~mm}, b_{c}=15 \mathrm{~mm}$ and $t=0,8 \mathrm{~mm}$, protected by $2 \times 12,5 \mathrm{~mm}$ gypsum boards and without insulation. 


\section{LOCAL BUCKLING OF THIN WALLED STEEL PLATES AND COLUMNS}

\subsection{General}

The load bearing resistance of thin walled steel sections is influenced by the slenderness of the individual plates. For shorter columns a failure mode by local buckling of the individual plate is the governing failure mode. In such a case one or more plates belong to class 4 section type. According to Eurocode 3, part 1-3 the whole section is then considered as a class 4 section.

First the buckling resistance of an individual plate is estimated by different methods and the results are fairly consistent. The resistance is estimated by using the Ansys, [21] commercially available FEM code. An analytical solution for an initially deflected plate is also shown and compared to an empirical model as well as a numerical estimation.

Second the local buckling resistance for short columns is estimated by using Abaqus, [22] commercially available FEM code, as well as the Swedish Code for Light-Gauge Metal Structures, StBK-N5, [23] and Eurocode 3, part 1-3. The comparison of the empirical and numerical models show that the load bearing resistance of $\mathrm{C}$-section columns is, just as the results for individual plates, fairly consistent. The reason to use different FEM codes was only practical.

\subsection{Structural model of a thin plane plate}

A rectangular plate compressed in one direction, simply supported along all four edges, Figure 3.1, represent the structural model. The displacements of the loaded edges are such that they remain straight and the longitudinal edges are free to move in the plane of the plate. With this model, the influence of initial deflection and local buckling can be determined and different kinds of solutions compared in case of elevated temperature. 


\subsection{Analytical solution for an initially deflected plate}

There are many methods to calculate the plate buckling resistance which includes the post critical behaviour. These methods can not be used to estimate the resistance of the plate because the influence of the initial deflections has to be considered. Fortunately, it is quite easy to add the influence of an initial deflection which is affine with the buckling deformation. It was shown by Nylander, [24] that it is only a matter of arithmetics to rescale the solution to include the effects of an initial deflection. The method seems to have been forgotten and a short summary will be presented. It will be used to estimate the resistance of compressed plates exposed to fire conditions.

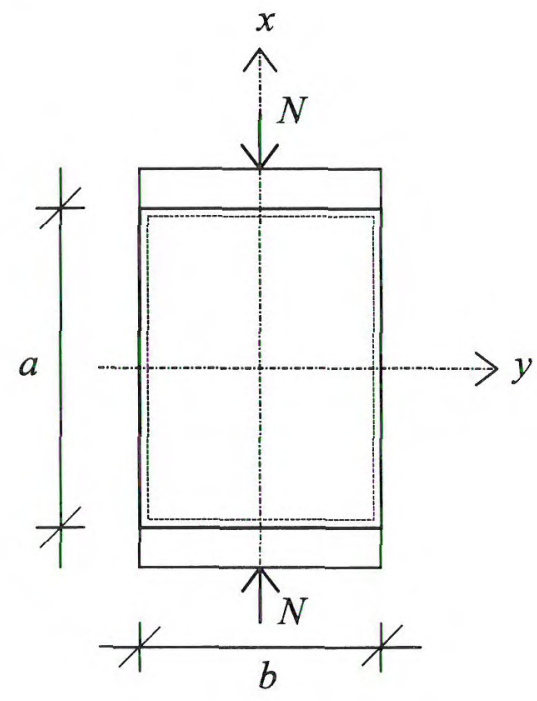

Figure 3.1 A plate compressed in one direction and simply supported along all four edges.

The following equations are valid for a plate with an initial deflection $W$ and additional deflection $w$ due to loading:

$$
\begin{aligned}
& \Delta \Delta \sigma=E\left[\left(w_{x y}\right)^{2}-w_{x x} w_{y y}+2 W_{x y} w_{x y}-W_{x x} w_{y y}-W_{y y} w_{x x}\right] \\
& \Delta \Delta w=\frac{t}{D}\left[\sigma_{y y}\left(W_{x x}+w_{x x}\right)+\sigma_{x x}\left(W_{y y}+w_{y y}\right)-2 \sigma_{x y}\left(W_{x y}+w_{x y}\right)\right]-\frac{q(x y)}{D}=0
\end{aligned}
$$


where subscripts $x$ and $y$ denote differentiation and $\Delta$ is the LaPlace operator. As the initial deflection $W$ is assumed to be affine with the additional deflection $w$ we can write:

$$
W=k w
$$

The parameter $k$ depends on the load but is independent of $x$ and $y$. Equations 3.1 and 3.2 can then be written:

$$
\begin{aligned}
& \Delta \Delta \sigma=E(1+2 k)\left[\left(w_{x y}\right)^{2}-w_{x x} w_{y y}\right] \\
& \left.\Delta \Delta w-\frac{t}{D}(1+k)\left[\sigma_{y y} w_{x x}+\sigma_{x x} w_{y y}-2 \sigma_{x y} w_{x y}\right)\right]-\frac{q(x y)}{D}=0
\end{aligned}
$$

For comparison, we write the equations of an initially plane plate by putting $W=0$.

$$
\begin{aligned}
& \Delta \Delta \sigma_{0}=E\left[\left(w_{0 x y}\right)^{2}-w_{0 x x} w_{0 y y}\right] \\
& \Delta \Delta w_{0}-\frac{t_{0}}{D_{0}}\left[\sigma_{0 y y} w_{0 x x}+\sigma_{0 x x} w_{0 y y}-2 \sigma_{0 x y} w_{0 x y}\right]-\frac{q_{0}(x y)}{D_{0}}=0
\end{aligned}
$$

A comparison between equations 3.3 and 3.5 on the one hand and equations 3.4 and 3.6 on the other hand shows that the functions $\sigma$ and $\sigma_{0}$, as well as $w$ and $w_{0}$ are affine under certain conditions. Therefore, we shall determine the conditions which must be fulfilled in order that the relations

$$
\begin{aligned}
& \sigma_{0}=c_{1} \sigma \\
& w_{0}=c_{2} w
\end{aligned}
$$

are fulfilled. If use is made of equations 3.7 and 3.8 then equations 3.5 and 3.6 become:

$$
\begin{aligned}
& \Delta \Delta \sigma=\frac{c_{2}^{2}}{c_{1}} E\left[\left(w_{x y}\right)^{2}-w_{x x} w_{y y}\right] \\
& \left.\Delta \Delta w-c_{1} \frac{t_{0}}{D_{0}}\left[\sigma_{y y} w_{x x}+\sigma_{x x} w_{y y}-2 \sigma_{x y} w_{x y}\right)\right]-\frac{1}{c_{2}} \frac{q_{0}(x y)}{D_{0}}=0
\end{aligned}
$$


A comparison between equations 3.3 and 3.9 on the one hand and equations 3.4 and 3.10 on the other hand yields the following necessary conditions which must be satisfied in order to fulfil equations 3.7 and 3.8 .

$$
\begin{aligned}
& \frac{c_{2}^{2}}{c_{1}}=(1+2 k) \\
& c_{1} \frac{t_{0}}{D_{0}}=(1+k) \frac{t}{D} \\
& \frac{1}{c_{2}} \frac{q_{0}(x y)}{D_{0}}=\frac{q(x y)}{D}
\end{aligned}
$$

If the equation $3.11,3.12$ and 3.13 are satisfied, then equation 3.9 is identically equal to equation 3.3 and equation 3.10 to equation 3.4. In that case, a solution of the fundamental equations of the initially plane plate also involves a solution of the fundamental equations of the initially deflected plate. This idea is applied to the structural model, Figure 3.1. In this case $q(x, y)=0$ and the longitudinal edges are free from stress. Using the notations given in Figure 3.2 we have the boundary conditions.

$$
\begin{aligned}
& y= \pm \frac{b}{2} ; \quad w=0 ; \quad \frac{\delta^{2} w}{\delta y^{2}}=0 \\
& x= \pm \frac{a}{2} ; \quad w=0 ; \quad \frac{\delta^{2} w}{\delta x^{2}}=0 \\
& y= \pm \frac{b}{2} ; \quad \tau_{x y}=0 ; \quad \sigma_{y}=0 \\
& x= \pm \frac{a}{2} \quad \tau_{x y}=0 \text { or } v=0
\end{aligned}
$$

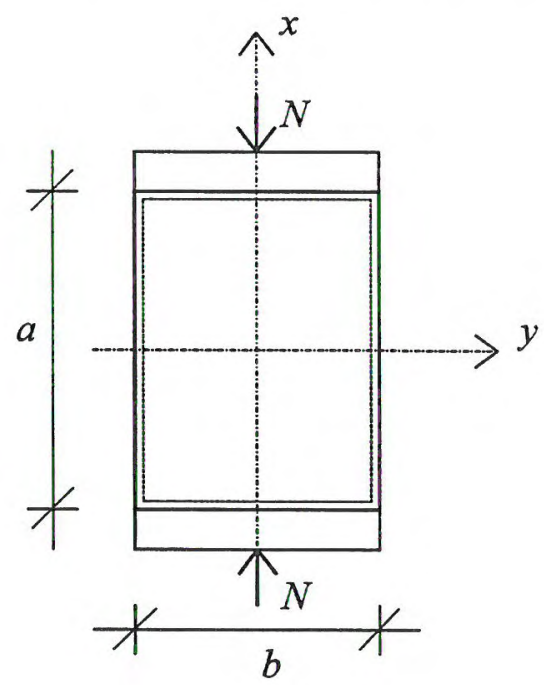

Figure 3.2 Notations and co-ordinate system used, [24]. 
A convenient method of dimensionless representation is to express the deflection $w$ in relation to the thickness of the plate $t$ as a function of $N / N_{c r}$. If then $t$ is the thickness of the initially deformed plate and $t_{0}$ is the thickness of the initially plane plate, we have:

$$
\begin{aligned}
& N_{c r}=k_{\sigma} \frac{\pi^{2} E t^{3}}{12\left(1-v^{2}\right)} \frac{1}{b} \\
& N_{0 c r}=k_{\sigma} \frac{\pi^{2} E t_{0}{ }^{3}}{12\left(1-v^{2}\right)} \frac{1}{b}
\end{aligned}
$$

where $k_{\sigma}$ is a constant which varies depending on the side ratio, $k_{\sigma}=4,0$ for a square plate, simply supported along all four edges. It can then be shown that, [24]:

$$
\begin{aligned}
& \frac{N}{N_{c r}}=\frac{1}{(1+k)} \frac{N_{0}}{N_{0 c r}} \\
& \frac{w_{\max }}{t}=\frac{w_{0 \max }}{t_{0}} \frac{1}{\sqrt{(1+2 k)(1+k)}}
\end{aligned}
$$

If then $W_{\max }=\alpha t=k w_{\max }$ this can be written:

$$
k=\alpha \frac{t_{0}}{w_{0 \max }} \sqrt{(1+2 k)(1+k)}
$$

Since the membrane state of stress in the initially deflected plate is a uniform enlargement of the membrane state of stress in the initially plane plate we have:

$$
\begin{aligned}
& \frac{\sigma_{\text {edge }}}{\sigma_{\text {mean }}}=\frac{\sigma_{\text {oedge }}}{\sigma_{0 \text { mean }}} \\
& \sigma_{\text {mean }}=N / t b
\end{aligned}
$$

Equations 3.16, 3.18 and 3.19 determine $\sigma_{\text {edge }} / \sigma_{\text {mean }}$ as a function of $N / N_{c r}$ for varying initial deflections. For a given solution of an initial plane plate, $N_{0} / N_{\text {ocr }}$ and $w_{0 \text { mor }} / t_{0}$ are known, with this knowledge $k$ and then also the present solution of $N / N_{c r}$ and $\sigma_{\text {edge }} / \sigma_{\text {mean }}$ can be written. The maximum load resistance is assumed to be reached when $\sigma_{\text {edge }}=f_{y}$. 
This method has been used to estimate the load bearing resistance, Tables 3.13.4, Figure 3.6 and the out of plane deflections shown in Figure 3.7, for initially deflected thin plates subjected to fire exposure, with reduced yield strength and elastic modulus using the solutions for an initially perfect plate, Figures 3.3 and 3.4 and the relative initial deflection $\alpha=0$, [25].

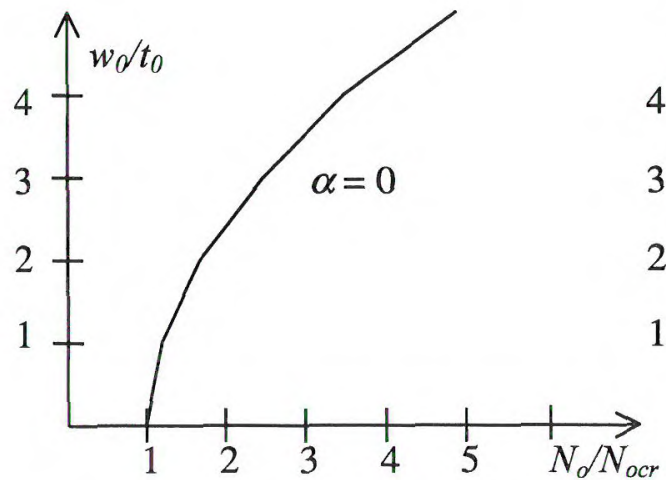

Figure 3.3 $w_{0} / t_{0}$ as a function of $N_{0} / N_{\text {Ocr }}$.

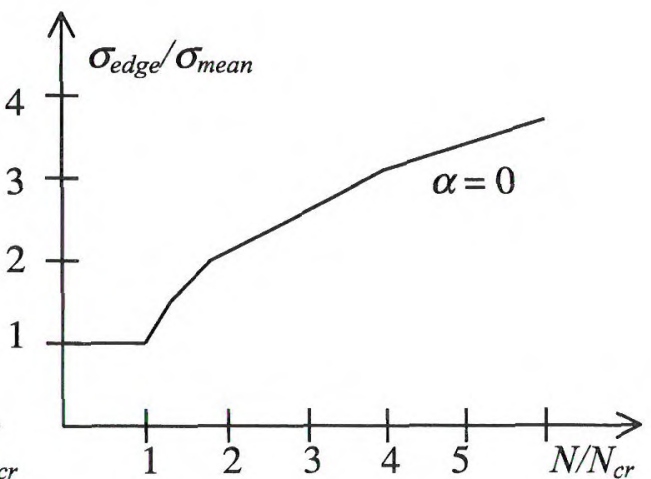

Figure 3.4 $\sigma_{\text {edge }} / \sigma_{\text {mean }}$ as a function of $N / N_{c r}$.

\subsection{Empirical estimation of plate resistance}

The load bearing resistance can be calculated by different models. One model is to apply the theory of von Kármán, [26], see Ranby, [27]. This model assumes that the compressive stresses are carried by two strips of width $b_{e f} / 2$, one on each side of the plate, Figure 3.5. The effective width was determined such that the maximum stress of the plate with width, $b_{e f}$ should be equal to the yield stress. With $k_{\sigma}=4$ in equation 3.14 we get 3.21.

$$
\begin{aligned}
& \sigma_{c r}=4 \frac{\pi^{2} E t^{2}}{12\left(1-v^{2}\right)} \frac{1}{b^{2}} \\
& \frac{b_{e f}}{b}=\sqrt{\frac{4 \pi^{2} E t^{2}}{12\left(1-v^{2}\right) b^{2}} \frac{1}{f_{y}}}=\sqrt{\frac{\sigma_{c r}}{f_{y}}}=\frac{1}{\lambda}
\end{aligned}
$$


The ultimate load resistance becomes:

$$
N_{u}=f_{y} t b_{e f}=1,90 t^{2} \sqrt{f_{y} E}
$$

It has been shown that the model of von Kármán overrates the ultimate load resistance. Another model considered was established by Winter, this model is used in Eurocode 3, part 1-3 in a slightly modified form, see section 3.8.2.

$$
\begin{array}{ll}
\frac{b_{e f}}{b}=\frac{1}{\lambda}\left(1-\frac{0,22}{\lambda}\right) & \lambda>0,673 \\
N_{u}=f_{y} t b_{\text {ef }} &
\end{array}
$$

Because of the high temperatures in case of fire exposure, the yield strength and elastic modulus will be reduced, and the ultimate load resistance will decrease as the temperature rises. The strength reduction factor and reduction factor for elastic modulus can be found in Table 1.1 in section 1.3. The ultimate load bearing resistance calculated according to the above mentioned models are given in Tables 3.1-3.4.

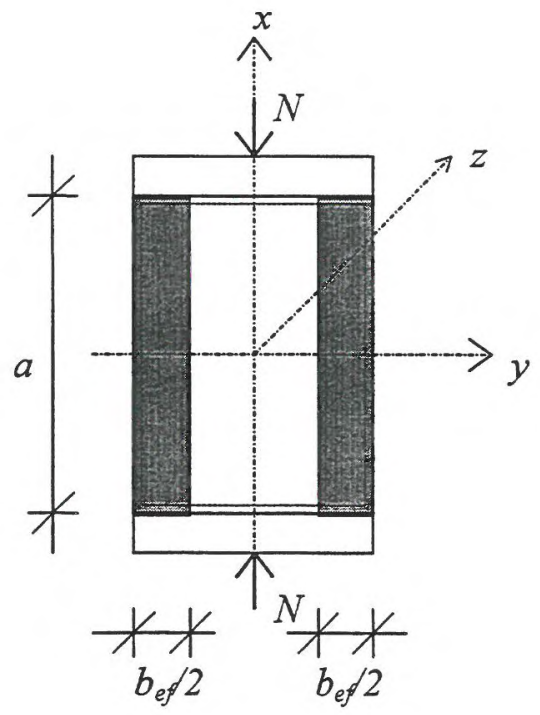

Figure 3.5 Plate model at ultimate state, it is assumed that the compressive stresses are carried by two strips of width $b_{e f} 2$. 
As the plate is given an increasing compression, different effects occur in the middle and along the edges of the plate. The edges remain strait and the compression leads to higher edge stresses. The plate middle deflects out of the plane and the stresses will not increase much. It can be shown that equations 3.26 and 3.27 are valid under linear elastic circumstances, excluding effects of initial deformations, Figure 3.7, [28].

$$
\begin{aligned}
& \frac{N}{N_{c r}}=1+0,52\left(\frac{w_{z}}{t}\right)^{2} \\
& w_{z}= \pm 1,39 t \sqrt{\frac{N}{N_{c r}}-1}
\end{aligned}
$$

\subsection{Resistance of plates estimated by $\mathrm{FE}$ analyses}

The FE analysis was carried out in two phases. First an elastic buckling analysis was performed to find the critical buckling mode and then a non-linear static analysis was used to calculate the ultimate load of the plate. The local buckling mode scaled to be the out of plane deformation was added to the model as an initial geometrical imperfection. The FE analyses were done by using the FEM code of Ansys. The ultimate load resistance calculated are shown in Tables 3.13.4 and Figure 3.6. The out of plane deflections are shown in Figure 3.7.

In the structural model the SHELL43 element was used, this is a rectangular four node elasto plastic element with 6 degrees of freedom per node. The model of size $800 \times 200 \mathrm{~mm}$ contained 256 elements in a $8 \times 32$ element mesh. The rectangular plate is compressed in one direction, simply supported along all four edges, Figure 3.1.

\subsection{Summary of results from the plate calculations}

The ultimate load resistance has been calculated according to the methods described above, Nylander, Eurocode 3, part 1-3 and the FE analysis. In the method given in Eurocode 3, part 1-3 initial deflections are taken into consideration implicitly. In Nylander and the FE analysis the resistance were calculated using an initial deflection of $b / 200$. The plate length $a$ was taken as $4 b$. 


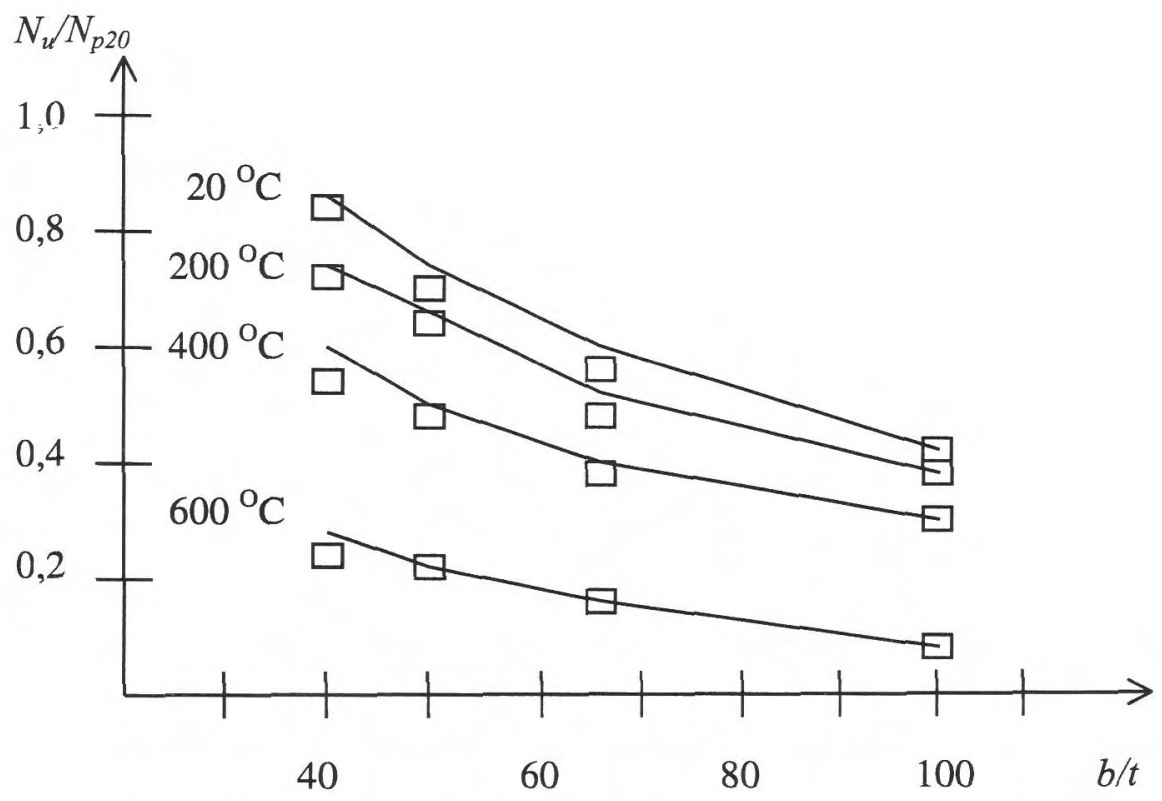

Figure 3.6 Ultimate load resistance at various temperature levels, $\square$ FE analysis , - von Karman.

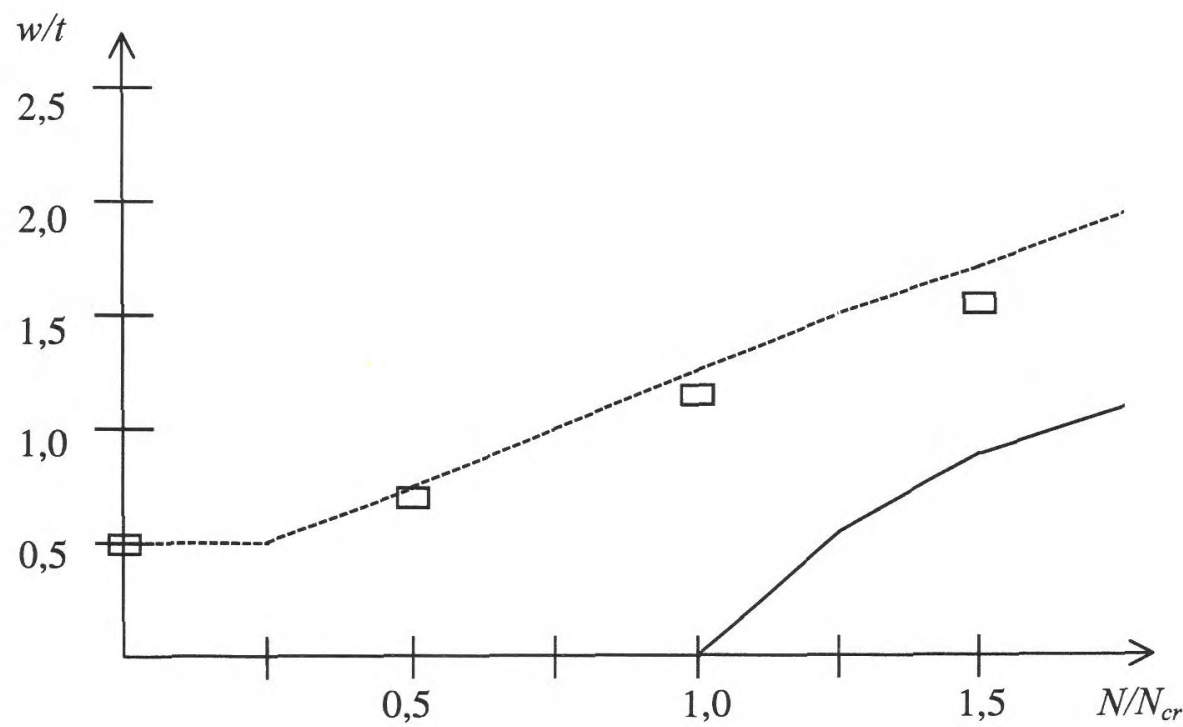

Figure 3.7 Out of plane deflection, $b / t=100$,

$\square F E$ analysis, - von Karman, - - Nylander. 
Table 3.1 Ultimate load resistance of a plane plate, $(\mathrm{kN}), b / t=100$.

\begin{tabular}{|c||c|c|c|c|c|c|}
\hline $\begin{array}{c}\text { Steel } \\
\text { temperature }\end{array}$ & $\mathrm{EC}_{0,1}$ & $\mathrm{Nyl}_{\cdot 0,1}$ & $\mathrm{EC}_{0,2}$ & $\mathrm{Nyl}_{\cdot 0,2}$ & FEA & $\begin{array}{c}\mathrm{EC}_{0,2} / \\
\mathrm{FEA}\end{array}$ \\
\hline \hline 20 & 59,0 & 60,6 & 59,0 & 60,6 & 64,0 & 0,98 \\
\hline 200 & 52,3 & 53,4 & 53,1 & 54,2 & 55,4 & 0,96 \\
\hline 300 & 45,9 & 46,5 & 47,2 & 47,8 & 48,0 & 0,98 \\
\hline 400 & 39,5 & 40,1 & 40,6 & 41,2 & 40,1 & 1,01 \\
\hline 500 & 32,9 & 33,1 & 33,7 & 33,9 & 32,8 & 1,03 \\
\hline 600 & 17,7 & 18,2 & 18,3 & 18,8 & 18,6 & 0,98 \\
\hline
\end{tabular}

Table 3.2 Ultimate load resistance of a plane plate, $(\mathrm{kN}), b / t=67$.

\begin{tabular}{|c||c|c|c|c|c|c|}
\hline $\begin{array}{c}\text { Steel } \\
\text { temperature }\end{array}$ & $\mathrm{EC}_{0,1}$ & $\mathrm{Nyl}_{0_{0,1}}$ & $\mathrm{EC}_{0,2}$ & $\mathrm{Nyl}_{\cdot 0,2}$ & FEA & $\begin{array}{c}\mathrm{EC}_{0,2} / \\
\mathrm{FEA}\end{array}$ \\
\hline \hline 20 & 125 & 119 & 125 & 119 & 124 & 1,00 \\
\hline 200 & 111 & 106 & 113 & 108 & 107 & 1,06 \\
\hline 300 & 97 & 93 & 100 & 96 & 93 & 1,07 \\
\hline 400 & 84 & 80 & 86 & 82 & 78 & 1,10 \\
\hline 500 & 69 & 66 & 71 & 68 & 64 & 1,11 \\
\hline 600 & 38 & 36 & 39 & 37 & 36 & 1,08 \\
\hline
\end{tabular}

Results from the calculations are summarised in Tables 3.1-3.4 for slenderness ratio of $b / t=100,67,50$ and 40. For Nylander and Eurocode 3, part 1-3 two different definitions of the yield point were used, 0,1 per cent proof stress and 0,2 per cent proof stress. As one can see the results are very close for $b / t=100$. As the slenderness decreases the differences between the results increase.

It is clear from Tables 3.1-3.4 that it does not matter much if the 0,1 per cent or 0,2 per cent proof stress is used. Considering also that the comparison of test results indicate underestimation of the calculated resistance at elevated temperatures, it seems reasonable to accept the plate buckling resistance according to Eurocode 3, part 1-3 also under fire conditions using the 0,2 per cent proof stress as the yield point. 
Table 3.3 Ultimate load resistance of a plane plate, $(\mathrm{kN}), \boldsymbol{b} / \boldsymbol{t}=\mathbf{5 0}$.

\begin{tabular}{|c||c|c|c|c|c|c|}
\hline $\begin{array}{c}\text { Steel } \\
\text { temperature }\end{array}$ & $\mathrm{EC}_{0,1}$ & Nyl.0,1 & $\mathrm{EC}_{0,2}$ & Nyl.0,2 & FEA & $\begin{array}{c}\mathrm{EC}_{0,2} / \\
\text { FEA }\end{array}$ \\
\hline \hline 20 & 209 & 200 & 209 & 200 & 207 & 1,01 \\
\hline 200 & 185 & 177 & 188 & 180 & 179 & 1,05 \\
\hline 300 & 162 & 154 & 167 & 159 & 155 & 1,08 \\
\hline 400 & 139 & 132 & 144 & 137 & 130 & 1,11 \\
\hline 500 & 115 & 109 & 119 & 113 & 106 & 1,12 \\
\hline 600 & 63 & 61 & 65 & 63 & 60 & 1,08 \\
\hline
\end{tabular}

Table 3.4 Ultimate load resistance of a plane plate, $(\mathrm{kN}), \mathrm{b} / \mathrm{t}=\mathbf{4 0}$.

\begin{tabular}{|c||c|c|c|c|c|c|}
\hline $\begin{array}{c}\text { Steel } \\
\text { temperature }\end{array}$ & $\mathrm{EC}_{0,1}$ & $\mathrm{Nyl}_{\cdot 0,1}$ & $\mathrm{EC}_{0,2}$ & Nyl $_{0,2}$ & FEA & $\begin{array}{c}\mathrm{EC}_{0,2} / \\
\text { FEA }\end{array}$ \\
\hline \hline 20 & 306 & 312 & 306 & 312 & 300 & 1,02 \\
\hline 200 & 271 & 276 & 275 & 281 & 260 & 1,06 \\
\hline 300 & 237 & 240 & 245 & 248 & 225 & 1,09 \\
\hline 400 & 203 & 205 & 210 & 214 & 188 & 1,12 \\
\hline 500 & 168 & 169 & 173 & 176 & 154 & 1,12 \\
\hline 600 & 91 & 92 & 95 & 98 & 87 & 1,09 \\
\hline
\end{tabular}

\subsection{Structural model of thin walled columns}

The structural model is a C-section column with a length of $800 \mathrm{~mm}$, Figure 3.8. The column is supported sideways along both flanges according to Figure 1.2. The axial load is applied at the centre of gravity and the buckling length is equal to the length of the column. In the empirical estimations the 0,2 per cent plastic strain limit was used to define the yield strength, Table 1.1. In the FE analysis the stress-strain relationship of Table 1.2 was used. 


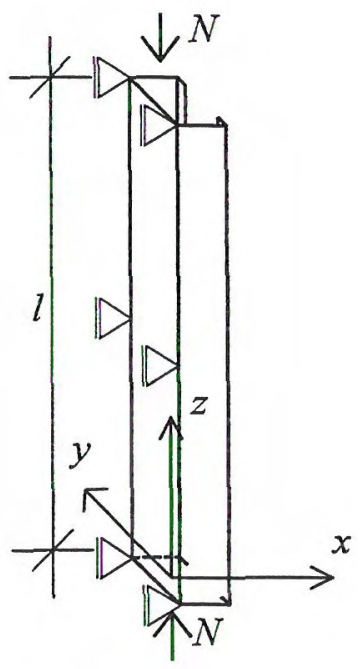

Figure 3.8 A short C-section column subjected to an axial load at the centre of gravity, supported continuously along both flanges to prevent displacements in the $x$-direction.

\subsection{Empirical estimation of the resistance of columns ?}

\subsubsection{StBK-N5}

The ultimate load $N_{u}$ with regard to local buckling can according to StBK-N5 be written as:

$$
N_{u}=f_{y} A_{e f}
$$

where:

$$
\begin{array}{ll}
A_{e f}=t b_{e f, w}+t b_{e f, f}+\frac{\sigma_{c}}{f_{y}}\left(t b_{e f, f}+2 t_{e f, c} b_{c}\right) \\
b_{e f}=b_{p} & \text { if } \lambda_{p} \leq 1,27 \\
b_{e f}=\frac{1,9 b_{p}}{\lambda_{p}}\left(1-\frac{0,42}{\lambda_{p}}\right) & \text { if } \lambda_{p}>1,27
\end{array}
$$




$$
\lambda_{p}=\frac{2}{\sqrt{k_{\sigma 1}}} \frac{b}{t} \sqrt{\frac{f_{y}}{E}}
$$

$k_{\sigma l}$ is the buckling factor of web and flanges, $k_{\sigma l}=4,0$

$$
\begin{aligned}
& t_{c f, c}=\beta_{c} t \\
& \beta_{c}=0,86 \frac{t}{b_{c}} \sqrt{\frac{k_{\sigma 2} E}{f_{y}}} \quad \text { maximum } 1,00
\end{aligned}
$$

$k_{\sigma 2}$ is the buckling factor of the flange stiffener $k_{\sigma 2}=0,5$.

$\sigma_{c}$ is determined as a function of $\lambda$ of the flange stiffener.

The yield strength and elastic modulus are reduced at elevated temperature, which cause a reduction of the load bearing resistance at elevated temperature. If the equations presented are applied at elevated temperature, the load bearing resistance of Table 3.5 is obtained.

Table 3.5 The ultimate load, $N_{u}$ with respect to local buckling for different steel columns according to StBK-N5, (kN).

\begin{tabular}{|c|c||c|c|c|c|}
\hline C-section & Thickness & \multicolumn{4}{|c|}{ Steel temperature, ${ }^{\circ} \mathrm{C}$} \\
$b_{w} \times b_{f} \times b_{c}$ & $t$ & 20 & 200 & 400 & 600 \\
\hline \hline $100 \times 40 \times 15$ & 1,0 & 46,0 & 41,4 & 31,7 & 14,3 \\
& 1,5 & 90,4 & 81,4 & 62,1 & 28,0 \\
\hline $200 \times 40 \times 15$ & 1,0 & 44,7 & 40,3 & 30,9 & 13,9 \\
& 1,5 & 90,2 & 81,2 & 62,0 & 28,0 \\
\hline
\end{tabular}




\subsubsection{Eurocode}

In accordance with Eurocode 3, part 1-3, $N_{u}$ can be estimated as:

$$
N_{u}=f_{y} A_{e f}
$$

where:

$$
A_{e f}=t b_{e f, w}+t b_{e f, f}+2 t\left(b_{e f, f} / 2+b_{e f, c}\right)
$$

$A_{e f}$ is determined as the sum of the different plane elements of effective width:

$$
\begin{array}{ll}
b_{e f}=\rho b & \text { for the web and flanges. } \\
\rho=1,0 & \text { if } \lambda_{p} \leq 0,673 \\
\rho=\frac{\left(1,0-0,22 / \lambda_{p}\right)}{\lambda_{p}} & \text { if } \lambda_{p}>0,673 \\
\lambda_{p}=1,052 \frac{b_{p}}{t} \sqrt{\frac{f_{y}}{E k_{\sigma}}} & \\
k_{\sigma}=4,0 \text { for the web and flanges. } & \\
b_{e f, c}=\rho b_{p, c} &
\end{array}
$$

The influence of the flange stiffener can be calculated in two ways by Eurocode 3 , part 1-3, by a general or simplified procedure. In this calculations the simplified way was used, as in StBK-N5, $k_{\sigma}=0,5$ for the flange stiffener.

Table 3.6 The ultimate load, $N_{u}$ with respect to local buckling for different steel columns according to Eurocode 3, part 1-3, (kN).

\begin{tabular}{|c|c||c|c|c|c|}
\hline C-section & Thickness & \multicolumn{4}{|c|}{ Steel temperature, ${ }^{\circ} \mathrm{C}$} \\
$b_{w} \times b_{f} \times b_{c}$ & $t$ & 20 & 200 & 400 & 600 \\
\hline $100 \times 40 \times 15$ & 1,0 & 48,0 & 43,2 & 33,0 & 14,9 \\
& 1,5 & 90,6 & 81,6 & 61,9 & 28,1 \\
\hline $200 \times 40 \times 15$ & 1,0 & 48,9 & 44,0 & 33,6 & 15,2 \\
& 1,5 & 93,4 & 84,1 & 63,9 & 29,0 \\
\hline
\end{tabular}




\subsection{Resistance of columns estimated by $\mathrm{FE}$ analyses}

Numerical calculations have been performed by using Abaqus, a set of engineering simulation programs based on the finite element method, FEM. The program was used to calculate the load bearing resistance.

In the software a structural model of elements is produced. A FE mesh of S8R5 shell elements were used, which are appropriate for thin shell applications. It is a rectangular elasto plastic element with 8 nodes element with 5 degrees of freedom per node, deflection in $x-y$-and $z$-direction and rotation in the plane, and reduced-order integration to form the element stiffness.

The structural model of the $800 \mathrm{~mm}$ long $\mathrm{C}$-section column according to Figure 3.8 was divided into 594 elements. The concentrated load at one end of the column and the support at the other end are applied at the centre of gravity. The ends are modelled with very stiff beam elements, named B31. In this way a uniform compression over the steel gross section was obtained. Totally, the model contains 2129 nodes.

Firstly, an elastic buckling analysis was performed in order to find and verify the critical load and the buckling modes. The critical loads are shown in Table 1.3. The result is then used in a non linear static analysis where the local initial deflections, as a component of the total imperfection, are prescribed in the same form. The maximum local initial deflection is set to $b / 200$ for the web. The results for the different $\mathrm{C}$-section columns are shown in Table 3.7. In the FE analysis the stress-strain relationship of BSK, [7] was used at room temperature. At elevated temperature the relationship of Table 1.2 was used. The relationship of load versus axial deformation is shown in Appendix B. A characteristic input file used in the non-linear FE analysis model is available on $\mathrm{CD}$, [5].

Table 3.7 The ultimate load, $N_{u}$ with respect to local buckling for different steel columns according to an $\mathrm{FE}$ analysis, (kN).

\begin{tabular}{|c|c||c|c|c|c|}
\hline C-section & \multicolumn{1}{|c||}{ Thickness } & \multicolumn{4}{|c|}{ Steel temperature, ${ }^{\mathrm{O}} \mathrm{C}$} \\
$b_{w} \times b_{f} \times b_{c}$ & $t$ & 20 & 200 & 400 & 600 \\
\hline \hline $100 \times 40 \times 15$ & 1,0 & 51,8 & 39,2 & 27,8 & 13,0 \\
& 1,5 & 88,5 & 67,3 & 47,0 & 25,8 \\
\hline $200 \times 40 \times 15$ & 1,0 & 54,8 & 42,7 & 30,2 & 14,1 \\
& 1,5 & 95,8 & 73,1 & 58,1 & 27,1 \\
\hline
\end{tabular}




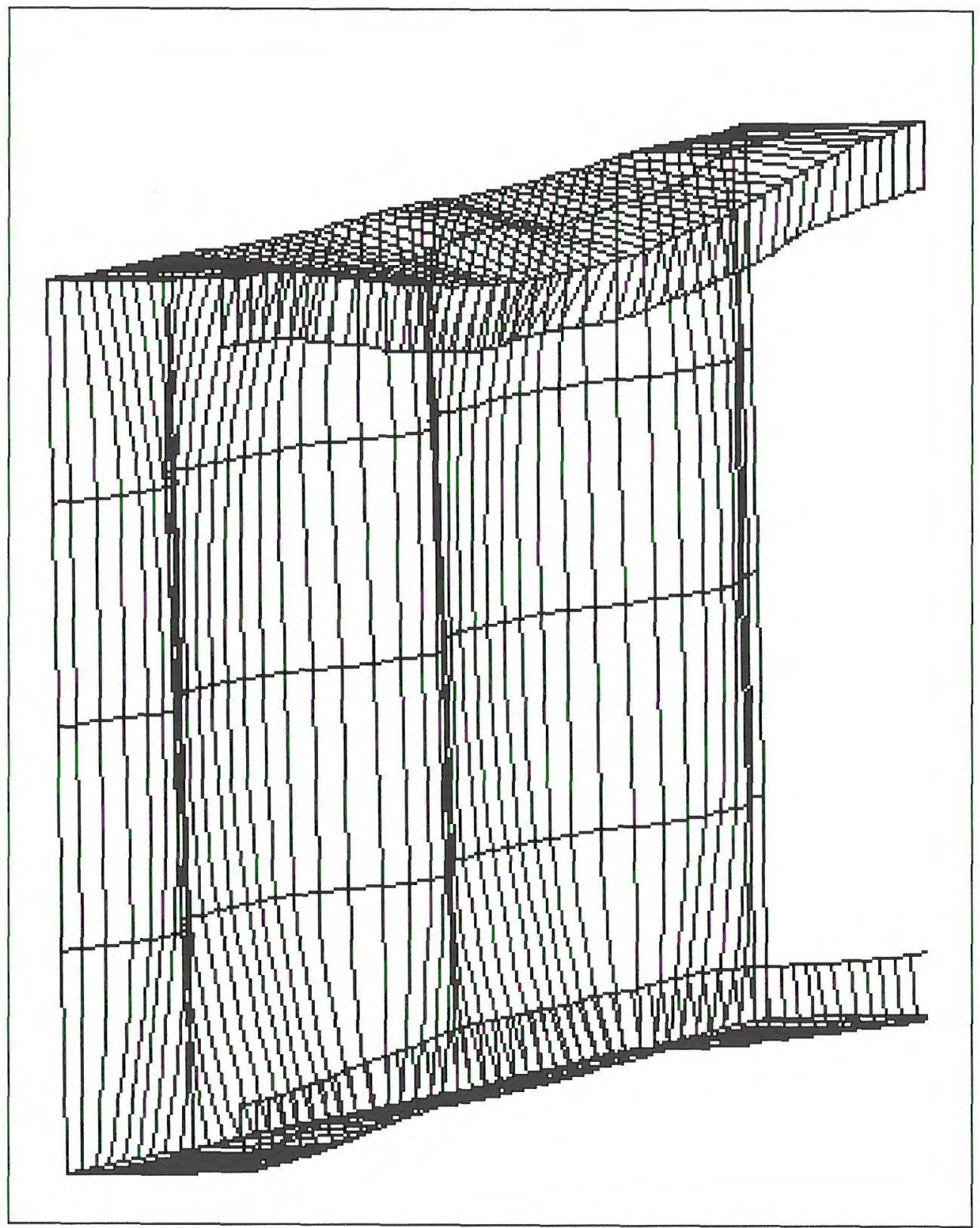

Figure 3.9 The failure mode of local buckling obtained by using Abaqus. 


\subsection{Summary of results from the calculations of columns}

The ultimate maximum load bearing resistance decreases with elevated temperature. For all combinations of $\mathrm{C}$-section columns and thicknesses it is shown that the relation of $\mathrm{FEA} / \mathrm{EC} 3$ gives the highest value at room temperature, $20^{\circ} \mathrm{C}$. This is caused by the strain hardening phase of the stress strain relationship. If the strength is limited to $355 \mathrm{MPa}$ also at room temperature, the ultimate load values of the FE analyses correspond better to Eurocode 3, part 1-3. Limiting the strength to $355 \mathrm{MPa}$ results in $45,2 \mathrm{kN}$ instead of $51,8 \mathrm{kN}$ in Table 3.8. This is approximately 0,94 per cent of $48,0 \mathrm{kN}$, given by the empirical estimation using Eurocode 3, part 1-3. A comparison of the results are shown in Tables 3.8-3.11.

Table 3.8 Ultimate load, $\mathrm{kN}$, according to $\mathrm{FE}$ analyses, Eurocode 3, part 1-3 and StBK-N5.

\begin{tabular}{|c||c|c|c|c|}
\hline \multicolumn{1}{|c||}{ Steel Temperature, ${ }^{\circ} \mathrm{C}$} & \multicolumn{4}{c|}{ C-section $100 \times 40 \times 15, t=1,0 \mathrm{~mm}$} \\
& FEA & EC 3 & StBK -N5 & FEA/EC 3 \\
\hline \hline 20 & 51,8 & 48,0 & 46,0 & 1,08 \\
200 & 39,2 & 43,2 & 41,4 & 0,91 \\
400 & 27,8 & 33,0 & 31,7 & 0,84 \\
600 & 13,0 & 14,9 & 14,3 & 0,87 \\
\hline
\end{tabular}

Table 3.9 Ultimate load, $\mathrm{kN}$, according to $\mathrm{FE}$ analyses, Eurocode 3, part 1-3 and StBK-N5.

\begin{tabular}{|c||c|c|c|c|}
\hline \multicolumn{1}{|c||}{ Steel Temperature, ${ }^{\mathrm{O}} \mathrm{C}$} & \multicolumn{4}{c|}{ C-section $100 \times 40 \times 15, t=1,5 \mathrm{~mm}$} \\
& FEA & EC 3 & StBK -N5 & FEA/EC 3 \\
\hline \hline 20 & 88,5 & 90,6 & 90,4 & 0,98 \\
200 & 67,3 & 81,6 & 81,4 & 0,83 \\
400 & 47,0 & 61,9 & 62,1 & 0,76 \\
600 & 25,8 & 28,1 & 28,0 & 0,92 \\
\hline
\end{tabular}


Table 3.10 Ultimate load, kN, according to $\mathrm{FE}$ analyses, Eurocode 3, part 1-3 and StBK-N5.

\begin{tabular}{|c||c|c|c|c|}
\hline \multicolumn{1}{|c||}{ Steel Temperature, ${ }^{\circ} \mathrm{C}$} & \multicolumn{4}{c|}{ C-section $200 \times 40 \times 15, t=1,0 \mathrm{~mm}$} \\
& FEA & EC 3 & StBK -N5 & FEA/EC 3 \\
\hline \hline 20 & 54,8 & 48,9 & 44,7 & 1,12 \\
200 & 42,1 & 44,0 & 40,3 & 0,96 \\
400 & 30,2 & 33,6 & 30,9 & 0,90 \\
600 & 14,1 & 15,2 & 13,9 & 0,94 \\
\hline
\end{tabular}

Table 3.11 Ultimate load, $\mathrm{kN}$, according to FE analyses, Eurocode 3, part 1-3 and StBK-N5.

\begin{tabular}{|c||c|c|c|c|}
\hline \multicolumn{1}{|c||}{ Steel Temperature, ${ }^{\circ} \mathrm{C}$} & \multicolumn{4}{c|}{ C-section $200 \times 40 \times 15, t=1,5 \mathrm{~mm}$} \\
& FEA & EC 3 & StBK -N5 & FEA/EC 3 \\
\hline \hline 20 & 95,8 & 93,4 & 90,2 & 1,03 \\
200 & 73,1 & 84,1 & 81,2 & 0,87 \\
400 & 58,1 & 63,9 & 62,0 & 0,91 \\
600 & 27,1 & 29,0 & 28,0 & 0,94 \\
\hline
\end{tabular}

\subsection{Verification of the FE analysis model}

A verification of the $\mathrm{FE}$ analysis results were done by comparison to test results from VTT Building Technology in Finland, [29]. A series of fire tests were carried out on cold formed rectangular hollow sections. One was $200 \times 200 \times 5,0$ mm of structural steel with $f_{y}=452 \mathrm{MPa}$. The sections used in the tests had rounded edges but in the $\mathrm{FE}$ analysis the edges were sharp. By adding the load bearing resistance of the round edges equal to their gross area times the yield strength to the FE analysed part, the total load bearing resistance of the section is obtained, Figure 3.10. This value can then be compared to the result of the test. The results are shown in Table 3.12. Like in the VTT report, the results from the FE analysis are lower than the test results at elevated temperatures. The reason for this difference has not been investigated but one possibility is that the actual material properties at elevated temperature are different from those assumed in the calculations. It should be noted that the tests were performed on quite stocky profiles. 


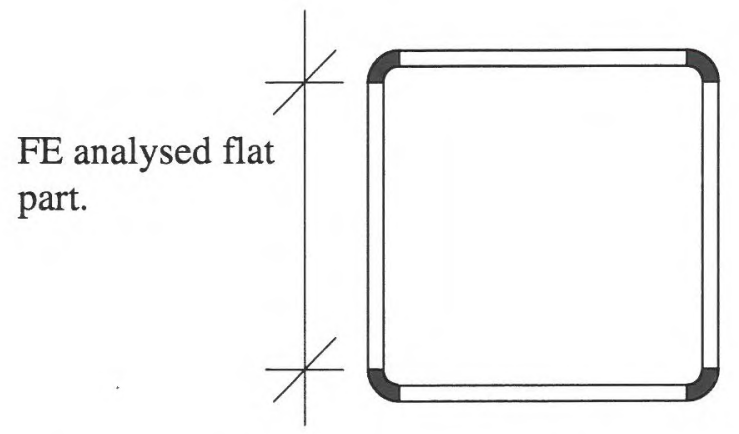

Figure 3.10 The hollow section tested at VTT, [29]. The strength of the rounded edges, black, equal to their gross area times the yield strength was added to the FE analysed flat part, white, to get the total load bearing resistance.

Table 3.13 Ultimate load resistance at elevated temperature of a $200 \times 200 \times 5 \mathrm{~mm}$ rectangular hollow section, $\mathrm{kN}$

\begin{tabular}{|c||c|c|c|}
\hline $\begin{array}{c}\text { Steel } \\
\text { temperature }\end{array}$ & FE analysis & VTT test & $\begin{array}{c}\text { VTT test / } \\
\text { FE analysis }\end{array}$ \\
\hline \hline 20 & 1480 & 1400 & 0,95 \\
\hline 400 & 990 & 1150 & 1,16 \\
\hline 500 & 720 & 850 & 1,18 \\
\hline 600 & 470 & 500 & 1,06 \\
\hline
\end{tabular}

\subsection{Conclusions}

By using the theoretical and empirical methods the ultimate load resistance of four different plates with slenderness $b / t=100,67,50$ and 40 were calculated. Comparative numerical calculations were done by FE analyses. In the empirical calculations the values of the yield strength and elastic modulus are reduced with regard to the elevated temperature. The yield strength was defined as the stress at the 0,1 and the 0,2 per cent plastic strain respectively and using the stress-strain relations in Eurocode 3, part 1-2. In the FE analysis, the full stressstrain relationship for elevated temperatures presented in Eurocode 3, part 1-2 were used. A verification of the FE results were done by comparison to experimental test results from VTT Building Technology in Finland. 
By the theory of Nylander we can study the effect of initial deflections in case of elevated temperatures, fire. Results show that initial deflections have the same relative influence on the load bearing resistance at room temperature as in case of fire. The theory gives a result rather in accordance with the rules of Eurocode 3, part 1-3.

Empirical calculations of the ultimate load show results fairly in agreement with the results from the FE analysis. Interesting is that the difference between resistance measured at tests and FE analysis is approximately of the same size as the difference between empirically calculated and $\mathrm{FE}$ analysed values. It is clear that it does not matter much if the 0,1 per cent or 0,2 per cent proof stress is used. As the FE analysis seem to underestimate the actual resistance with about the same amount as it overestimates it compared to the codes, the conclusion is that a code resistance can be used as a fair estimate of the actual resistance, also at elevated temperatures.

The result shows that a calculation of the local buckling resistance according to Eurocode 3, part 1-3 with a reduced yield strength and elastic modulus is accurate enough at elevated temperatures provided that the yield strength is taken as the 0,2 per cent proof stress. The results also show, that with the typical values of the load reduction factor of 0,6 , the maximum steel temperature with regard to the load bearing resistance is clearly above $350{ }^{\circ} \mathrm{C}$ and rather in the range of $450^{\circ} \mathrm{C}$. 


\section{FLEXURAL BUCKLING OF THIN WALLED STEEL COLUMNS}

\subsection{General}

Calculation of the load bearing resistance with regard to flexural buckling of thin walled steel C-section columns is based partly on the total effective cross sectional area, composed of the effective area of the different parts, web, flanges and flange stiffeners, see chapter 3, and partly on the stiffness, EI. A Csection column can be considered as concentrically compressed if the load affects the section at the centre of gravity of the net section. For a symmetrical $\mathrm{C}$-section the centre of gravity may shift slightly along the line of symmetry as the cross section changes from gross to net section. However, if the C-section is braced laterally at both flanges there will be no lateral bending and the section can be designed as concentrically loaded in despite the actual load application.

How this is solved empirically by using StBK-N5, is presented below. In the Eurocode 3, part 1-3 another empirical estimation is shown. These two models do not give exactly the same result. Comparisons to numerical FEA calculations have also been done. The FEA calculations are verified by comparisons to tests available in the literature, [30].

Results show fairly good agreement between the empirical estimations of StBK$\mathrm{N} 5$ and Eurocode 3, part 1-3. In comparison to the results from the FE analysis, the empirical estimations give higher values of the ultimate load at elevated temperature. At room temperature the opposite is valid. This is, as mentioned before, probably because of the strain hardening considered in the numerical model at room temperature.

\subsection{Structural model}

The structural model used is a C-section column with a length of $2500 \mathrm{~mm}$, Figure 4.1. It is supported along both flanges according to Figure 1.2, to avoid flexural buckling in the weak $x$-direction and possible torsion. The axial load is applied at the centre of gravity of the gross section and the buckling length is equal to the length of the column. In the empirical estimations the 0,2 per cent plastic strain limit was used to define the yield strength, Table 1.1. 


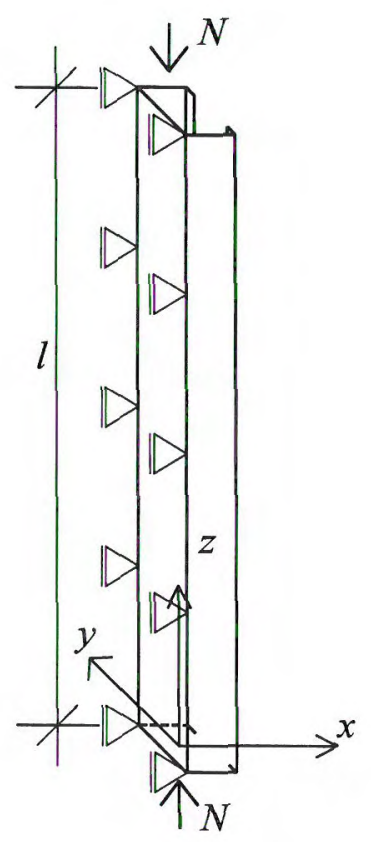

Figure 4.1 A C-section column, affected by an axial load at the centre of gravity, sideways supported along both flanges and prevented to move in the x-direction will buckle flexurally, provided that it is long enough.

\subsection{Empirical estimation of the resistance}

\subsubsection{StBK-N5}

The resistance to column buckling can according to StBK-N5 be written as:

$$
N_{u}=\sigma_{c} A_{e f} \quad \text { but not more than } 0,8 \sigma_{c \mathrm{lg}} A_{g r}
$$

where $A_{e f}$ is calculated in the same way as in section 3.8.1. $\sigma_{c}$ is the stress in compression and $\sigma_{e l g}$ is the critical stress for flexural buckling calculated with regard to the gross sectional area . 


$$
\lambda=\sqrt{\frac{f_{y}}{\sigma_{e l}}}=\frac{l}{i_{e f}} \frac{1}{\pi} \sqrt{\frac{f_{y}}{E}}
$$

$\sigma_{e l}$ is the elastic stress and the relationship of $\lambda$ decides the value of the stress in compression $\sigma_{c}$.

Table 4.1 The design stress value $\sigma_{c}$ with regard to flexural buckling.

\begin{tabular}{|c||c|}
\hline$\lambda$ & $\sigma_{c} / f_{y}$ \\
\hline \hline$\lambda \leq 0,30$ & 1,00 \\
\hline $0,30<\lambda \leq 1,85$ & $1,126-0,419 \lambda$ \\
\hline $1,85<\lambda$ & $1,2 / \lambda^{2}$ \\
\hline
\end{tabular}

Since the yield strength and elastic modulus are reduced at elevated temperature, the load bearing resistance for flexural buckling decreases at elevated temperatures. If the equations presented above are valid also at elevated temperatures, the following load bearing resistances are obtained, Table 4.2.

Table 4.2 The ultimate load, $N_{u}$ with respect to flexural buckling for different columns supported sideways along both flanges, according to StBK-N5, (kN).

\begin{tabular}{|c|c||c|c|c|c|}
\hline C-section & Thickness & \multicolumn{4}{|c|}{ Steel temperature, ${ }^{\mathrm{O}} \mathrm{C}$} \\
$b_{w} \times b_{f} \times b_{c}$ & $t$ & 20 & 200 & 400 & 600 \\
\hline \hline $100 \times 40 \times 15$ & 1,0 & 38,4 & 34,6 & 26,6 & 11,9 \\
& 1,5 & 74,6 & 67,1 & 51,1 & 23,1 \\
\hline $200 \times 40 \times 15$ & 1,0 & 44,3 & 39,9 & 30,6 & 13,7 \\
& 1,5 & 89,0 & 80,1 & 61,3 & 27,6 \\
\hline
\end{tabular}




\subsubsection{Eurocode}

In accordance with Eurocode 3, part 1-3, the resistance to flexural buckling can be written:

$$
N_{u}=\chi A_{e f} f_{y}
$$

where $A_{e f}$ is calculated in the same way as in section 3.8.2.

$$
\begin{array}{ll}
\chi=\frac{1}{\phi+\left[\phi^{2}-\bar{\lambda}^{2}\right]^{0,5}} & \text { but } \chi \leq 1,0 \\
\phi=0,5\left[1+\alpha(\bar{\lambda}-0,2)+\bar{\lambda}^{2}\right] & \\
\bar{\lambda}=\frac{1}{\pi} \frac{l}{i} \sqrt{\frac{f_{y}}{E} \beta_{A}} & \\
\beta_{A}=\frac{A_{e f}}{A_{g r}} & \\
i=\sqrt{\frac{I_{g r}}{A_{g r}}}
\end{array}
$$

For the C-sections studied $\alpha=0,34$ is assumed.

Table 4.3 The ultimate load, $N_{u}$ with respect to flexural buckling according to Eurocode 3, part 1-3, (kN).

\begin{tabular}{|c|c||c|c|c|c|}
\hline C-section & \multicolumn{1}{|c||}{ Thickness } & \multicolumn{4}{|c|}{ Steel temperature, ${ }^{\circ} \mathrm{C}$} \\
$b_{w} \times b_{f} \times b_{c}$ & $t$ & 20 & 200 & 400 & 600 \\
\hline \hline $100 \times 40 \times 15$ & 1,0 & 38,5 & 34,6 & 26,6 & 11,9 \\
& 1,5 & 69,6 & 62,6 & 48,0 & 21,6 \\
\hline $200 \times 40 \times 15$ & 1,0 & 47,2 & 42,5 & 32,5 & 14,6 \\
& 1,5 & 91,5 & 82,4 & 62,8 & 28,4 \\
\hline
\end{tabular}


The design curve in Eurocode 3 is more or less based on comparisons to tests but it also possible to calculate the curve using an assumed global imperfection $l / 1000$ and a assumed distribution of residual stresses. The different bucklingcurves are shown in Figure 4.2.

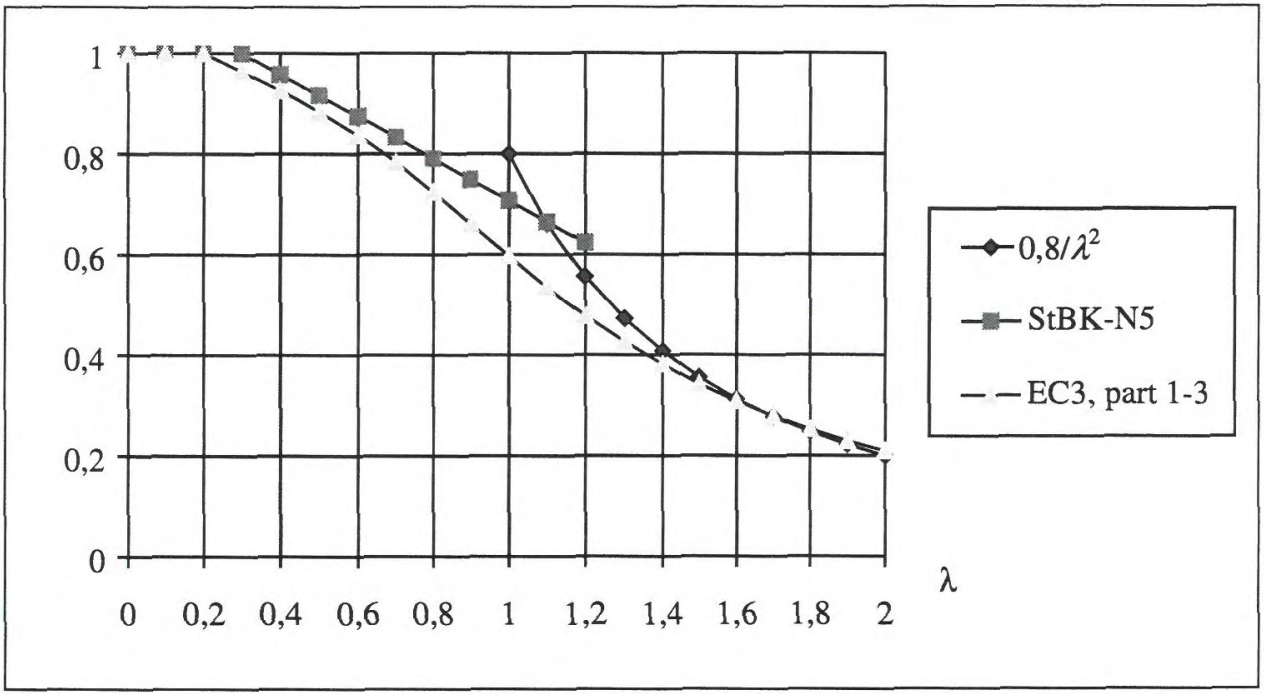

Figure 4.2 The buckling curves used in the different empirical models. The curve $0,8 / \lambda^{2}$ with $\lambda$ for the gross area is used as the upper limit in StBK-N5.

The so called European buckling curves in Eurocode 3 were originally developed for hot rolled or welded sections, based on experimental results from tests and theoretical analysis. The calculations included a global out-ofstraightness of $l / 1000$ and different residual stress patterns for different sections. Later their use was extended also to thin walled sections in Eurocode 3 , part 1-3. Thin walled sections have fairly small residual stresses and the residual stresses are likely to vanish at high temperatures. For simplicity the FE analysis includes only an initial out-of-straightness of $l / 1000$. This may lead to a higher predicted resistance at room temperature than according to codes but it is believed to give a fair estimate at high temperatures. 


\subsection{Resistance estimated by $\mathrm{FE}$ analyses}

Numerical calculations have been performed using the FE analysis software Abaqus, principally in the same way as described in section 3.9. But, an additional elastic static analysis was used to obtain a global component of the total initial geometrical imperfection.

The geometrical initial imperfections for the non-linear analysis was assumed as the sum of the global initial imperfections and the local initial imperfections. The local component of the initial imperfection was modelled in a form of plate buckling, Figure 4.3. The maximum local initial deflections were set to $b / 200$.

The global component of the initial imperfection is based on the assumption that the column section is crooked. This initial crookedness is taken into account in a form of half sinus wave with an amplitude of $l / 1000$.

As the length of the C-section is $2500 \mathrm{~mm}$, the total number of elements is 1084 and the number of nodes is 4187 . A characteristic input file used in the non-linear FE analysis model is available on $\mathrm{CD}$, [5].

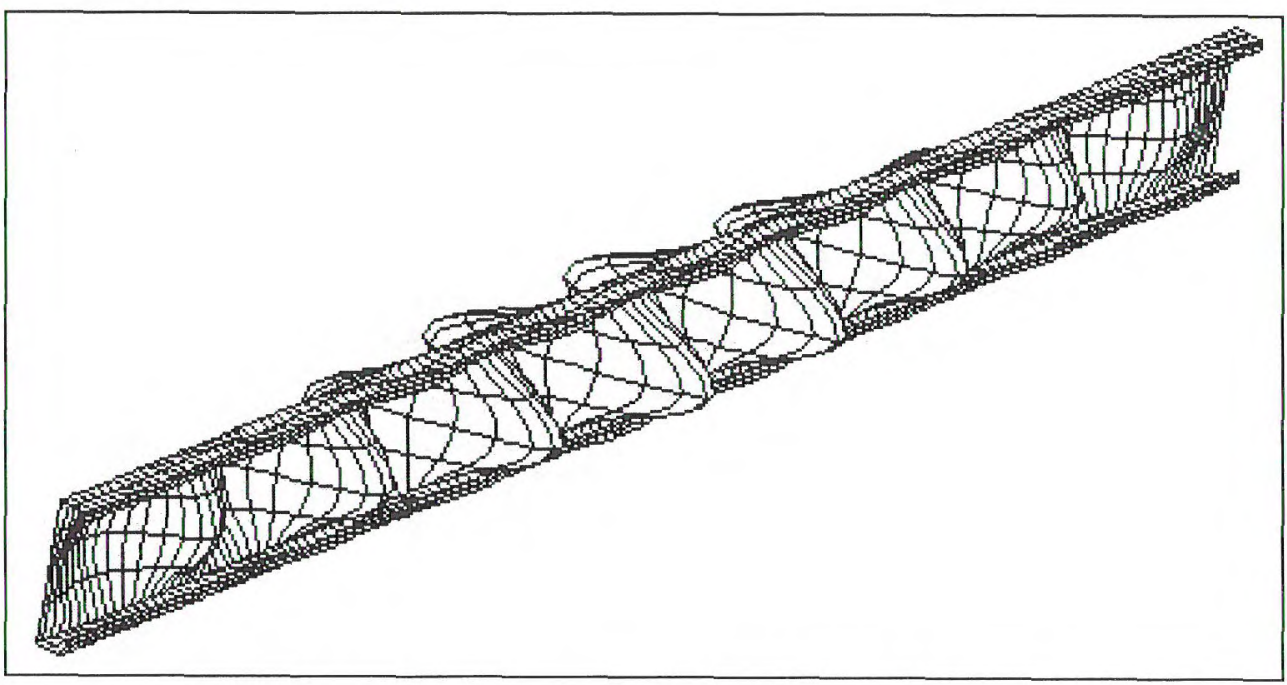

Figure 4.3 Local buckling mode of the column calculated by Abaqus. 
The result for the different $\mathrm{C}$-sections is shown in Table 4.4. In the FE analysis the stress-strain relationship of BSK, [7] was used at room temperature, at elevated temperature the relationship of Table 1.2 was used. The deformations calculated, excluding the initial deformations, are shown in Annex C. The mode of local buckling is shown in Figure 4.3.

Table 4.4 The ultimate load, $N_{u}$ with respect to flexural buckling according to $\mathrm{FE}$ analyses, $(\mathrm{kN})$. The columns are supported sideways along both flanges.

\begin{tabular}{|c|c||c|c|c|c|}
\hline C-section & \multicolumn{1}{|c||}{ Thickness } & \multicolumn{4}{c|}{ Steel temperature, ${ }^{\circ} \mathrm{C}$} \\
$b_{w} \times b_{f} \times b_{c}$ & $t$ & 20 & 200 & 400 & 600 \\
\hline \hline $100 \times 40 \times 15$ & 1,0 & 49,5 & 38,1 & 27,0 & 11,2 \\
& 1,5 & 88,4 & 65,2 & 46,1 & 19,8 \\
\hline $200 \times 40 \times 15$ & 1,0 & 52,5 & 42,1 & 28,9 & 12,4 \\
& 1,5 & 92,7 & 75,2 & 53,2 & 25,5 \\
\hline
\end{tabular}

\subsection{Verification of the FE analysis model}

To verify the numerical FE analysis model, tests done at the Department of Structural Engineering at the Royal Institute of Technology have been used. Two different panels which consist of two $\mathrm{C}$-section columns and a gypsum board attached to both flange were used in the experiment. The panel was nominally $600 \mathrm{~mm}$ wide and $2500 \mathrm{~mm}$ long, [30].

In the tests, the web began to buckle at the end of the strut when the load reached one fourth of the ultimate load. When the load reached half the ultimate value, the web was strongly buckled along the whole profile length. A short moment later the flange ends began to buckle. The ultimate load was reached when the flanges buckled.

The C-section columns had a slotted web to fulfil requirements of insulation. This alters the shear characteristics radically, reduces the load bearing resistance and complicates calculations. The tests were still used to verify the $\mathrm{FE}$ analysis because they were done recently, and similar tests were also done on simply supported sections, similar to those used in Chapter 5. 
Table 4.5 Measured cross section data, $(\mathrm{mm})$ of the columns tested, [30] specimens 1 and 2 , totally four $\mathbf{C}$-section columns.

\begin{tabular}{|c||c|c|c|c|c|c|c|c|}
\hline $\begin{array}{c}\text { Measured } \\
\text { data }\end{array}$ & $b_{s 1}{ }^{*}$ & $b_{c 1}$ & $b_{f 1}$ & $b_{s 2}{ }^{*}$ & $b_{c 2}$ & $b_{f 2}$ & $b_{w}$ & $b_{\text {slits }}$ \\
\hline \hline 1 & 19,0 & 11,0 & 39,5 & 20,0 & 10,0 & 43,5 & 148,5 & 72,0 \\
\hline 2 & 19,5 & 11,0 & 39,5 & 20,0 & 10,0 & 43,5 & 148,5 & 72,0 \\
\hline 3 & 19,5 & 11,0 & 40,0 & 20,5 & 11,0 & 44,0 & 149,0 & 72,0 \\
\hline 4 & 20,0 & 11,0 & 40,0 & 20,0 & 11,0 & 44,0 & 149,0 & 72,0 \\
\hline \hline $\begin{array}{c}\text { Mean } \\
\text { values }\end{array}$ & 20,0 & 11,0 & 40,0 & 20,0 & 11,0 & 44,0 & 149,0 & 72,0 \\
\hline
\end{tabular}

* $b_{s}$ is the edge part of the web not slotted

** $b_{\text {slits }}$ is the part of the web slotted.

The finite element mesh was created using mean geometrical values obtained from measurements on two specimens, Table 4.5. The measured plate thickness of $0,95 \mathrm{~mm}$ and material characteristics obtained from the uniaxial tensile tests were used in the analysis.

The geometry was modelled considering the slotted web in a rather realistic manner using 19000 elements and 21000 nodes. Shell elements appropriate for analysis of thin plates were used. The actual boundary conditions were modelled by using non-linear springs. These springs lie between the section and support nodes. They have large compressive stiffness and negligible tensile stiffness. In this way only compressive forces are transferred from the support nodes to the section. The uniform displacement was applied to the support nodes. Both flanges were latterally supported at the nodes at the middle of the flanges. The distance between the supports was $300 \mathrm{~mm}$.

The initial imperfections were modelled in a similar manner as discussed in section 4.4. Global imperfections are imposed in direction around the stronger axis of the cross section. The local buckling was taken into account using an elastic buckling analysis and the maximum amplitude was $0,75 \mathrm{~mm}$, imposed at the middle of the web. 


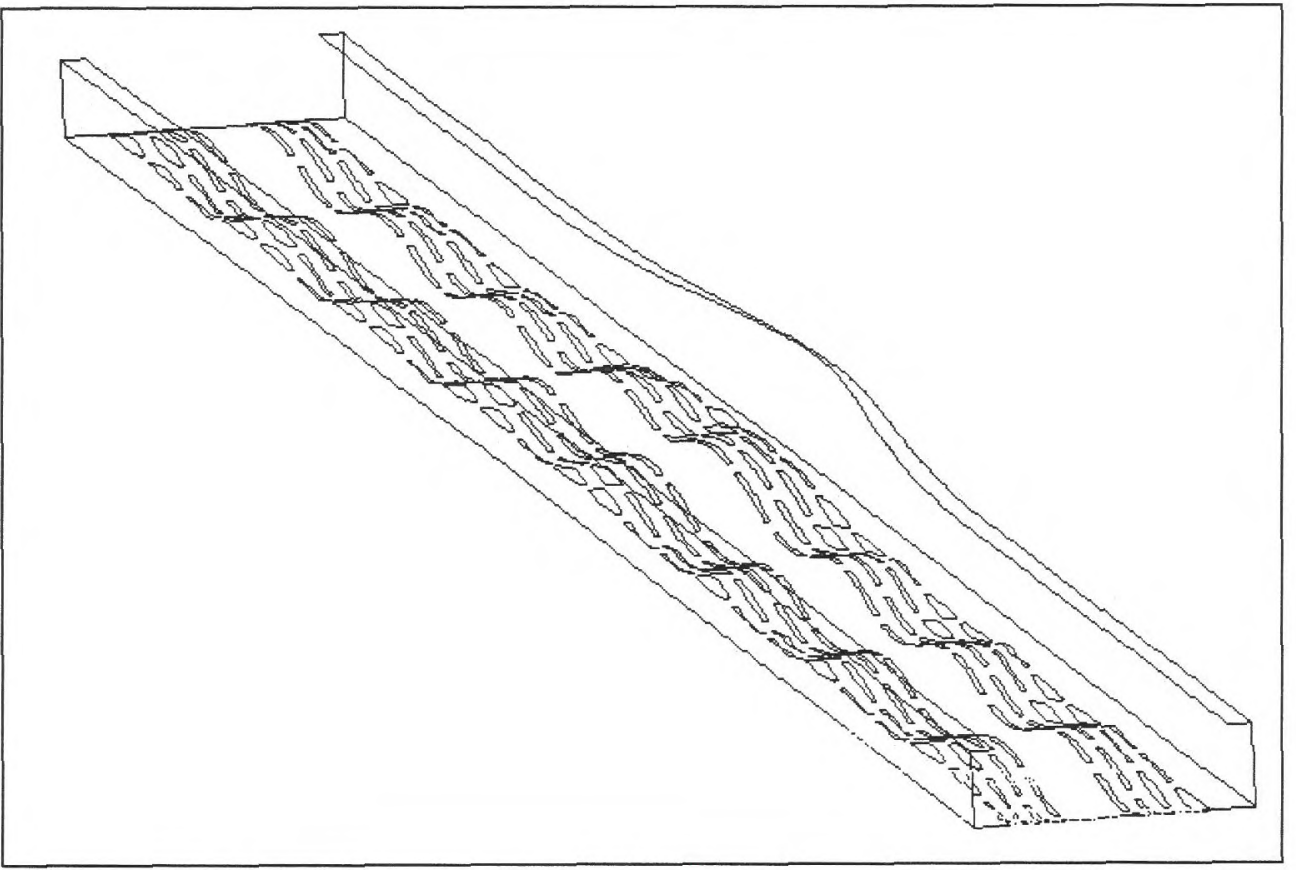

Figure 4.4 The displacement of the slotted section at the ultimate load, used to verify the FE-analysis model.

The influence of the gypsum plate on the lateral deformation of the column was modelled as a fixed support at the middle of the flanges. This means that the influence of the connection flexibility is neglected. Flexural stiffness of the gypsum plate and its influence to prevent displacements in the plane of the cross section was taken into account by linear springs.

The results obtained from the $\mathrm{FE}$ analysis, $30,1 \mathrm{kN}$ is almost the same as the two experimental results of 29,0 and $30,8 \mathrm{kN}$, Table 4.6 . The failure mode obtained from FEA is rather similar to the one observed in the experiments. However, the section shortering at the maximum load obtained from FEA is much smaller than the change of the length. This difference was expected since no flexibility of the connection between the section and gypsum plate was considered. 
Table 4.6 Ultimate load resistance of the different columns tested and analysed, (kN).

\begin{tabular}{|c||c|c|c|}
\hline Test & FE analysis & KTH test & $\begin{array}{c}\text { FE analysis / } \\
\text { KTH test }\end{array}$ \\
\hline \hline 1 & \multirow{2}{*}{30,1} & 29,0 & 1,04 \\
\cline { 3 - 4 } & & 30,8 & 0,98 \\
\hline
\end{tabular}

\subsection{Summary of results from calculations}

The ultimate load resistance with respect to flexural buckling can be estimated in different ways. In this chapter the models presented in StBK-N5 and Eurocode 3, part 1-3 are described. In comparison to the FE analysis done, these empirical models give higher values of the ultimate load. But, it is evident that the relation of FEA/EC 3 gives higher values at a room temperature of $20^{\circ} \mathrm{C}$. This is, as described in section 3.11, caused by the steel hardening phase of the stress strain relationship. For higher temperatures the result is the opposite, Tables 4.7-4.10.

Table 4.7 Ultimate load, (kN) according to $\mathrm{FE}$ analyses, Eurocode 3, part 1-3 and StBK-N5.

\begin{tabular}{|c||c|c|c|c|}
\hline \multicolumn{1}{|c||}{ Steel Temperature, ${ }^{\circ} \mathrm{C}$} & \multicolumn{4}{c|}{ C-section $100 \times 40 \times 15, t=1,0 \mathrm{~mm}$} \\
& FEA & EC 3 & StBK -N5 & FEA/EC 3 \\
\hline \hline 20 & 49,2 & 38,5 & 38,4 & 1,28 \\
200 & 38,1 & 34,6 & 34,6 & 1,16 \\
400 & 27,0 & 26,6 & 26,6 & 1,02 \\
600 & 11,2 & 11,9 & 11,9 & 0,94 \\
\hline
\end{tabular}

Table 4.8 Ultimate load, ( $\mathrm{kN}$ ) according to $\mathrm{FE}$ analyses, Eurocode 3 , part 1-3 and StBK-N5.

\begin{tabular}{|c||c|c|c|c|}
\hline \multicolumn{1}{|c||}{ Steel Temperature, ${ }^{\circ} \mathrm{C}$} & \multicolumn{4}{c|}{ C-section $100 \times 40 \times 15, t=1,5 \mathrm{~mm}$} \\
& FEA & EC 3 & StBK -N5 & FEA/EC 3 \\
\hline \hline 20 & 88,4 & 69,6 & 74,6 & 1,27 \\
200 & 65,2 & 62,6 & 67,1 & 1,04 \\
400 & 46,1 & 48,0 & 51,1 & 0,96 \\
600 & 19,8 & 21,6 & 23,1 & 0,92 \\
\hline
\end{tabular}




\subsection{Conclusions}

Results show fairly good agreement between the empirical estimations of StBK$\mathrm{N} 5$ and Eurocode 3, part 1-3. In comparison to the results from the FE analysis, the empirical estimations give higher values of the ultimate load at elevated temperature. At room temperature the opposite is valid. This is, as mentioned before, probably because of the strain stress hardening phase of the stress strain relationship used in the numerical model. For both the empirical estimations the 0,2 per cent plastic strain limit was used to define the yield strength. The comparison in this chapter shows that the 0,2 per cent limit is suitable also in the field of flexural buckling.

The FE analysis has been verified by comparing it to experimental test results. In these tests slotted C-section columns were compressed to failure. The result of the comparison shows a pretty good agreement between the tests and FE analysis, as the obtained numerical result was almost the same as the two experimental results.

Table 4.9 Ultimate load, (kN) according to FE analyses, Eurocode 3, part 1-3 and StBK-N5.

\begin{tabular}{|c||c|c|c|c|}
\hline \multicolumn{1}{|c||}{ Steel Temperature, ${ }^{\mathrm{O}} \mathrm{C}$} & \multicolumn{4}{c|}{ C-section $200 \times 40 \times 15, t=1,0 \mathrm{~mm}$} \\
& FEA & EC 3 & StBK -N5 & FEA/EC 3 \\
\hline \hline 20 & 52,5 & 47,2 & 44,3 & 1,11 \\
200 & 42,1 & 42,5 & 39,9 & 0,99 \\
400 & 28,9 & 32,5 & 30,6 & 0,89 \\
600 & 12,4 & 14,6 & 13,7 & 0,85 \\
\hline
\end{tabular}

Table 4.10. Ultimate load, (kN) according to FE analyses, Eurocode 3, part 1-3 and StBK-N5.

\begin{tabular}{|c||c|c|c|c|}
\hline \multicolumn{1}{|c||}{ Steel Temperature, ${ }^{\circ} \mathrm{C}$} & \multicolumn{4}{c|}{ C-section $200 \times 40 \times 15, t=1,5 \mathrm{~mm}$} \\
& FEA & EC 3 & StBK -N5 & FEA/EC 3 \\
\hline \hline 20 & 92,7 & 91,5 & 89,0 & 1,01 \\
200 & 75,2 & 82,4 & 80,1 & 0,92 \\
400 & 53,2 & 62,8 & 61,3 & 0,85 \\
600 & 25,5 & 28,4 & 27,6 & 0,90 \\
\hline
\end{tabular}


The very good accordance between empirical estimations, FE analysis and test results confirm the conclusions in section 3.12. Eurocode 3, part 1-3 with reduced yield strength and elastic modulus is accurate enough to use also at elevated temperatures provided that the yield strength is taken as the 0,2 per cent proof stress. From the result, it is also clear that with the typical value of the load reduction factor of 0,6 , the maximum steel temperature regarding the load bearing resistance is clearly above $350{ }^{\circ} \mathrm{C}$ and rather in the range of $450{ }^{\circ} \mathrm{C}$. 


\section{TORSIONAL-FLEXURAL BUCKLING OF THIN WALLED STEEL COLUMNS}

\subsection{General}

A thin walled steel C-section column supported laterally along one of the flanges will buckle both in torsion and flexure. Torsional-flexural buckling is characterised of the fact that the unsupported flange is bent in the $x$-direction while the other flange remains straight in the $x$-direction. This situation leads to a buckling deformation combined of torsion and lateral bending about the longitudinal axis. The deformation may in this case be described as a pure rotation about the supported axis. Calculation of the load bearing resistance with regard to torsional-flexural buckling of a thin walled steel C-section column according to Eurocode 3, part 1-3, is similar to the procedure for finding the resistance due to flexural buckling. The starting point is to find the elastic critical load, which is calculated for the gross cross-section. The next step is to calculate the slenderness parameter:

$$
\lambda=\sqrt{\frac{f_{y}}{\sigma_{c r}} \beta_{A}}
$$

The critical stress is normally defined as the maximum compressive stress caused by the critical load and it is calculated using the gross cross-section. In this case the relevant stress is the stress in the unsupported flange which varies from a maximum at the end to a minimum at the middle of the length. In a laterally buckled state there are axial stresses from axial loading, bending in the strong direction and lateral bending. The design cross section should be the one where the sum of these stresses has a maximum. The location of this crosssection will depend on the relation between stresses caused by axial loading and strong axis bending. The FE simulations indicate that the location will be in the middle of the steel column.

The critical stress has two components, one from the axial force and one from the bending moment. Instead of using equation 5.1, the critical stress will be calculated using effective section properties from the critical load, which still is calculated using gross section properties. This procedure is more accurate than equation 5.1 and this accuracy is thought to be needed because the critical stress is the difference between two components. 
Torsional-flexural buckling is used to model the fire exposure situation, resulting in loss of the support of the exposed flange. How this is solved empirically is presented below. Comparative numerical FE analysis calculations are also presented. They are verified by tests available in the literature, [30].

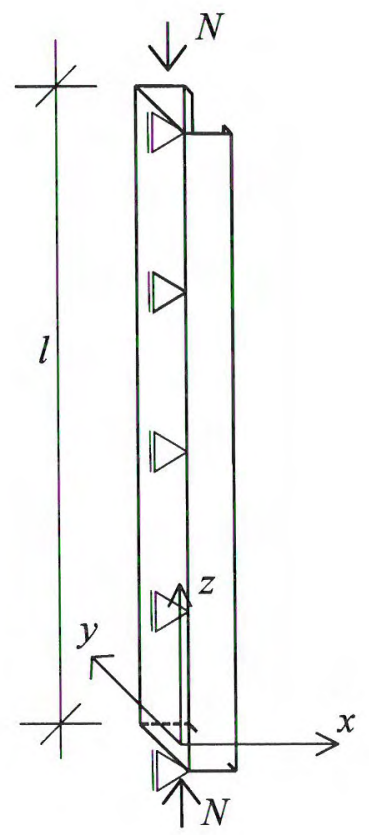

Figure 5.1 A C-section column, affected by an axial load at the centre of gravity, supported along one flange will buckle in torsion and flexure.

\subsection{Structural model}

The structural model used is a C-section column with a length of $2500 \mathrm{~mm}$, Figure 5.1. It is supported sideways along one flange according to Figure 5.2. The axial load affects the column at the centre of gravity and the buckling length is taken as equal to the length of the profile. For the empirical estimations the 0,2 per cent plastic strain limit was used to define the yield strength, Table 1.1. 

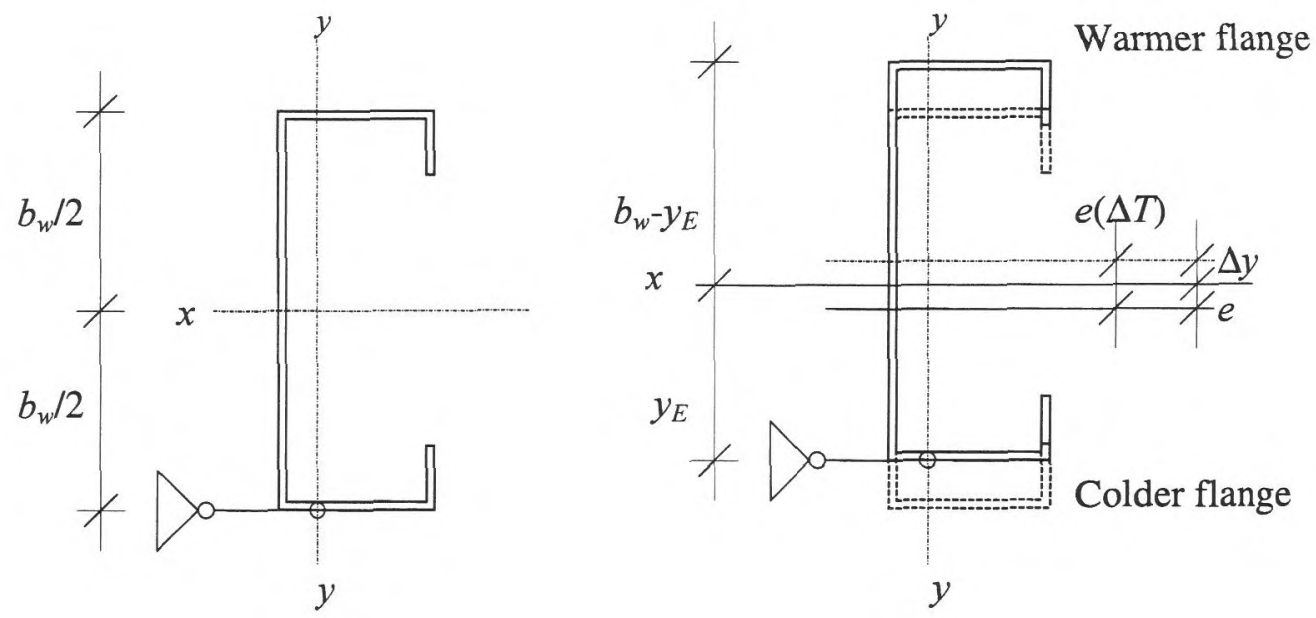

Figure 5.2 AC-section, thermally deflected in the $y$-direction, $e(\Delta T)$. The centre of gravity will move towards the supported cold outer flange since the highest elastic modulus is in this part. The effective eccentricity is then $e=e(\Delta T)-\left(b_{w} / 2-y_{E}\right)$.

\subsection{Empirical estimation of the resistance}

The critical torsional buckling load, according to section 1.4, can be written:

$$
N_{c r}=\frac{1}{b^{2}+i_{p}^{2}-e \frac{8 b_{w}}{3 \pi}}\left[\left(B_{y} b^{2}+C_{w}\right) \frac{\pi^{2}}{l^{2}}+C\right]
$$

The critical stress is written:

$$
\begin{aligned}
& \sigma_{c r}=\frac{N_{c r}}{A_{e f}}+\frac{M_{c r}}{W_{e f}} \\
& M_{c r}=-N_{c r} e
\end{aligned}
$$


The effective cross sectional area, $A_{e f}$ is determined for the different plane elements based on their effective width. $e(\Delta T)$ is the thermal eccentricity caused by the temperature gradient across the steel section. The difference in thermal elongation between the flanges will cause a deflection, shaped as a circle bow of the column. This circle shape is approximated by half a sine wave. The "elastic centre of gravity" moves towards the supported colder outer flange since the elastic modulus is higher in this part. The effective eccentricity is then reduced with the difference between $b_{w} / 2$ and $y_{E}$, Figure 5.2.

$$
\begin{aligned}
& e=e(\Delta T)-\Delta y \\
& \Delta y=b_{w} / 2-y_{E}
\end{aligned}
$$

Then, with respect to the warmer unsupported flange:

$$
W_{e f}=\frac{I_{e f}}{b_{w}-y_{E}}
$$

Equation 5.3 can now be written:

$$
\sigma_{c r}=\frac{N_{c r}}{A_{e f}}-\frac{N_{c r} e\left(b_{w}-y_{E}\right)}{I_{e f}}
$$

As the critical torsional buckling load can be calculated according to equation 5.2, the slenderness parameter can be written:

$$
\lambda=\sqrt{\frac{f_{y}}{\frac{N_{c r}}{A_{e f}}-\frac{N_{c r} e\left(b_{w}-y_{E}\right)}{I_{e j}}}}
$$

The slenderness parameter is calculated for the warmer inner side and $f_{y}$ is reduced for the steel temperature in this flange. Then:

$$
\begin{aligned}
& \phi=0,5\left[1+\alpha(\lambda-0,2)+\lambda^{2}\right] \quad \text { where } \alpha=0,34 \\
& \chi=\frac{1}{\phi+\left[\phi^{2}-\lambda^{2}\right]^{0,5}}
\end{aligned}
$$


The ultimate load bearing resistance, in accordance to Eurocode 3, part 1-3, is written:

$$
\frac{N_{u}}{\not f_{y} A_{e f}}+\frac{\kappa_{x} M_{u}}{f_{y} W_{e f}} \leq 1,0
$$

$f_{y}$ is reduced with respect to the maximum steel temperature and $\kappa_{x}$ is explained in equation 5.23. For the warmer inner flange this leads to equation 5.13 as the thermal deflection will cause tension in this flange.

$$
N_{u}=\frac{\chi f_{y} A_{e f}}{1-\frac{\kappa_{x} e\left(b_{w}-y_{E}\right) \chi A_{e f}}{I_{e f}}}
$$

This equation is valid for the mid section. But, as $e(\Delta T)=0$ at the ends of the column, equation 5.13 valid for the ends can the be written:

$$
N_{u}=\frac{\chi f_{y} A_{e f}}{1+\frac{\kappa_{x} \Delta y\left(b_{w}-y_{E}\right) \chi A_{e f}}{I_{e f}}}
$$

If there is no difference in temperature between the two flanges, the load affects the section at the centre of gravity, both $e(\Delta T)=\Delta y=0$. The load bearing resistance can then be written:

$$
N_{u}=\chi f_{y} A_{e f}
$$

Table 5.1 The resistance, $N_{u}$ with respect to torsional-flexural buckling, $(\mathrm{kN})$. The column is supported along one flange and $e(\Delta T)=0$.

\begin{tabular}{|c|c||c|c|c|c|}
\hline C-section & \multicolumn{1}{|c||}{ Thickness } & \multicolumn{4}{c|}{ Steel temperature, ${ }^{\circ} \mathrm{C}$} \\
$b_{w} \times b_{f} \times b_{k}$ & $t$ & 20 & 200 & 400 & 600 \\
\hline \hline $100 \times 40 \times 15$ & 1,0 & 15,2 & 13,6 & 10,5 & 4,7 \\
& 1,5 & 23,4 & 21,0 & 16,3 & 7,2 \\
\hline $200 \times 40 \times 15$ & 1,0 & 18,2 & 16,4 & 12,7 & 5,6 \\
& 1,5 & 28,4 & 25,5 & 19,8 & 8,8 \\
\hline
\end{tabular}


The critical torsional buckling load, $N_{c r}$ has been determined in section 1.4. The actual yield stress $f_{y}$ is reduced with respect to the maximum steel temperature. The ultimate load $N_{u}$ with respect to torsional-flexural buckling without any eccentricity is presented in Table 5.1 above.

If there is a temperature difference, temperature gradient, across the steel section, an out of plane deformation in the $y$-direction arises because of the differences in the thermal elongation. The axial load then gives rise to a moment. The difference in thermal elongation between the flanges can be written, see section 1.3:

$$
\Delta l=l\left[1,2 \times 10^{-4}\left(T_{\max }-T_{\min }\right)+0,4 \times 10^{-8}\left(T_{\max }^{2}-T_{\min }^{2}\right)\right]
$$

By using the geometrical equation of a circular arc the mid length deflection of the steel section column can be calculated. This thermal deflection is written as a half sinus curve, having its maximum at $z=l / 2$ and equal to zero at the ends of the column, see section 1.4.2.

For the empirical estimations, a linear temperature gradient was assumed, Table 5.2. This temperature development can reasonably be the case for an axially compressed thin walled steel column between two layers of gypsum boards in a wall subjected to fire. The thermal mid length deflection is presented in Table 5.2 .

Table 5.2 The mid length deflection, maximum eccentricity $e(\Delta T)_{\max }$ caused by the temperature gradient, $l=2500 \mathrm{~mm}$.

\begin{tabular}{|c||c|c|c|c|c|}
\hline \multicolumn{1}{|c||}{} & \multicolumn{5}{c|}{ Approximate time after ignition, minutes } \\
& 40 & 45 & 48 & 51 & 53 \\
\hline \hline$T_{f o}{ }^{\circ} \mathrm{C}$ & 100 & 100 & 100 & 200 & 250 \\
\hline$T_{\text {web }}{ }^{\mathrm{O}} \mathrm{C}$ & 150 & 200 & 250 & 350 & 400 \\
\hline$T_{f i}{ }^{\mathrm{O}} \mathrm{C}$ & 200 & 300 & 400 & 500 & 550 \\
\hline$\Delta T{ }^{\circ} \mathrm{C}$ & 100 & 200 & 300 & 300 & 300 \\
\hline $\begin{array}{c}e(\Delta T)_{\max } \mathrm{mm} \\
b_{w}=100 \mathrm{~mm}\end{array}$ & 10 & 19 & 28 & 29 & 30 \\
\hline $\begin{array}{l}e(\Delta T)_{\max } \mathrm{mm} \\
b_{w}=200 \mathrm{~mm}\end{array}$ & 5 & 10 & 15 & 16 & 16 \\
\hline
\end{tabular}


The deflection due to the temperature gradient will increase as a consequence of the bending moment caused by the axial force.

$$
e=e_{o} \frac{1}{1-\frac{N_{u}}{N_{c r, x}}}
$$

This equation is iterative solved to find the ultimate load $N_{u} \cdot e_{0}$ is the original effective eccentricity and $N_{c r, x}$ is the critical Euler load, written:

$$
N_{c r, x}=\frac{\pi^{2} \Sigma E I_{g r}}{l^{2}}
$$

The eccentricity shall be referred to the effective centre of gravity for the cross section area weighted with regard to their different elastic modulus and $\Sigma E I_{g r}$ symbolises the bending stiffness of the cross section.

The ultimate load $N_{u}$ with regard to torsional-flexural buckling for different eccentricities at elevated temperature is shown in Table 5.3. The temperature of the warm inner flange was used to determine the elastic modulus when the critical torsional buckling load was calculated, equation 5.2. This temperature was also used to determine the slenderness parameter of equation 5.9 and the ultimate load bearing resistance of equations $5.13,5.14$ and 5.15 .

Table 5.3 The resistance, $N_{u}$ with respect to torsional-flexural buckling, calculated at mid length, $(\mathrm{kN})$. The maximum steel temperature was used.

\begin{tabular}{|c|c||c|c|c|c|c|}
\hline C-section & \multicolumn{1}{|c||}{ Thickness } & \multicolumn{5}{c|}{ Steel temperature, ${ }^{\circ} \mathrm{C}, T_{f o}, T_{\text {web }}, T_{f i}$} \\
$b_{w} \times b_{f} \times b_{k}$ & $t$ & 100 & 100 & 100 & 200 & 250 \\
& & 150 & 200 & 250 & 350 & 400 \\
& & 200 & 300 & 400 & 500 & 550 \\
\hline \hline \multicolumn{2}{|c|}{$e(\Delta T)_{\max }, \mathrm{mm}$} & 10 & 19 & 28 & 29 & 30 \\
\hline $100 \times 40 \times 15$ & 1,0 & 14,1 & 12,0 & 8,3 & 6,8 & 5,9 \\
& 1,5 & 20,4 & 15,5 & 9,1 & 7,3 & 7,0 \\
\hline \hline \multicolumn{2}{|c|}{$e(\Delta T)_{\max }, \mathrm{mm}$} & 5,0 & 10 & 15 & 16 & 16 \\
\hline $200 \times 40 \times 15$ & 1,0 & 16,4 & 14,4 & 12,6 & 10,7 & 7,5 \\
& 1,5 & 25,5 & 22,6 & 21,1 & 16,6 & 12,0 \\
\hline
\end{tabular}


Later the same procedure was repeated. But now with the average steel temperature was used to determine the elastic modulus for the critical torsional buckling load, the slenderness parameter and the ultimate load bearing resistance, Table 5.4.

Table 5.4 The resistance, $N_{u}$ with respect to torsional-flexural buckling, calculated at mid length, $(\mathrm{kN})$. The average steel temperature was used.

\begin{tabular}{|c|c||c|c|c|c|c|}
\hline C-section & Thickness & \multicolumn{5}{c|}{ Steel temperature, ${ }^{\circ} \mathrm{C}, T_{f o}, T_{\text {web, }} T_{f i}$} \\
$b_{w} \times b_{f} \times b_{k}$ & $t$ & 100 & 100 & 100 & 200 & 250 \\
& & 150 & 200 & 250 & 350 & 400 \\
& & 200 & 300 & 400 & 500 & 550 \\
\hline \hline \multicolumn{2}{|c||}{$e(\Delta T)_{\max }, \mathrm{mm}$} & 10 & 19 & 28 & 29 & 30 \\
\hline $100 \times 40 \times 15$ & 1,0 & 14,9 & 13,4 & 9,4 & 8,3 & 7,2 \\
& 1,5 & 21,5 & 17,2 & 11,2 & 9,0 & 9,9 \\
\hline \hline \multicolumn{2}{|c|}{$e(\Delta T)_{\max }, \mathrm{mm}$} & 5,0 & 10 & 15 & 16 & 16 \\
\hline $200 \times 40 \times 15$ & 1,0 & 17,3 & 16,3 & 15,4 & 13,5 & 11,8 \\
& 1,5 & 26,9 & 25,4 & 24,0 & 21,1 & 18,9 \\
\hline
\end{tabular}

The result shown in Tables 5.3 and 5.4 is the resistance with respect to torsional-flexural buckling. As the increasing moment has a positive effect on the load bearing resistance, the resistance with respect to flexural buckling has to be checked as well.

This will be governed by the supported colder outer flange. In this estimation the elastic modulus and yield strength are reduced with respect to the average temperature, since the first term in equation 5.19 is predominant. The colder outer supported flange is compressed both of the axial load and the bending moment.

The resistance with respect to flexural buckling according to Eurocode 3, part 1-3 is written:

$$
\frac{N_{u}}{\not f_{y} A_{e f}}+\frac{\kappa_{x} M_{u}}{f_{y} W_{e f}} \leq 1
$$


For the colder outer flange the combination of compression and bending leads to equation 5.22 as:

$$
\begin{array}{ll}
M_{u}=N_{u} e & \\
W_{e f}=\frac{I_{e f}}{y_{E}} & \\
\frac{N_{u}}{\chi f_{y} A_{e f}}+\frac{K_{x} N_{u} e y_{E}}{f_{y} I_{e f}} \leq 1 & \text { but } \kappa_{x} \leq 1,5 \\
\kappa_{x}=1-\frac{\mu_{x} N_{u}}{\chi \chi_{y} A_{e f}} & \text { but } \mu_{x} \leq 0,90 \\
\mu_{x}=\bar{\lambda}\left(2 f_{M, x}-4\right) & \text { where } \beta_{A}=\frac{A_{e f}}{A_{g r}} \\
\beta_{M, x}=1,3 & \text { where } \alpha=0,34 \\
\bar{\lambda}=\frac{1}{\pi} \frac{l}{i} \sqrt{\frac{f_{y}}{E} \beta_{A}} & \text { but } \chi \leq 1,0 \\
\phi=0,5\left[1+\alpha(\bar{\lambda}-0,2)+\bar{\lambda}^{2}\right] & \\
\chi=\frac{1}{\phi+\left[\phi^{2}-\bar{\lambda}^{2}\right]^{0,5}} &
\end{array}
$$

In this calculation the thermal deflection $e$ equal to $e(\Delta T)-\Delta y$ with respect to the half sinus curve form of thermal deflection. The factor $\beta_{M, x}=1,3$ according to Eurocode 3, part 1-3. 
Table 5.5 The resistance, $N_{u}$ with respect to flexural buckling, $(\mathrm{kN})$.

\begin{tabular}{|c|c||c|c|c|c|c|}
\hline C-section & Thickness & \multicolumn{5}{c|}{ Steel temperature, ${ }^{\circ} \mathrm{C}, T_{f o}, T_{\text {web }}, T_{f i}$} \\
$b_{w} \times b_{f} \times b_{k}$ & $t$ & 100 & 100 & 100 & 200 & 250 \\
& & 150 & 200 & 250 & 350 & 400 \\
& & 200 & 300 & 400 & 500 & 550 \\
\hline \hline \multicolumn{2}{|c|}{$e(\Delta T)_{\max }, \mathrm{mm}$} & 10 & 19 & 28 & 29 & 30 \\
\hline $100 \times 40 \times 15$ & 1,0 & 29,8 & 24,9 & 21,6 & 18,8 & 19,8 \\
& 1,5 & 52,4 & 45,3 & 37,4 & 32,8 & 34,5 \\
\hline \hline \multicolumn{2}{|c|}{$e(\Delta T)_{\max }, \mathrm{mm}$} & 5,0 & 10 & 15 & 16 & 16 \\
\hline $200 \times 40 \times 15$ & 1,0 & 44,8 & 42,8 & 40,8 & 35,8 & 37,7 \\
& 1,5 & 85,4 & 81,4 & 77,7 & 68,5 & 72,5 \\
\hline
\end{tabular}

The ultimate load starts to increase for the warmest alternative of all sections. This is caused by the fact that the "elastic centre of gravity" moves and reduces the eccentricity which compensates for the reduced material properties. A comparison to Tables 5.3 and 5.5 shows that the flexural buckling check will not be the governing failure mode.

\subsection{Resistance estimated by $F E$ analyses}

Numerical calculations have been performed using the FE analysis software of Abaqus, principally in the same way as described in section 4.4. The sinus half formed deflection caused by the temperature gradient has been added to the initial imperfections described in section 4.4.

In the FE model used to model torsional-flexural failure the load is transferred to the corners of the C-section through "virtual" spreader beams and appropriate spring elements. This is done in such a manner that simply supported boundary conditions are obtained even for lateral bending of the flanges. The load is always introduced at the original centre of gravity of the cross section. As described in section 4.4 three types of analyses were performed in order to estimate the ultimate load resistance of the section. A characteristic input file used of the non-linear FE analysis model is available on $\mathrm{CD}$, [5]. 
Elastic static and elastic buckling analyses were used to obtain an initial geometry for a non-linear static analysis. Local initial imperfections were taken into account in the form of the buckling mode that shows the buckling pattern of the components of the cross-section. The maximum magnitude of the imperfections was $b / 200$ and it was applied to the web.

Two components of the initial global imperfections, bending about the stronger axis of the section and a sideway bending of the unconstrained flange, were taken into account by the static analysis. In the static analysis a displacement field in the form of half a sinus wave was applied to two edges of the unconstrained flange with amplitude $l / 1000$. The same FE procedure was used to impose the imperfection in the lateral direction of the unsupported flange. The total geometrical imperfection is obtained by summing all imperfections mentioned above. However, such an approach does not always leads to the minimum resistance. For a deeper profile, e.g. $200 \times 40 \times 15$, a local imperfection of the edge stiffener of the unsupported flange have to be considered. This type of local imperfections leads to a lower resistance of the cross section for a more slender edge stiffener, Figure 5.3. No initial stresses exist in the model.

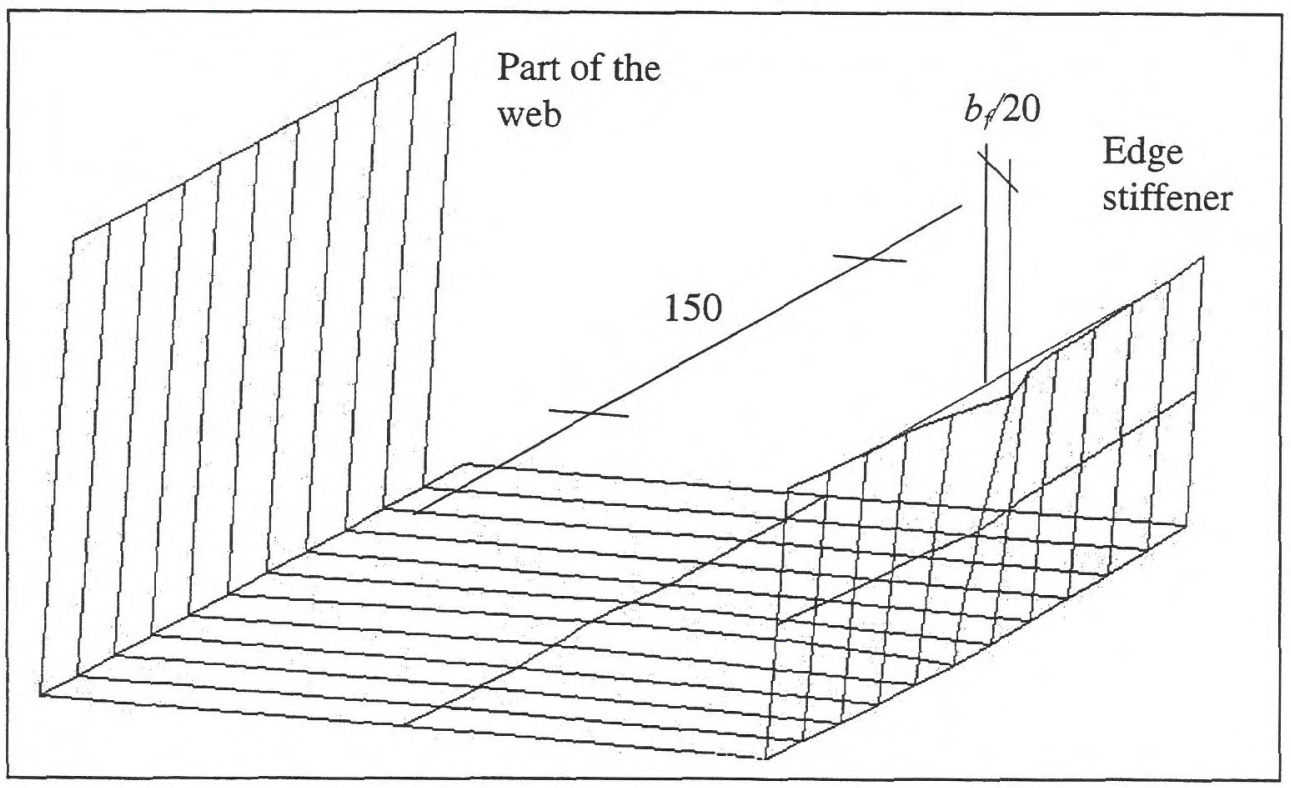

Figure 5.3 Imperfection of the edge stiffener. 
Both possible local imperfection types were considered in the case of $\mathrm{C}$ $200 \times 40 \times 15$ for thicknesses $1,0 \mathrm{~mm}$ and $1,5 \mathrm{~mm}$ at room temperature. The thicker profile had approximately the same resistance independent of which type of local imperfection that was imposed. The ultimate resistance obtained was $33,7 \mathrm{kN}$ and $34,8 \mathrm{kN}$ when a local imperfection of the edge stiffener and a local imperfection in the form of a critical mode were used respectively.

For the $1,0 \mathrm{~mm}$ thick profile the ultimate resistance is overwhelmingly influenced by the type of local imperfection imposed.17,5 $\mathrm{kN}$ and $23,6 \mathrm{kN}$ was obtained when a local imperfection of the edge stiffener and a local imperfection in the form of the critical mode were used respectively.

Such big influence of the type of local imperfection is the main characteristic for the stability problems of columns where critical loads for different eigen modes are very close.

The results for the different $\mathrm{C}$-section columns are shown in Tables 5.6 and 5.7. In the FE analysis the stress-strain relationship of BSK, [7] was used at room temperature. At elevated temperature the relationship of Table 1.2 was used.

The temperatures valid when there is a gradient are shown in Table 5.2. They will cause different reduced values of the yield strength and elastic modulus for different parts of the same C-section. The failure mode is shown in Figure 5.4.

All results shown in Table 5.6 and Table 5.7 were obtained using the same FE model. In almost all calculations the maximum load is clearly defined since the calculation has converged within the same accuracy in the post ultimate region as during the load increase.

Table 5.6. The resistance, $N_{u}$ with respect to torsional-flexural buckling according to $\mathrm{FE}$ analyses, $(\mathrm{kN})$. No temperature gradient is present.

\begin{tabular}{|c|c||c|c|c|c|}
\hline C-section & \multicolumn{1}{|c||}{ Thickness } & \multicolumn{4}{c|}{ Steel temperature, ${ }^{\circ} \mathrm{C}$} \\
$b_{w} \times b_{f} \times b_{k}$ & $t$ & 20 & 200 & 400 & 600 \\
\hline \hline $100 \times 40 \times 15$ & 1,0 & 15,7 & 12,1 & 10,7 & 5,8 \\
& 1,5 & 26,0 & 18,2 & 17,2 & 8,9 \\
\hline $200 \times 40 \times 15$ & 1,0 & $23,6 / 17,5$ & 18,9 & 15,0 & 7,0 \\
& 1,5 & $34,8 / 33,7$ & 28,1 & 25,8 & 12,3 \\
\hline
\end{tabular}


Table 5.7 The resistance, $N_{u}$ with respect to torsional-flexural buckling according to $\mathrm{FE}$ analyses, $(\mathrm{kN})$. A temperature gradient is present.

\begin{tabular}{|c|c||c|c|c|c|c|}
\hline C-section & Thickness & \multicolumn{5}{|c|}{ Steel temperature, ${ }^{\mathrm{O}} \mathrm{C}, T_{\text {for }}, T_{\text {web }}, T_{f i}$} \\
$b_{w} \times b_{f} \times b_{k}$ & $t$ & 100 & 100 & 100 & 200 & 250 \\
& & 150 & 200 & 250 & 350 & 400 \\
& & 200 & 300 & 400 & 500 & 550 \\
\hline \hline $100 \times 40 \times 15$ & 1,0 & 11,9 & 11,5 & 10,8 & 9,5 & 8,1 \\
& 1,5 & 18,3 & 17,3 & 14,4 & 12,6 & 11,1 \\
\hline $200 \times 40 \times 15$ & 1,0 & 18,2 & 17,7 & 16,4 & 14,5 & 13,4 \\
& 1,5 & 29,1 & 27,6 & 25,5 & 23,0 & $15,6^{*}$ \\
\hline
\end{tabular}

* Abaqus calculation stopped due to numerical problems.

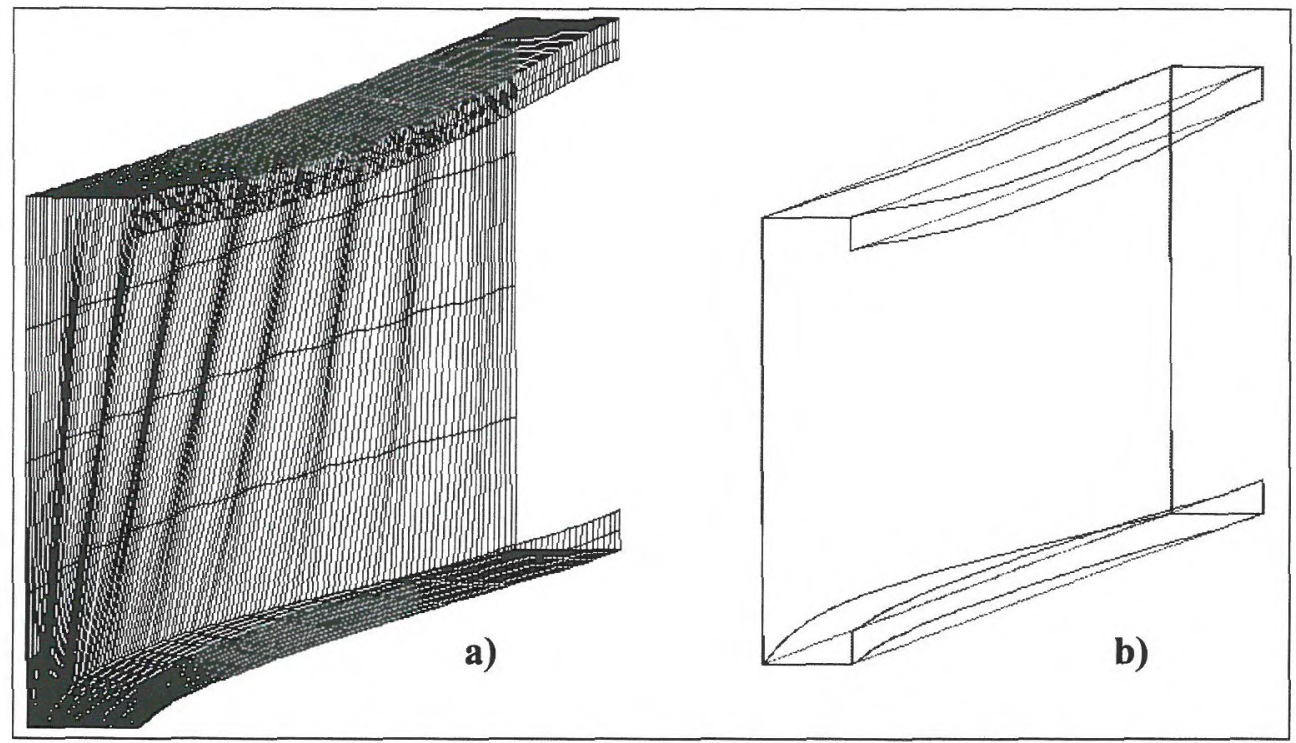

Figure 5.4 The failure mode of torsional-flexural buckling by Abaqus.

a. Finite element mesh, notice buckling in the web.

b. Perimeter plot, original plot, original and displace state. 


\subsection{Verification of the $\mathrm{FE}$ analysis model}

To verify the FE analysis model, tests done at the Department of Structural Engineering at the Royal Institute of Technology in Stockholm have been used as a reference. In the test, a panel which consists of two C-section columns and a gypsum board attached to one flange was used. The panel was nominally $600 \mathrm{~mm}$ wide and $2500 \mathrm{~mm}$ long, [30].

During the tests, the web began to buckle when the load reached one third of the ultimate load. The web buckling was fully developed when two thirds of the ultimate load had been reached. Just before the ultimate load was reached, the unsupported flange buckled laterally. When the load was increased further, this deformation grew and resulted in failure near the middle of the $\mathrm{C}$-section.

In the FE analysis only one column was modelled. One flange was fully constrained against lateral displacement at nine nodes. These nodes correspond to sections where the board was attached by screws with a spacing of $300 \mathrm{~mm}$.

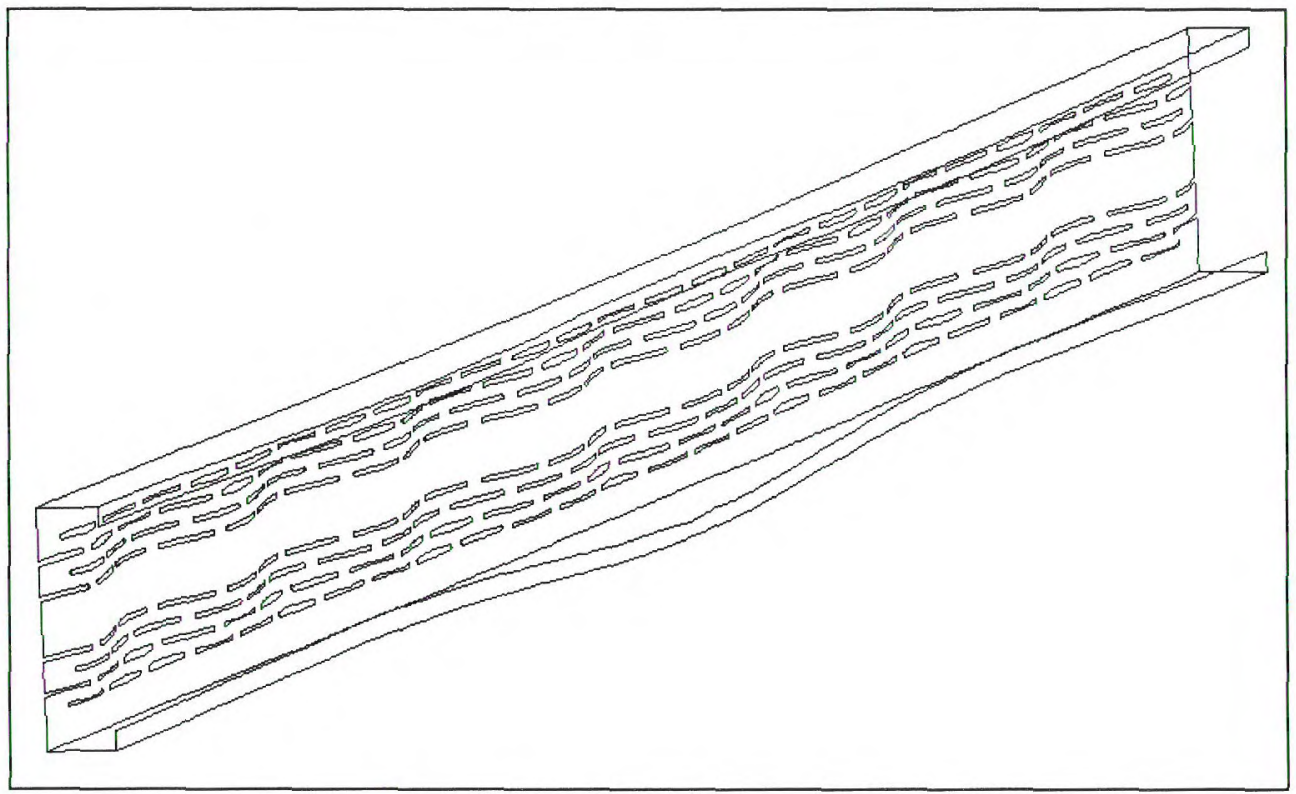

Figure 5.5 The failure mode of the slotted section tested at the Royal Institute of Technology, calculated by Abaqus. 
Table 5.8 Measured cross section data, $(\mathrm{mm})$ of the columns tested, [30] specimens 9 and 10 , totally four $\mathbf{C}$-section columns.

\begin{tabular}{|c||c|c|c|c|c|c|c|c|}
\hline $\begin{array}{c}\text { Measured } \\
\text { data }\end{array}$ & $b_{s 1}{ }^{*}$ & $b_{c 1}$ & $b_{f 1}$ & $b_{s 2}{ }^{*}$ & $b_{c 2}$ & $b_{f 2}$ & $b_{w}$ & $b_{s l i t s}$ \\
\hline \hline 1 & 19,5 & 11,0 & 39,5 & 20,5 & 9,5 & 43,5 & 148,5 & 72,0 \\
\hline 2 & 19,5 & 10,5 & 39,0 & 20,5 & 10,0 & 43,5 & 149,0 & 72,0 \\
\hline 3 & 19,5 & 11,5 & 40,0 & 21,0 & 10,5 & 44,0 & 148,5 & 72,0 \\
\hline 4 & 19,5 & 11,0 & 39,0 & 20,0 & 10,5 & 43,5 & 148,5 & 72,0 \\
\hline \hline $\begin{array}{c}\text { Mean } \\
\text { values }\end{array}$ & 19,5 & 11,0 & 39,0 & 20,5 & 10,0 & 43,5 & 148,5 & 72,0 \\
\hline
\end{tabular}

$* b_{s}$ is the edge part of the web not slotted

** $b_{\text {slits }}$ is the part of the web slotted.

The finite element mesh was created using mean values of the measured cross section since only one cross section was used in FEA. The plate thickness was $0,93 \mathrm{~mm}$. Material characteristics obtained from uniaxial tensile tests were used in the analysis, the yield stress was $362 \mathrm{MPa}$.

The initial imperfections were modelled in a similar manner as discussed in section 5.4. The only difference is that a component of initial imperfection that corresponds to a local imperfection was taken into account using only elastic static analysis. The edge stiffener displacement as shown in Figure 5.3 was applied at the unsupported flange.

The length of this imperfection was $150 \mathrm{~mm}$. Such a local imperfection gives lower column resistance than when the local imperfection in the shape of the local buckling mode is used, as described in section 5.4. The slotted web has almost no contribution to the column resistance.

Table 5.9 Ultimate resistance and column shortening due to two different edge stiffener imperfections.

\begin{tabular}{|c||c|c|}
\hline $\begin{array}{c}\text { Edge stiffener imperfection } \\
\mathrm{mm}\end{array}$ & $\begin{array}{c}\text { Ultimate resistance } \\
\mathrm{kN}\end{array}$ & $\begin{array}{c}\text { Column shortening } \\
\mathrm{mm}\end{array}$ \\
\hline \hline$b_{f} / 20 \approx 1,1$ & 15,4 & 1,2 \\
\hline$b_{f} / 40 \approx 2,2$ & 15,4 & 1,3 \\
\hline
\end{tabular}


The magnitude of the imperfection is not as important as the form of the imperfection and its orientation. The form of local imperfections that causes the same failure mode as observed for the tests was used in FEA. There is almost no difference in the ultimate resistance even if the magnitude is doubled. A slightly more flexible response is the only consequence if the larger imperfection is applied, the following results were obtained.

The ultimate resistance obtained from the FE analysis is approximately 16 per cent higher than the experimental results, $15,4 \mathrm{kN}$ in comparison to the two experimental results obtained $13,0 \mathrm{kN}$ and $13,5 \mathrm{kN}$. The influence of the gypsum board on the lateral deformation of the column was modelled as nine fixed supports along the centre line of the supported flange. This means that the influence of the connection flexibility in the flange plane was neglected. Also, the flexural stiffness of the gypsum plate and its influence to prevent displacement in the plane of the cross section was neglected.

Finally, the uniform displacement in the longitudinal direction was applied to all nodes of the end cross section. This is different from the theoretical simply supported boundary conditions which were used in section 5.4 where the displacement (load) was applied at the centre of gravity. This approximation of the experimental boundary conditions means that the spreader beams used in the test set-up were very rigid and that they were always in contact with the whole cross section of the column.

The failure mode obtained in FEA is rather similar to the one observed in the experiments. However, the column shortening at the maximum load obtained from FEA is much smaller than measured. This difference was expected since no flexibility of the connection between the section and gypsum plate was considered. This failure mode is very sensitive to initial geometrical imperfections, which have not been available and therefore this result is seen as acceptable.

Table 5.10 Ultimate load resistance of the different columns tested and analysed, (kN).

\begin{tabular}{|c||c||c||c|}
\hline Test & FE analysis & KTH test & $\begin{array}{c}\text { FE analysis / } \\
\text { KTH test }\end{array}$ \\
\hline \hline 1 & 15,4 & 13,0 & 1,18 \\
\hline 2 & & 13,5 & 1,14 \\
\hline
\end{tabular}




\subsection{Summary of results from calculations}

The ultimate resistance of columns failing in torsional-flexural buckling can be estimated as shown in section 5.3. Tables 5.11-5.14 show the results when $e(\Delta T)=0$ meaning that there is no temperature gradient or thermal deflection. The comparison shows a rather good agreement.

Tables 5.15-5.18 show the results in case of a temperature gradient with different temperatures in flanges and web. The ultimate resistance obtained by FE analysis is in most cases, up to 20 per cent higher than empirical estimations. In three cases, for the C-profile with $b_{w}=100 \mathrm{~mm}$, the FE analysis result is lower than the corresponding estimation. The reason for this has not been investigated further because in real cases torsional-flexural buckling would not be the determining failure mode at this low temperature. The ultimate load resistance with respect to flexural buckling according to Eurocode 3, part 1-3 are given in Table 5.4. These results are compared to two different models available in the literature, see section 6.4 .

Table 5.11 Ultimate load, (kN) according to $\mathrm{FE}$ analysis and Eurocode 3, part 1-3.

\begin{tabular}{|c||c|c|c|}
\hline \multicolumn{1}{|c||}{ Steel Temperature, ${ }^{\circ} \mathrm{C}$} & \multicolumn{3}{c|}{ C-section $100 \times 40 \times 15, t=1,0 \mathrm{~mm}$} \\
$T$ & FEA & EC 3 & FEA/EC 3 \\
\hline \hline 20 & 15,7 & 15,2 & 1,03 \\
200 & 12,1 & 13,6 & 0,89 \\
400 & 10,7 & 10,5 & 1,02 \\
600 & 5,8 & 4,7 & 1,23 \\
\hline
\end{tabular}

Table 5.12 Ultimate load, (kN) according to FE analysis and Eurocode 3, part 1-3.

\begin{tabular}{|c||c|c|c|}
\hline \multicolumn{1}{|c||}{ Steel Temperature, ${ }^{\circ} \mathrm{C}$} & \multicolumn{3}{c|}{ C-section $100 \times 40 \times 15, t=1,5 \mathrm{~mm}$} \\
$T$ & FEA & EC 3 & FEA/EC 3 \\
\hline \hline 20 & 26,0 & 23,4 & 1,11 \\
200 & 18,2 & 21,0 & 0,87 \\
400 & 17,2 & 16,3 & 1,06 \\
600 & 8,9 & 7,2 & 1,23 \\
\hline
\end{tabular}


Table 5.13 Ultimate load, $(\mathrm{kN})$ according to $\mathrm{FE}$ analysis and Eurocode 3, part 1-3.

\begin{tabular}{|c||c|c|c|}
\hline \multicolumn{1}{|c||}{ Steel Temperature, ${ }^{\circ} \mathrm{C}$} & \multicolumn{3}{c|}{ C-section $200 \times 40 \times 15, t=1,0 \mathrm{~mm}$} \\
$T$ & FEA & EC 3 & FEA/EC 3 \\
\hline \hline 20 & $23,6 / 17,5$ & 18,2 & $1,30 / 0,96$ \\
200 & 18,9 & 16,4 & 1,15 \\
400 & 15,0 & 12,7 & 1,18 \\
600 & 7,0 & 5,6 & 1,25 \\
\hline
\end{tabular}

Table 5.14 Ultimate load, (kN) according to $\mathrm{FE}$ analysis and Eurocode 3, part 1-3.

\begin{tabular}{|c||c|c|c|}
\hline \multicolumn{1}{|c||}{ Steel Temperature, ${ }^{\circ} \mathrm{C}$} & \multicolumn{3}{c|}{ C-section $200 \times 40 \times 15, t=1,5 \mathrm{~mm}$} \\
$T$ & FEA & EC 3 & FEA/EC 3 \\
\hline \hline 20 & $34,8 / 33,7$ & 28,4 & $1,22 / 1,18$ \\
200 & 28,1 & 25,5 & 1,10 \\
400 & 25,8 & 19,8 & 1,30 \\
600 & 12,3 & 8,8 & 1,40 \\
\hline
\end{tabular}

Table 5.15 Ultimate load, $(\mathrm{kN})$ according to $\mathrm{FE}$ analysis and empirical estimation.

\begin{tabular}{|rc||c|c|c|}
\hline \multicolumn{1}{|c||}{ Steel Temperature, ${ }^{\mathrm{O}} \mathrm{C}$} & \multicolumn{3}{c|}{ C-section $100 \times 40 \times 15, t=1,0 \mathrm{~mm}$} \\
$T_{f o}, \quad T_{w e b}, \quad T_{f i}$ & FEA & Estimation & FEA/Estimation \\
\hline \hline $100,150,200$ & 11,9 & 14,9 & 0,80 \\
$100,200,300$ & 11,5 & 13,4 & 0,86 \\
$100,250,400$ & 10,8 & 9,4 & 1,15 \\
$200,350,500$ & 9,5 & 8,3 & 1,15 \\
$250,400,550$ & 8,1 & 7,2 & 1,12 \\
\hline
\end{tabular}

Table 5.16 Ultimate load, (kN) according to FE analysis and empirical estimation.

\begin{tabular}{|rc||c|c|c|}
\hline \multicolumn{2}{|c||}{ Steel Temperature, ${ }^{0} \mathrm{C}$} & \multicolumn{3}{c|}{ C-section $100 \times 40 \times 15, t=1,5 \mathrm{~mm}$} \\
$T_{f o}, T_{\text {web }}, T_{f i}$ & FEA & Estimation & FEA/Estimation \\
\hline \hline $100,150,200$ & 18,3 & 21,5 & 0,85 \\
$100,200,300$ & 17,3 & 17,2 & 1,01 \\
$100,250,400$ & 14,4 & 11,2 & 1,30 \\
$200,350,500$ & 12,6 & 9,0 & 1,40 \\
$250,400,550$ & 11,1 & 9,9 & 1,12 \\
\hline
\end{tabular}


Table 5.17 Ultimate load, (kN) according to $\mathrm{FE}$ analysis and empirical estimation.

\begin{tabular}{|rr||c|c|c|}
\hline \multicolumn{1}{|c||}{ Steel Temperature, ${ }^{\circ} \mathrm{C}$} & \multicolumn{3}{c|}{ C-section $200 \times 40 \times 15, t=1,0 \mathrm{~mm}$} \\
$T_{f o}, T_{\text {web }}, T_{f i}$ & FEA & Estimation & FEA/Estimation \\
\hline \hline $100, \quad 150,200$ & 18,2 & 17,3 & 1,05 \\
$100,200,300$ & 17,7 & 16,3 & 1,09 \\
$100,250,400$ & 16,4 & 15,4 & 1,06 \\
$200,350,500$ & 14,5 & 13,5 & 1,07 \\
$250,400,550$ & 13,4 & 11,8 & 1,14 \\
\hline
\end{tabular}

Table 5.18 Ultimate load, $(\mathrm{kN})$ according to $\mathrm{FE}$ analysis and empirical estimation.

\begin{tabular}{|r|c|c|c|c|}
\hline \multicolumn{1}{|c||}{ Steel Temperature, ${ }^{\circ} \mathrm{C}$} & \multicolumn{3}{c|}{ C-section $200 \times 40 \times 15, t=1,5 \mathrm{~mm}$} \\
$T_{f o}, T_{w e b}, \quad T_{f i}$ & FEA & Estimation & FEA/Estimation \\
\hline \hline $100, \quad 150, \quad 200$ & 29,1 & 26,9 & 1,08 \\
$100, \quad 200,300$ & 27,6 & 25,4 & 1,09 \\
$100, \quad 250,400$ & 25,5 & 24,0 & 1,06 \\
$200,350,500$ & 23,0 & 21,1 & 1,09 \\
$250,400, \quad 550$ & 15,6 & 18,9 & 0,83 \\
\hline
\end{tabular}

\subsection{Conclusions}

The ultimate load resistance of thin walled steel columns which fail in a torsional-flexural buckling mode is possible to calculate empirically. By using the critical torsional-flexural buckling load, determining the slenderness parameter of the column and reducing the thermal deflection by the distance between the original and elastic centre of gravity the ultimate load resistance can be calculated according to Eurocode 3, part 1-3.

In comparison to the results from the $\mathrm{FE}$ analysis, the empirical estimation gives slightly lower values, in most cases 10 - 20 per cent. This is quite acceptable considering the complicated behaviour of a $\mathrm{C}$-section column which fail in a torsional-flexural buckling mode. The columns were initially deflected and had different temperatures and material properties over the cross section. In three cases for the section with $b_{w}=100 \mathrm{~mm}$ the $\mathrm{FE}$ analysis gave a lower ultimate load resistance than the empirical estimation. 
This have not been investigated in detail and it is without practical importance as the section will never turn into a torsional-flexural buckling mode at temperatures of $100-300{ }^{\circ} \mathrm{C}$.

The assumptions in the empirical estimation, using the 0,2 per cent plastic strain limit, a new centre of gravity and equations of Eurocode 3, part 1-3 are likely to be conservative.

The comparison between the $\mathrm{FE}$ analysis and experimental test results differ about 16 per cent, see Table 5.10. It is not as good as the comparison of flexural buckling, section 4.5. However, the failure mode obtained in FEA is very similar to the one observed in experiments. Since this failure mode is very sensitive to initial geometrical imperfections, and actual ones have not been available, this result is seen as acceptable.

The structural fire design model of torsional-flexural buckling shows, with respect to the different difficulties of the problem, a rather good agreement with the FE analysis and experimental tests. This once again, confirm the statement of using the 0,2 per cent plastic strain limit.

Earlier, it was also clear that with the typical value of the load reduction factor of 0,6 , the maximum steel temperature with regard to the load bearing resistance could be $450{ }^{\circ} \mathrm{C}$. By the double effect of flexural buckling turning into torsional-flexural buckling and temperature developing in the section the ultimate load resistance is only about 20 - 30 per cent, on the condition that the steel temperature in the section is 200,350 and $500{ }^{\circ} \mathrm{C}$ in the outer flange, web and inner flange, respectively.

As the increasing moment has a positive effect of the load bearing resistance, the resistance with respect to flexural buckling has been studied as well. These calculations were done according to Eurocode 3, part 1-3, but have not been compared to any FE analysis. A comparison have instead been done to earlier models by Gerlich, [3], section 6.3 and Klippstein, [4], section 6.4 . 


\section{A MODEL FOR LOAD BEARING FIRE RESISTANCE OF THIN WALLED STEEL COLUMNS}

\subsection{General}

When calculating the load bearing resistance of thin walled steel columns in wall constructions at elevated temperature, a lot of phenomena must be taken into consideration. In this thesis, these have been analysed and the effect of elevated temperature has been calculated both empirically and numerically.

The structural model of the load bearing $\mathrm{C}$-section column is changing as the temperature develops because of thermal deformations caused by the temperature gradient and the loss of gypsum boards at the fire side. At room temperature, at the time of fire ignition, the load bearing resistance can be calculated by different well known empirical models like StBK-N5 and Eurocode 3, part 1-3. The ultimate load is governed by flexural buckling, in interaction with local buckling.

As the fire grows, the temperature rises and a gradient in the steel column arises. A growing thermal deflection causes a moment from the axial load. At the same time the yield strength and elastic modulus are reduced because of the elevated temperature. The ultimate load is now governed by flexural buckling under an increasing bending moment.

When the temperature of the cavity side of the fire side gypsum boards reaches about $550{ }^{\circ} \mathrm{C}$, these boards will crack and fall off. The load bearing resistance has to be calculated for torsional-flexural buckling. But, the flexural buckling must also be checked as the moment of the growing thermal deflection has a positive effect with respect to torsional-flexural buckling. It decreases the compressive stresses in the unsupported hot flange and increases the compressive stresses in the less hot and supported flange.

A model for the load bearing fire resistance of thin walled steel columns, used to estimate the ultimate load, must include both flexural and torsional-flexural buckling taking thermal deflection, reduced yield strength and elastic modulus into account. 
The size of thermal deflection and the reduction of yield strength and elastic modulus are significant at the ultimate load.

In section 6.3 and 6.4, two models of the load bearing fire resistance of thin walled steel columns are presented. In section 6.2 a structural design model developed from the results in this thesis is presented.

\subsection{Structural design model}

The content of a structural design model for load bearing fire resistance depends on the actual temperature situation and fire protection. If the temperature development is limited to levels beneath the gypsum board calcination temperature or the steel column is protected by a fire resistant gypsym board or incombustible board, the steel column will be supported laterally along both flanges. Then the design model can be based on a model of flexural buckling in the plane of the web. If the fire side gypsum board will calcinate and be lost, the structural design model for the load bearing fire resistance must instead be based on a model of torsional-flexural buckling. A design method is found in Eurocode 3, part 1-3, that is valid at room temperature.

Because of the temperature gradient over the steel section, a thermally induced deflection will occur. The size of the thermal deflection is estimated by the different thermal elongation's of the flanges and is very important for the load bearing resistance. In the calculations the size of the thermal deflection was estimated based on an approximate temperature difference. An alternative to this, is presented in section 6.3. To get an acceptable result of the load bearing resistance, it is important and relevant to study the temperature gradient more thoroughly, which can be done by using e.g. Super-Tasef.

The yield strength and elastic modulus are reduced at elevated temperature according to Eurocode 3, part 1-2. The effects of initial deformations, local and global, are included in the resistance functions of the code. 


\subsubsection{Flexural buckling design model}

The model of flexural buckling describes the situation for an axially compressed steel column with a thermal deflection. It is relevant for the temperature range before the gypsum board calcinates on the fire side. The model is based on an equation given in Eurocode 3, part 1-3:

$$
N_{u}=\frac{\chi f_{y} A_{e f}}{1+\frac{\kappa_{x} e y_{E} \chi A_{e f}}{I_{e f}}}
$$

$f_{y}$ is the 0,2 per cent proof stress for the average temperature over the cross section.

$A_{e f}$ and $I_{e f}$ are determined with respect to varying elastic modulus e.g. by weighting the area elements with respect to their elastic modulus.

$e$ is determined in by using equation 6.12 .

$y_{E}$ is the distance in the $y$-direction between the colder supported flange and the modified centre of gravity due to the elastic properties of the flanges.

$$
\begin{array}{ll}
\chi=\frac{1}{\phi+\left[\phi^{2}-\bar{\lambda}^{2}\right]^{0,5}} & \text { but } \chi \leq 1,0 \\
\phi=0,5\left[1+\alpha(\bar{\lambda}-0,2)+\bar{\lambda}^{2}\right] & \text { where } \alpha=0,34 \\
\bar{\lambda}=\frac{1}{\pi} \frac{l}{i} \sqrt{\frac{f_{y}}{E} \beta_{A}} & \text { where } \beta_{A}=\frac{A_{e f}}{A_{g r}} \\
\kappa_{x}=1-\frac{\mu_{x} N_{u}}{\chi f_{y} A_{e f}} & \text { but } \kappa_{x} \leq 1,5 \\
\mu_{x}=\bar{\lambda}\left(2 \beta_{M, x}-4\right) & \text { but } \mu_{x} \leq 0,90 \\
\beta_{M, x}=1,3 &
\end{array}
$$




\subsubsection{Torsional-flexural buckling design model}

This model describes the ultimate stage when the fire side gypsum board is lost and the $\mathrm{C}$-section column is supported sideways only along one flange. The interaction between local and global buckling is taken into account in a simplified way.

The torsional buckling length is very important, as it affects the critical load. By limiting the warping at the ends of the steel column, the torsional buckling length is reduced. By estimating the torsional buckling length to be equal to the length of the $\mathrm{C}$-section column a conservative result is obtained.

The model of torsional-flexural buckling is based on equations given in StBK$\mathrm{K} 2$, [9] and Eurocode 3, part 1-3. The resistance is given by the following;

$$
N_{u}=\frac{\chi f_{y} A_{e f}}{1-\frac{\kappa_{x} e\left(b_{w}-y_{E}\right) \chi A_{e f}}{I_{e f}}}
$$

$f_{y}$ is the 0,2 per cent proof stress for the average temperature over the cross section.

$A_{e f}$ and $I_{e f}$ are determined with respect to varying elastic modulus e.g. by weighting the area elements with respect to their elastic modulus.

$$
\begin{aligned}
& \chi=\frac{1}{\phi+\left[\phi^{2}-\lambda^{2}\right]^{0,5}} \\
& \phi=0,5\left[1+\alpha(\lambda-0,2)+\lambda^{2}\right] \quad \text { where } \alpha=0,34 \\
& \lambda=\sqrt{\frac{f_{y}}{N_{c r}}-\frac{N_{c r} e\left(b_{w}-y_{e}\right)}{I_{e f}}}
\end{aligned}
$$




$$
N_{c r}=\frac{1}{\frac{b_{w}{ }^{2}}{4}+i_{p}{ }^{2}-e \frac{8 b_{w}}{3 \pi}}\left[\left(B_{y} \frac{b_{w}{ }^{2}}{4}+C_{w}\right) \frac{\pi^{2}}{l^{2}}+C\right]
$$

$N_{c r}$ is calculated for the gross area, but with reduced elastic properties. The shift in centre of gravity due to different elastic modulus is neglected.

$$
\begin{aligned}
& e=e(\Delta T)-\Delta y \\
& \Delta y=b_{w} / 2-y_{E}
\end{aligned}
$$

where $e(\Delta T)$ is the thermal eccentricity, equation 6.20 .

$y_{E}$ is the distance in the $y$-direction between the supported flange and the modified centre of gravity due to the elastic properties of the flanges.

$$
\begin{array}{ll}
\kappa_{x}=1-\frac{\mu_{x} N_{u}}{\not f_{y} A_{e f}} & \text { but } \kappa_{x} \leq 1,5 \\
\mu_{x}=\bar{\lambda}\left(2 \beta_{M, x}-4\right) & \text { but } \mu_{x} \leq 0,90 \\
\beta_{M, x}=1,3 &
\end{array}
$$

The deflection due to the temperature gradient will increase as a consequence of the bending moment caused by the axial force.

$$
e=e_{0} \frac{1}{1-\frac{N_{u}}{N_{c r, x}}}
$$

This equation is iterative solved to find the ultimate load $N_{u} . e_{0}$ is the original effective eccentricity and $N_{c r, x}$ is the critical Euler load, written;

$$
N_{c r, x}=\frac{\pi^{2} \Sigma E I_{g r}}{l^{2}}
$$

The eccentricity shall be referred to the effective centre of gravity for the cross section area weighted with regard to their different elastic modulus and $\Sigma E I_{g r}$ symbolises the bending stiffness of the cross section. 


\subsection{Model presented by Gerlich}

A design model for load bearing light steel frame walls for fire resistance was presented by Gerlich in 1995, [3]. The study describes the parameters, which affect the performance of load bearing wall systems of thin walled steel columns exposed to fire. Methods are presented for calculating the reduction of steel strength and stiffness at elevated temperatures and for predicting the deformations resulting from temperature gradients and deflection effects. The model is based on the AISI design manual, [31].

The proposed model gives a prediction ranging between 80 to 97 per cent of the test results. The best accuracy is obtained when predictions are based on measured temperatures.

In the model, the yield strength and elastic modulus are reduced according to AISI, [32], and the reduction factors can be written:

$$
k_{y, T}=1-5,3 \times 10^{-4} T_{s}+4,0 \times 10^{-6} T_{s}^{2}-1,9 \times 10^{-8} T_{s}^{3}+1,7 \times 10^{-11} T_{s}^{4}
$$

and

$$
k_{E, T}=1-3,0 \times 10^{-4} T_{s}+3,7 \times 10^{-7} T_{s}^{2}-6,1 \times 10^{-9} T_{s}^{3}+5,4 \times 10^{-12} T_{s}^{4}
$$

The thermal deflection as a result of the temperature gradient across the steel section can be calculated using equation 6.20, [33]. By using the mean steel temperature to calculate the coefficient of thermal expansion, $\alpha_{T}$ in accordance with equation 6.21 and $\Delta T$ for the temperature difference, the thermal deflection is written:

$$
\begin{aligned}
& e(\Delta T)=\frac{\alpha_{T} l^{2} \Delta T}{8 b_{w}} \\
& \alpha_{T}=\left(0,004 T_{s}+12\right) \times 10^{-6}
\end{aligned}
$$


The total horizontal displacement will be the sum of the thermal deflection, $e(\Delta T)$ and deflection of the bending moment, $e(M)$.

$$
E_{T} I \frac{\delta^{2} e(M)}{\delta z^{2}}=N_{u}(e(\Delta T)+e(M))
$$

The solution of equation 6.22 for $e(M)$ at mid length is obtained as equation $6.23,[34]$.

$$
\begin{aligned}
& e(M)=e(\Delta T)\left[\cos \frac{\mu l}{2}+\left(\frac{1}{\sin \mu l}-\frac{1}{\tan \mu l}\right) \sin \frac{\mu l}{2}-1\right] \\
& \mu=\sqrt{\frac{N}{E_{T} I}}
\end{aligned}
$$

The total mid length deflection thus becomes $e(\Delta T)+e(M)$. Due to the temperature gradient over the steel section the convex side is always towards the fire. As shown in Table 6.1, the total mid length deflection of Gerlich is larger than the deflection calculated in section 5.3. This difference is caused by the additional deflection of the bending moment $e(\Delta M)$.

\begin{tabular}{|c|c|c|c|c|c|c|}
\hline & C-section & \multicolumn{5}{|c|}{ Steel temperature, ${ }^{\circ} \mathrm{C}$} \\
\hline & \multirow{3}{*}{$b_{w}$} & 100 & 100 & 100 & 200 & 250 \\
\hline & & 150 & 200 & 250 & 350 & 400 \\
\hline & & 200 & 300 & 400 & 500 & 550 \\
\hline Section 5.3 & \multirow[t]{2}{*}{100} & 10 & 19 & 28 & 29 & 30 \\
\hline Gerlich & & 14 & 27 & 40 & 41 & 42 \\
\hline Section 5.3 & \multirow[t]{2}{*}{200} & 5 & 10 & 15 & 16 & 16 \\
\hline Gerlich & & 6 & 11 & 17 & 18 & 18 \\
\hline
\end{tabular}

Table 6.1 The total mid height deflection according to section 5.3 and Gerlich, (mm). 
The influence of local buckling is considered according to the design manuals of AISI, BS5950 or AS1538, [31, 35, 36] with the section form factor, $Q=A_{\text {ef }} / A_{g r}$. The steel stresses in the C-section flanges can be calculated using the following expressions. For the hot inner flange:

$$
\sigma_{i f}=N / A-\frac{N(e(\Delta T)+e(M))}{W}
$$

For the cold outer flange:

$$
\sigma_{u f}=N / A+\frac{N(e(\Delta T)+e(M))}{W}
$$

A critical temperature is found at which the permissible load is equal to the applied axial load. This temperature is then compared to the compression outer flange temperature on the ambient side to find the time of failure. The model presented for estimating the ultimate load bearing resistance does not take torsional-flexural buckling into consideration.

Compared to the results of lateral-flexural buckling presented in Chapter 5, the result of the Gerlich model is lower. This is reasonable because of the consideration of an additional deflection caused by the bending moment.

Table 6.2 The ultimate resistance estimated using the procedure of Gerlich, (kN).

\begin{tabular}{|c|c||c|c|c|c|c|c|}
\hline $\begin{array}{c}\text { C-section } \\
b_{w} \times b_{f} \times b_{c}\end{array}$ & \multirow{2}{*}{$t$} & 20 & 100 & 100 & 100 & 200 & 250 \\
& & 20 & 150 & 200 & 250 & 350 & 400 \\
& & 20 & 200 & 300 & 400 & 500 & 550 \\
\hline \hline \multicolumn{2}{|c||}{$e(\Delta T)+e(M)$} & 0 & 14 & 27 & 40 & 41 & 42 \\
\hline $100 \times 40 \times 15$ & 1,0 & 38,2 & 27,7 & 23,5 & 20,8 & 19,5 & 18,3 \\
& 1,5 & 71,7 & 46,3 & 38,4 & 33,3 & 31,3 & 29,4 \\
\hline \hline \multicolumn{2}{|c|}{$e(\Delta T)+e(M)$} & 0 & 6 & 11 & 17 & 18 & 18 \\
\hline $200 \times 40 \times 15$ & 1,0 & 45,4 & 42,5 & 40,7 & 39,0 & 37,0 & 35,3 \\
& 1,5 & 86,8 & 79,8 & 75,3 & 71,3 & 67,5 & 64,4 \\
\hline
\end{tabular}




\subsection{Model presented by Klippstein}

Another model for structural fire design of thin walled steel sections has been presented by Klippstein in 1978, [4]. The objectives were to develop an analytical method for predicting the structural behaviour of the steel columns and to define possible improvements in the ASTM-E119 fire test standard, [37]. The results show that the structural behaviour of walls with thin walled steel columns exposed to ASTM-E119 fires can be predicted with reasonable accuracy for temperatures up to $650^{\circ} \mathrm{C}$. The ASTM-E1 19 fire is equal to the ISO 834 temperature development. This model is based on the AISI design manual, [31], as well.

In the model of Klippstein, the following must be known for the encountered range of temperatures:

- the mechanical properties of the steel used for the steel sections,

- the strength-reduction factors for local buckling and developing temperature for the particular section configuration used,

- the lateral deflection at mid length and

- the average steel section temperature at the time of failure.

Further, the following assumptions are made:

- the gypsum boards on the hot inner side of the wall and the exterior boards prevent failure by weak axis buckling and torsional buckling up to the failure time,

- the gypsum board does not carry any vertical load and

- the stress-strain curve is linear up to the yield strength.

The failure load at room temperature according to AISI is:

$$
N_{u 20}=\frac{23}{12} \sigma_{c a} A_{g r}
$$


The factor 23/12 is the reciprocal of the safety factor incorporated in the allowable stress. The allowable stress at room temperature for axially loaded compression members is:

$$
\sigma_{c a}=\frac{12}{23} Q f_{y}-\frac{3}{23} \frac{\left(Q f_{y}\right)^{2}}{\pi^{2} E}\left(\frac{l}{i}\right)^{2}
$$

$Q$ is the section form factor according to the AISI design manual, see section 6.3. Thus, the failure load at room temperature can be calculated as:

$$
N_{u 20}=\left[Q f_{y}-\frac{1}{E}\left(\frac{Q f_{y} l}{2 i \pi}\right)^{2}\right] A_{g r}
$$

The ultimate load at elevated temperature can not be determined by equation 6.29 because the yield strength and modulus of elasticity are known to change as functions of temperature. Also, the section form factor, $Q$ is expected to change because it is a function of the yield strength and elastic modulus. In addition, the steel column deflects laterally as the temperature is rising, causing bending stresses, which must be considered in calculating $N_{u}$.

By using equation 6.28 the allowable stress for an axial load at failure temperature can be determined if the reduced values of yield strength, elastic modulus and section form factor $Q$, with respect to an actual temperature are used. The interaction equation for combined axial and bending stresses at mid length can be written:

$$
\frac{\sigma_{c}}{\sigma_{c a T}}+\frac{\sigma_{b}}{\sigma_{b a T}}<1,0
$$

The stresses of $\sigma_{c a T}$ and $\sigma_{b a T}$ should be multiplied by the safety factors $23 / 12$ and $5 / 3$, respectively. Thus, with $5 / 3 \sigma_{b a T}=f_{y T}$. Since :

$$
\begin{aligned}
& \sigma_{c}=\frac{N_{u}}{A_{g r}} \\
& \sigma_{b}=\frac{N_{u} e(\Delta T)}{W_{g r}}
\end{aligned}
$$


the failure condition at elevated temperature is reduced to:

$$
N_{u}=\frac{1,0}{A_{g r}\left(\frac{23}{12} \sigma_{c a T}\right)}+\frac{e(\Delta T)}{W_{g r} f_{y T}}
$$

where $e(\Delta T)$ is the mid length deflection including any amplification effects.

The total section form factor, $Q$, at room and elevated temperature is shown in Table 6.3. The factor contains two parts, the first can be determined by local buckling as $A_{e f} / A_{g r}$, the second is determined as a function of temperature.

Table 6.3 The total section form factor, $Q$ at room and elevated steel temperature.

\begin{tabular}{|c|c||c|c|c|c|c|c|}
\hline C-section & \multicolumn{1}{|c||}{} & \multicolumn{7}{c|}{ Steel temperature, ${ }^{\circ} \mathrm{C}$} \\
$b_{w} \times b_{f} \times b_{c}$ & $t$ & 20 & 100 & 200 & 300 & 400 & 500 \\
\hline \hline $100 \times 40 \times 15$ & 1,0 & 0,65 & 0,64 & 0,62 & 0,58 & 0,54 & 0,50 \\
& 1,5 & 0,85 & 0,83 & 0,78 & 0,73 & 0,68 & 0,63 \\
\hline $200 \times 40 \times 15$ & 1,0 & 0,45 & 0,45 & 0,44 & 0,42 & 0,40 & 0,38 \\
& 1,5 & 0,59 & 0,58 & 0,57 & 0,55 & 0,53 & 0,51 \\
\hline
\end{tabular}

The mid length thermal deflection, $e(\Delta T)$ is estimated in section 5.3 when determining the eccentricity of a $2500 \mathrm{~mm}$ long thin walled steel column. By using the total strength reduction factor, the yield strength reduction factor and reduction factor for elastic modulus presented in section 1.3 the ultimate load bearing resistance can be estimated by the model of Klippstein.

As mentioned, like in the model of Gerlich, the model estimating the ultimate load bearing resistance does not take torsional-flexural buckling into consideration. 
The result, shown in Table 6.4, is in comparison to the result of Gerlich not conservative. The difference is partially due to different ways of estimating the deflection, $e$, Table 6.1. In the model of Gerlich, equation 6.22 were used, in the model of Klippstein the thermal deformations of section 5.3 were used.

Table 6.4 The ultimate resistance estimated using Klippstein's theory, $(\mathbf{k N})$.

\begin{tabular}{|c|c|c|c|c|c|c|c|}
\hline \multirow{4}{*}{$\begin{array}{c}\text { C-section } \\
b_{w} \times b_{f} \times b_{c}\end{array}$} & \multirow{4}{*}{$t$} & \multicolumn{6}{|c|}{ Steel temperature, ${ }^{\circ} \mathrm{C}$} \\
\hline & & 20 & 100 & 100 & 100 & 200 & 250 \\
\hline & & 20 & 150 & 200 & 250 & 350 & 400 \\
\hline & & 20 & 200 & 300 & 400 & 500 & 550 \\
\hline \multicolumn{2}{|l|}{$e(\Delta T)$} & 0 & 10 & 15 & 28 & 29 & 30 \\
\hline \multirow[t]{2}{*}{$100 \times 40 \times 15$} & 1,0 & 47,4 & 36,5 & 29,7 & 24,3 & 20,0 & 17,7 \\
\hline & 1,5 & 92,1 & 65,9 & 51,6 & 41,5 & 34,2 & 30,3 \\
\hline \multicolumn{2}{|l|}{$e(\Delta T)$} & 0 & 5 & 10 & 15 & 16 & 16 \\
\hline \multirow[t]{2}{*}{$200 \times 40 \times 15$} & 1,0 & 48,9 & 44,6 & 39,8 & 34,8 & 29,2 & 26,1 \\
\hline & 1,5 & 95,4 & 84,6 & 75,1 & 65,6 & 54,8 & 50,2 \\
\hline
\end{tabular}

\subsection{Summary of results from calculations}

The flexural buckling design model of section 6.2.1 should reasonably give approximately the same result as the models of Gerlich and Klippstein, taking the thermal deflection into account. A comparison of the different models is presented in Table 6.5-6.8. The comparison shows a fairly good agreement between the model of Gerlich and the proposed flexural buckling design model, they differ in most cases only about maximum 10 per cent. The model of Gerlich is conservative in comparison to Klippstein when $b_{w}=100 \mathrm{~mm}$. When $b_{w}=200 \mathrm{~mm} \mathrm{Klippstein} \mathrm{is} \mathrm{conservative} \mathrm{instead.}$

In the comparison the yield strength and elastic modulus are reduced with respect to the average steel temperature in the web in the proposed model and model of Klippstein.In the model of Gerlich the temperature in the outer cold flange is used. 
Table 6.5 The resistance estimated by the proposed design model in comparison to the models of Gerlich and Klippstein, $(\mathbf{k N})$.

\begin{tabular}{|c||c|c|c|c|c|c|}
\hline \multicolumn{1}{|c||}{ C-section } & \multicolumn{6}{c|}{ Steel temperature, ${ }^{\mathrm{O}} \mathrm{C}$} \\
$100 \times 40 \times 15$ & 20 & 100 & 100 & 100 & 200 & 250 \\
$t=1,0$ & 20 & 150 & 200 & 250 & 350 & 400 \\
& 20 & 200 & 300 & 400 & 500 & 550 \\
\hline \hline EC 3 & 38,4 & 29,8 & 24,9 & 21,6 & 18,8 & 19,8 \\
\hline Gerlich & 38,2 & 27,7 & 23,5 & 20,8 & 19,5 & 18,3 \\
\hline Klippstein & 47,4 & 36,5 & 29,7 & 24,3 & 20,0 & 17,7 \\
\hline \hline Gerlich/EC 3 & 0,99 & 0,93 & 0,94 & 0,96 & 1,04 & 0,92 \\
\hline Klippstein/EC 3 & 1,23 & 1,22 & 1,19 & 1,12 & 1,06 & 0,89 \\
\hline
\end{tabular}

Table 6.6 The resistance estimated by the proposed design model in comparison to the models of Gerlich and Klippstein, $(\mathbf{k N})$.

\begin{tabular}{|c||c|c|c|c|c|c|}
\hline \multicolumn{1}{|c||}{ C-section } & \multicolumn{6}{c|}{ Steel temperature, ${ }^{\mathrm{O}} \mathrm{C}$} \\
$100 \times 40 \times 15$ & 20 & 100 & 100 & 100 & 200 & 250 \\
$t=1,5$ & 20 & 150 & 200 & 250 & 350 & 400 \\
& 20 & 200 & 300 & 400 & 500 & 550 \\
\hline \hline EC 3 & 69,6 & 52,4 & 45,3 & 37,4 & 32,8 & 34,5 \\
\hline Gerlich & 71,7 & 46,3 & 38,4 & 33,3 & 31,3 & 29,4 \\
\hline Klippstein & 92,1 & 65,9 & 51,6 & 41,5 & 34,2 & 30,3 \\
\hline \hline Gerlich/EC 3 & 1,03 & 0,88 & 0,85 & 0,89 & 0,95 & 0,85 \\
\hline Klippstein/EC 3 & 1,32 & 1,25 & 1,14 & 1,11 & 1,04 & 0,88 \\
\hline
\end{tabular}

The eccentricity used is different in the models. In the proposed model, the effective eccentricity, $e$ have been used, in the model of Gerlich the sum of the thermal deflection and deflection of the bending moment is used, $e(\Delta T)+e(\Delta M)$. Klippstein states that the mid length thermal deflection, $e(\Delta T)$ shall be used. This means that the calculated eccentricities are largest in the model of Gerlich, and less in the proposed model. As the eccentricities are less for the $b_{w}=200$ $\mathrm{mm}$ section, the difference is also less in the comparison shown in Tables 6.7 and 6.8. In the model of Klippstein, the section form factor $Q$ is important. It is only determined by tests and the values used in these calculations are only approximate. 
Table 6.7 The resistance estimated by the proposed design model in comparison to the models of Gerlich and Klippstein, $(\mathrm{kN})$.

\begin{tabular}{|c||c|c|c|c|c|c|}
\hline \multicolumn{1}{|c||}{ C-section } & \multicolumn{6}{c|}{ Steel temperature, ${ }^{\mathrm{O}} \mathrm{C}$} \\
$200 \times 40 \times 15$ & 20 & 100 & 100 & 100 & 200 & 250 \\
$t=1,0$ & 20 & 150 & 200 & 250 & 350 & 400 \\
& 20 & 200 & 300 & 400 & 500 & 550 \\
\hline \hline EC 3 & 47,2 & 44,8 & 42,8 & 40,8 & 35,8 & 37,7 \\
\hline Gerlich & 45,4 & 42,5 & 40,7 & 39,0 & 37,0 & 35,3 \\
\hline Klippstein & 48,9 & 44,6 & 39,8 & 34,8 & 29,2 & 26,1 \\
\hline \hline Gerlich/EC 3 & 0,96 & 0,95 & 0,95 & 0,96 & 1,03 & 0,94 \\
\hline Klippstein/EC 3 & 1,04 & 1,00 & 0,93 & 0,85 & 0,82 & 0,70 \\
\hline
\end{tabular}

Table 6.8 The resistance estimated by the proposed design model in comparison to the models of Gerlich and Klippstein, (kN).

\begin{tabular}{|c||c|c|c|c|c|c|}
\hline \multicolumn{1}{|c||}{ C-section } & \multicolumn{7}{c|}{ Steel temperature, ${ }^{\mathrm{O}} \mathrm{C}$} \\
$200 \times 40 \times 15$ & 20 & 100 & 100 & 100 & 200 & 250 \\
$t=1,5$ & 20 & 150 & 200 & 250 & 350 & 400 \\
& 20 & 200 & 300 & 400 & 500 & 550 \\
\hline \hline EC 3 & 91,5 & 85,4 & 81,4 & 77,7 & 68,5 & 72,5 \\
\hline Gerlich & 86,8 & 79,8 & 75,3 & 71,3 & 67,5 & 64,4 \\
\hline Klippstein & 95,4 & 84,6 & 75,1 & 65,6 & 54,8 & 50,2 \\
\hline \hline Gerlich/EC 3 & 0,95 & 0,93 & 0,93 & 0,92 & 0,99 & 0,89 \\
\hline Klippstein/EC 3 & 1,04 & 0,99 & 0,93 & 0,85 & 0,80 & 0,70 \\
\hline
\end{tabular}




\section{DISCUSSION AND CONCLUSIONS}

\subsection{Discussion}

Using the well known equations of Eurocode 3, part 1-3, but with reduced material properties and considering a thermal deflection, is an easy way to implement an alternative to the conservative limit of the temperature to $350{ }^{\circ} \mathrm{C}$, now stated in Eurocode 3, part 1-2. With such a model the fire design can be done together with the normal design work, relatively quick and easy.

When designing thin walled steel structures at elevated temperature, the 0,2 per cent plastic strain limit can be used to define the yield strength in estimations. This is proportionately conservative to Eurocode 3, part 1-2 which defines the yield strength at 2 per cent total strain. This definition may be relevant where no instability influences the behaviour of the structure, but it is clearly too optimistic when instability governs. The Steel Construction Institute, [10] propose an 0,1 per cent strain limit for columns and 0,5 per cent strain limit for beams, leading to critical temperatures of $450{ }^{\circ} \mathrm{C}$ for columns of class 4 section, when the load level at a fire limit state is 0,6 times the normal design load. For beams, the corresponding critical temperature is $530^{\circ} \mathrm{C}$. Eurocode 3, part 1-2 treats the problem simply by limiting the maximum temperature to $350{ }^{\circ} \mathrm{C}$ for all class 4 cross sections. Eurocode is accordingly quite restrictive and as a contrast the praxis in Sweden since 25 years is to use the normal design rules for design against instability, but with material data for the relevant temperature and normally the 0,2 per cent proof stress limit.

One problem is to estimate the steel temperature and its gradient. A good agreement between tests and numerical analysis using Super-Tasef were found for the different wall structures studied in this thesis. But, there are always different design solutions of load bearing walls. Differences in densities and thermal properties of different materials of insulation and boards influence the gradient relatively much. The difficulty of trying to tabulate general steel temperature gradients is that such tables will always be limited and conservative. 
The comparisons and verifications of the models used are commented at the end of each Chapter. Generally, there are always differences in the results. The quotients of Eurocode 3, part 1-3 calculations, to numerical analysis and tests are consertvative why the proposed design model should be reliable enough to use.

Empirical calculations of the ultimate load due to local buckling show results quite in agreement with the FE analysis. Interesting is that the difference between resistance measured for test specimens and resistance obtained from FE analysis is approximately of the same size as the difference between empirically calculated values and values computed by $\mathrm{FE}$ analysis. As the FE analysis seem to underestimate the actual resistance by about the same amount as it overestimates it compared to the empirical result, the conclusion is that the code resistance can be used.

This is also the case for flexural buckling, even though there is no difference between test and FE analysis results. For torsional-flexural buckling the FE analysis gives higher values in comparison to both test results and empirical estimations. This means that the present model for torsional-flexural buckling is conservative.

\subsection{Conclusions}

- The steel temperature in a wall structure of gypsum board, mineral wool insulation and thin walled steel columns can be calculated using the FE analysis program, Super-Tasef. It is possible to get a good result of the temperature development in the steel section. The temperature gradient over the cross section is, also computed. This gradient shows a good agreement with real test results.

- The steel temperature in different kinds of wall structures, presented in Appendix A, shows a rather slow development during the first 45 minutes, the hot flange reaches approximately $300^{\circ} \mathrm{C}$ and the cold flange $100{ }^{\circ} \mathrm{C}$. After the first 45 minutes the steel temperature rises faster since the gypsum 
boards have calcinated. During the last 15 minutes, of a 60 minutes ISO 834 temperature development, the steel temperature in walls not insulated reaches nearly $900{ }^{\circ} \mathrm{C}$ in the hot flange and $700{ }^{\circ} \mathrm{C}$ in the cold flange. In insulated walls the cold flange, depending on the type and density of the insulation, only reaches $100-300^{\circ} \mathrm{C}$.

- The load bearing resistance of thin walled steel columns is influenced by local buckling. This gives the ultimate resistance for plates and short compressed columns, $800 \mathrm{~mm}$. As the column gets longer the influence of flexural buckling will increase. The ultimate load resistance is an interaction between local buckling depending on the width and thickness of the different plane elements, and flexural buckling depending on the column slenderness of the section.

- It is possible to calculate the load bearing resistance of thin walled steel columns at elevated temperature, using the same methods as at room temperature for local buckling, flexural buckling and torsional-flexural buckling. The estimates give results fairly in agreement with computer FE analysis. Also the initial deflections have the same relative influence on the load bearing resistance at room temperature as in case of elevated temperature. In the estimates the 0,2 per cent plastic strain is used to define the yield strength. The elastic modulus is reduced according to Eurocode 3, part 1-2. For the FE analysis, the whole stress-strain relationship is used. The verification of the $\mathrm{FE}$ calculations according to tests show an acceptable agreement between the experimental test results and the FE computations.

- The effect of the temperature gradient must be taken into account. The gradient causes a thermally induced deflection of the steel column, which is of great importance for the ultimate load bearing resistance. The deflection is rather large and it reduces the ultimate load bearing resistance when flexural buckling in the plane of the web is governing. When the gypsum board of the fire side gradually calcinate, the steel column is no longer supported along this flange and a torsional-flexural buckling phase will begin. In case of torsional-flexural buckling the thermally induced deflection increases the resistance compared to that of a straight column. 
- A fire design model for calculating the ultimate load bearing resistance cannot be based on just one structural model, because the conditions for the structure will change due to the temperature. At the beginning, it is possible to estimate the resistance due to flexural buckling and later flexural buckling with addition of a developed thermal deflection. When the fire side gypsum board is gone, the resistance has to be estimated with respect to torsionalflexural buckling instead. This means, that when designing the steel columns of a wall structure the temperature development must be known. Using the ISO 834 standard fire curve, the fire temperature will reach $800{ }^{\circ} \mathrm{C}$ after 30 minutes.

This is approximately the time after which the fire side gypsum board starts to calcinate and the torsional-flexural buckling structural model must be used. Calculations done in this thesis show that the load bearing resistance at this stage is about 20 - 30 per cent of the ultimate load bearing resistance for flexural buckling at room temperature. This is relevant for a typical light gauge wall with $2 \times 12,5 \mathrm{~mm}$ gypsum boards, about 50 minutes after ignition, due to the ISO 834 standard fire development.

- The proposed design model for load bearing thin walled steel columns at elevated temperature is based on the Eurocode 3, part 1-3 model of flexural buckling and torsional-flexural buckling. The yield strength is defined at the 0,2 per cent plastic strain and the elastic modulus is reduced at elevated temperature according to Eurocode 3, part 1-2. The proposed model shows rather good agreement to numerical analyses and tests. It is easy to use and reliable enough for practical design.

\subsection{Future work}

This thesis has dealt only with finding the actual temperature development in wall structures with respect to the ISO 834 standard fire test. Future work could be done in order to study the temperature development more exactly due to natural and parametric fire models. The load bearing resistance can also be more carefully calculated if exactly the right temperature gradient is known, for a certain C-section column, as its influence on the displacement and load bearing resistance is great. Further, the effect of a more restrained steel column with reduced buckling length would be interesting to study. In such a model the thermal deflection would be less. 
Of course, a well performed fire test series on C-section columns would be very useful to compare the temperatures, deformations, the phenomena of local buckling, flexural buckling and torsional flexural buckling with the results of the presented design model.

In the present study the effective yield strength at 0,2 per cent plastic strain is used. This adoption is based on praxis. Future work can be done to study other strength definitions and reduction functions.

Since load bearing C-section columns are commonly used in facade walls, it will also be necessary to develop a structural fire design model for slotted thin walled steel columns. In such future work the presented design model would be a good basis. The verification of the FEM analysis results with regard to flexural buckling and torsional-flexural buckling has been done by comparing with experimental test results from slotted $\mathrm{C}$-sections and it shows that this development could be relatively easy to do.

In steel framed apartment blocks and residential houses the structural load bearing floor system also has to be designed with respect to a temperature development. The thin walled steel beams are transversally loaded and the influence of a temperature gradient can be both positive and negative depending on the fire situation. Also, such future work can be based on the presented design model. 
[1] Eurocode 3, part 1-3, (1996). Design of steel structures, General rules, Supplementary rules for cold formed thin gauge members and sheeting, European Committee for Standardisation, ENV 1993-1-3: 1996, Brussels, BE

[2] Eurocode 3, part 1-2, (1995). Design of steel structures, General rules. Structural fire design, European Committee for Standardisation, ENV 1993-1-2:1995, Brussels, BE

[3] Gerlich, J. T., (1995). Design of Loadbearing Light Steel Frame Walls for Fire Resistance, Fire Engineering Research Report 95/3, School of Engineering, University of Canterbury, Christchurch, NZ

[4] Klippstein, K. H., (1978). Strength of Cold-Formed Steel Studs Exposed to Fire, Int Spec Conference, $4^{\text {th }}$, St Louis, Mo, University of Montana, Rolla, Mo, US

[5] Structural Fire Design of Thin Walled Steel Sections - Appendix F, Input files used in non-linear analysis with Abaqus version 5.6 to version 5.8, CD, (1999). Luleå University of Technology, Luleå, SE

[6] European Recommendations for the Fire Safety of Steel Structures, (1983). ECCS Technical Committee 3, Elsvier, Amsterdam, NL

[7] BSK 94, (1994). Swedish Regulations for Steel Structures, Swedish Board of Housing, Building and Planning, Karlskrona, SE

[8] Chilver, A. H. (1967). Thin Walled Structures, A collection of papers on stability and strength of thin walled structural members and frames, Chatto and Windus, London, UK

[9] StBK-K2, (1973). Knäckning, vippning och buckling, Kommentarer till stålbyggnadsnorm 70, Statens stålbyggnadskommitté, Svensk Byggtjänst, Stockholm, SE

[10] Building Design using Cold Formed Steel Section: Fire protection, (1993). The Steel Construction Institute, Publication P129, Ascot, UK 
[11] ISO 834, (1975). Fire-resistance tests - Elements of Building Construction, International Organization for Standardization Organisation, ISO 834-1975, Berlin, DE

[12] Eurocode 1, part 2-2, (1994). Basis of design and action on structures, Actions on structures exposed to fire, European Committee for Standardisation, ENV 1991-2-2:1994, Brussels, BE

[13] Petterson, O. Magnusson, S-E. Thor, J., (1976). Fire Engineering Design of Steel Structures, Swedish Institute of Steel Construction, Publication 50, Stockholm, SE

[14] Gustafsson, H. Carlsson, P. Wickström, U., (1993). Super-Tasef Version 2.0, Swedish National Testing and Research Institutet, Borås, SE

[15] Ranby, A., (1994). Erforderligt brandskydd av stålpelare i fasad, Swedish Institute of Steel Construction, Report 165:1, Stockholm, SE

[16] Andersson, L. Jansson, B., (1986). En undersökning av gipsskivans termiska egenskaper - Teori och försök, Report LUTVDG/(TVBB5001), Lund Institute of Technology, Lund, SE

[17] Simon, (1970). Simulation analoggique de la conduction vive, notamment dans une couche de platre soumise a des dissociations pear echauffement, Rev. Gener.Thermm. pp102

[18] Beträffande värmeledningstalets variation med temperaturen hos $13 \mathrm{~mm}$ tjocka gipsskivor av fabrik Gyproc, (1968). Swedish National Testing and Research Institutet, Report 7040 384C, Stockholm, SE

[19] NT FIRE 005, ISO 834-1975, (1975). Fire-resistance tests - Elements of building construction, Adopted 1976-03. Nordtest, Espoo, FI

[20] Ranby, A., (1997). Temperaturberäkningar i brandutsatta stålregelväggar, Swedish Institute of Steel Construction, Report 188:2, Stockholm, SE 
[21] Ansys/User's Manual, (1992). Version 5.0, Swanson Analysis Systems, Inc, Houston, PA, US

[22] Abaqus/Standard User's Manual, (1996). Vol I-III. Ver 5.6, Pawtucket: Hibbitt, Karlsson \& Sorensen, Inc.

[23] StBK-N5, (1980). Norm för tunnplåtskonstruktioner 79, Statens stålbyggnadskommitté, Svensk Byggtjänst, Stockholm, SE

[24] Nylander, H., (1951). Initially Deflected Thin Plate with Initial Deflection Affine to Additional Deflection, Preprinted from the eleventh Volume of the Publications, IABSE, Zurich, $\mathrm{CH}$

[25] Cox, H. L., (1933). Buckling of Thin Plates in Compression. Aer. Res. Com. Reports and Mem, No 1554, London, UK

[26] von Kármán, T., Sechler, E. E., Donnell, L. H., (1932). Paper, ASME, vol.54, p.53, US

[27] Ranby A., (1997). Buckling av brandutsatta tunna plåtar, Report 188:3, Swedish Institute of Steel Construction, Stockholm, SE

[28] Timoshenko, S., Gere J., (1963). Theory of elastic stability, McGrawHill Book Company, New York, US

[29] Ala-Outinen, T., Myllymäki J., (1995). The local buckling of RHS members at elevated temperatures, VTT Research notes 1672, Espoo, FI

[30] Borglund, J., Jonsson, J., (1997). Bärförmåga för slitsade stålreglar, Report ISRN/BKN/EX-84-SE, Royal Institute of Technology, Stockholm, SE

[31] AISI, (1991). Load and Resistance Factor Design Specification for Cold-Formed Steel Structural Members. American Iron and Steel Institute, Washington, US

[32] Klippstein, K. H., (1980). Strength of Cold-formed Studs Exposed to Fire. American Iron and Steel Institute, Washington, US 
[33] Cooke, G. M. E., (1987). Thermal Bowing and how it Affects the Design of Fire Separating Construction. Fire Research Station, Building Research Establishment, Herts, UK

[34] Deam, B. L., (1993). A Design Procedure for Timber Stud Wall Framing - Part 1: End Fixity and Lining Contributions. Confidential Report STR 5100/1. Building Technology Limited, Judgeford, NZ

[35] BS5950, part 5, (1987). Structural Use of Steelwork in Building. Part 5. Code of practice for Design of Cold-Formed Sections, British Standards Institution, London, UK

[36] AS1538, (1988), SAA Cold-Formed Steel Structures Code, Standards Association of Australia, North Sydney, NSW, AUS

[37] ASTM-E119-79, (1979). Standard Methods of Fire Tests of Building Construction and Materials. American Society for Testing and Materials, US 


\section{APPENDIX A}

\section{Temperature development in different wall constructions.}

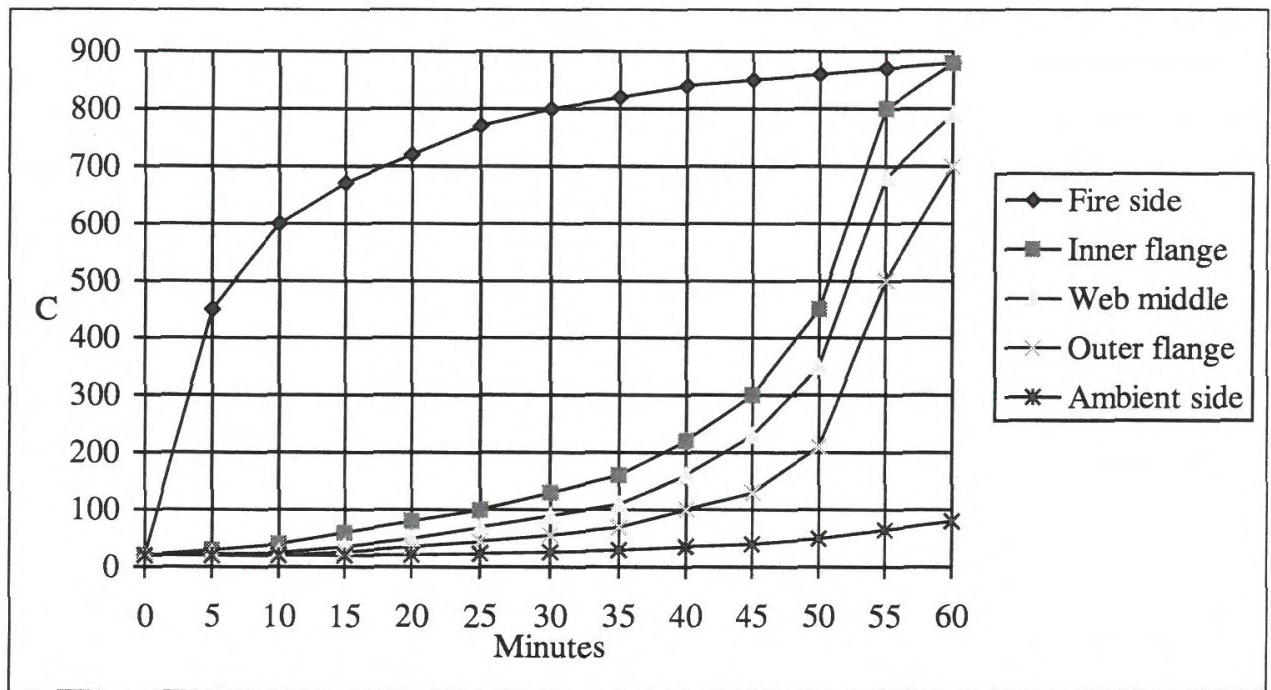

Figure A.1 Temperature development in a C-section, $b_{w}=150 \mathrm{~mm}, b_{f}=40 \mathrm{~mm}$,

$b_{c}=15 \mathrm{~mm}, \mathrm{t}=0,8 \mathrm{~mm}$ protected by $2 \times 13 \mathrm{~mm}$ gypsum boards on both sides and without insulation.

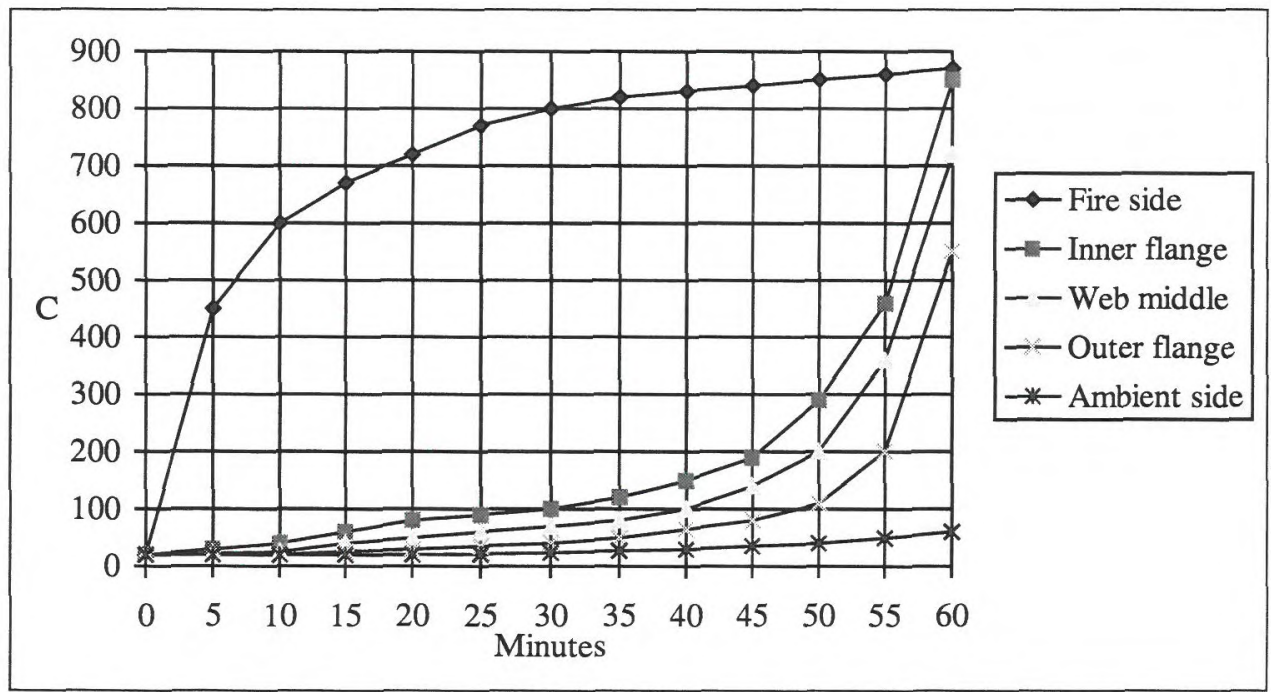

Figure A.2 Temperature development in a C-section, $b_{w}=150 \mathrm{~mm}, b_{f}=40 \mathrm{~mm}$, $b_{c}=15 \mathrm{~mm}, \mathrm{t}=0,8 \mathrm{~mm}$ protected by $2 \times 15 \mathrm{~mm}$ gypsum boards on both sides and without insulation. 


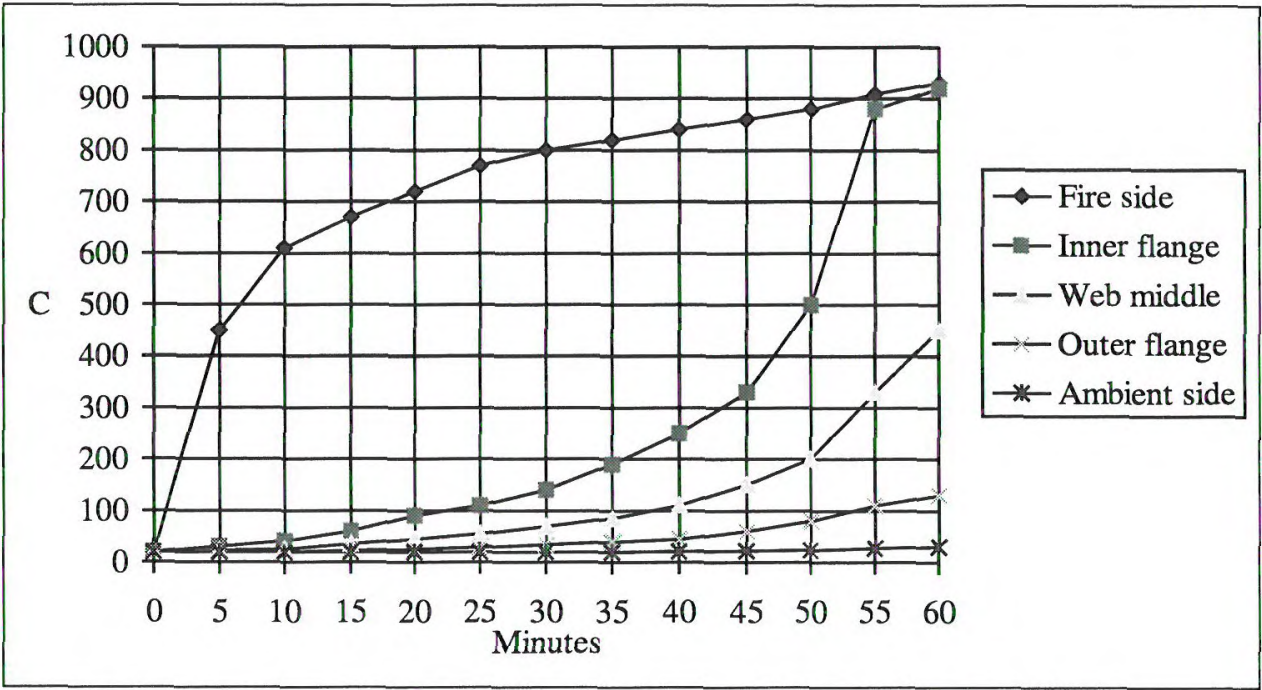

Figure A.3 Temperature development in a C-section, $b_{w}=150 \mathrm{~mm}, b_{f}=40 \mathrm{~mm}$, $\mathrm{b}_{\mathrm{c}}=15 \mathrm{~mm}, \mathrm{t}=0,8 \mathrm{~mm}$ protected by $2 \times 12,5 \mathrm{~mm}$ gypsum boards on both sides and insulated with rock fibre wool, $\rho=30 \mathrm{~kg} / \mathrm{m}^{3}$.

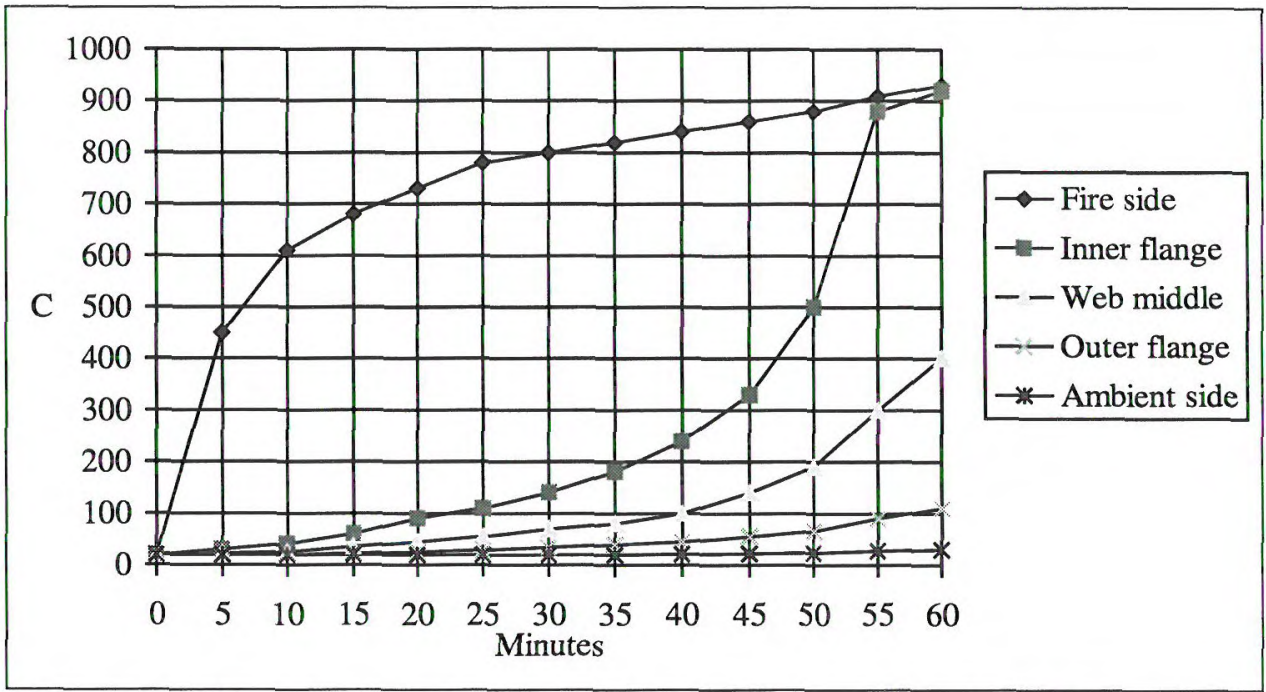

Figure A.4 Temperature development in a C-section, $b_{w}=150 \mathrm{~mm}, b_{f}=40 \mathrm{~mm}$, $\mathrm{b}_{\mathrm{c}}=15 \mathrm{~mm}, \mathrm{t}=0,8 \mathrm{~mm}$ protected by $2 \times 12,5 \mathrm{~mm}$ gypsum boards on both sides and insulated with rock fibre wool, $\rho=50 \mathrm{~kg} / \mathrm{m}^{3}$. 


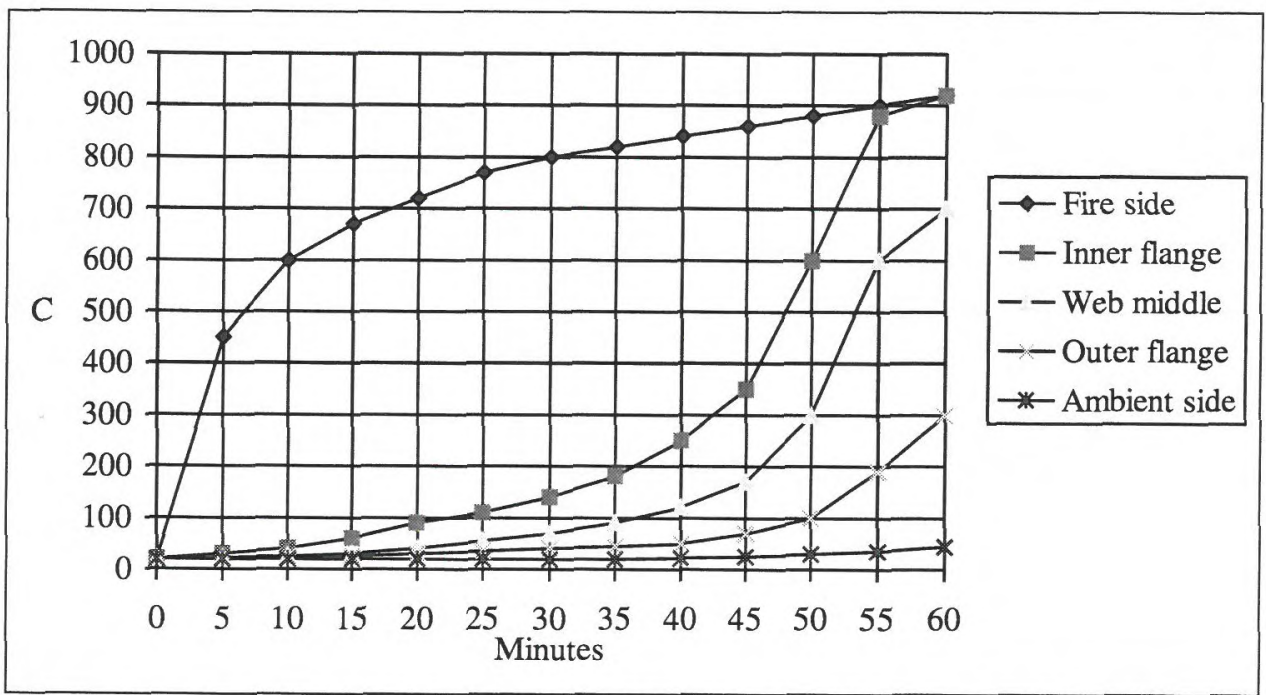

Figure A.5 Temperature development in a C-section, $b_{w}=150 \mathrm{~mm}, b_{f}=40 \mathrm{~mm}$, $\mathrm{b}_{\mathrm{c}}=15 \mathrm{~mm}, \mathrm{t}=0,8 \mathrm{~mm}$ protected by $2 \times 12,5 \mathrm{~mm}$ gypsum boards on both sides and insulated with glass fibre wool, $\rho=15 \mathrm{~kg} / \mathrm{m}^{3}$.

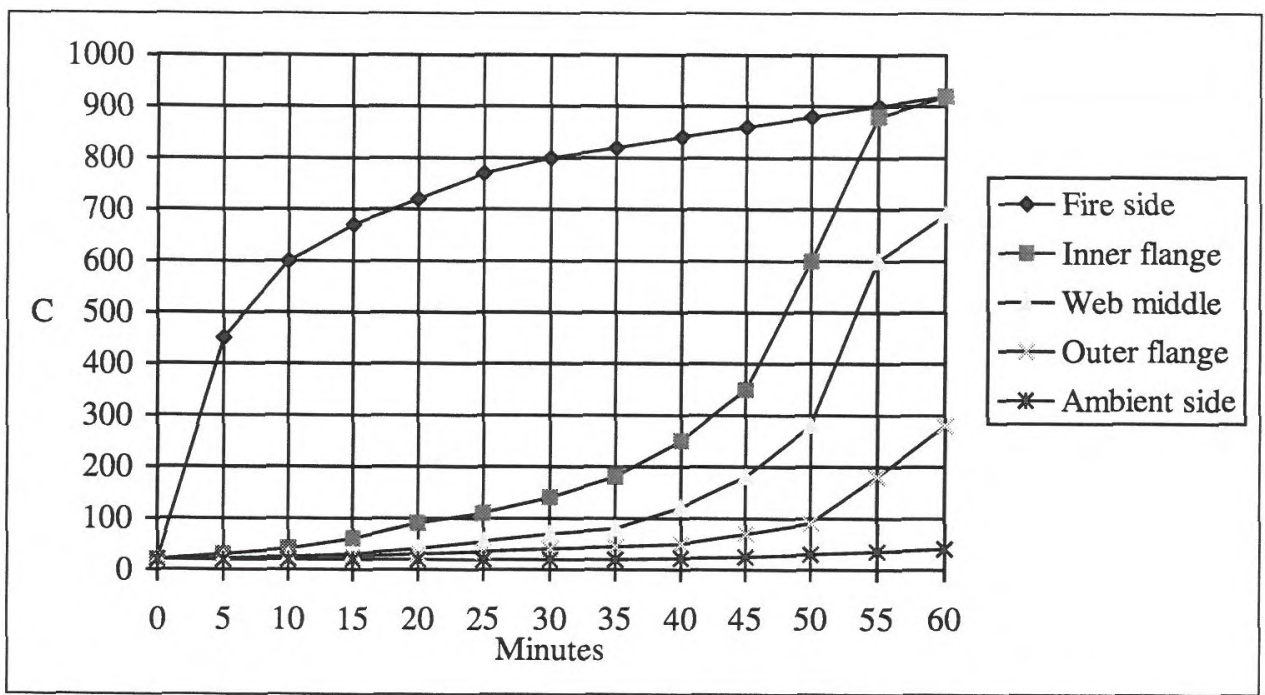

Figure A.6 Temperature development in a C-section, $b_{w}=150 \mathrm{~mm}, b_{f}=40 \mathrm{~mm}$, $\mathrm{b}_{\mathrm{c}}=15 \mathrm{~mm}, \mathrm{t}=0,8 \mathrm{~mm}$ protected by $2 \times 12,5 \mathrm{~mm}$ gypsum boards on both sides and insulated with glass fibre wool, $\rho=30 \mathrm{~kg} / \mathrm{m}^{3}$. 


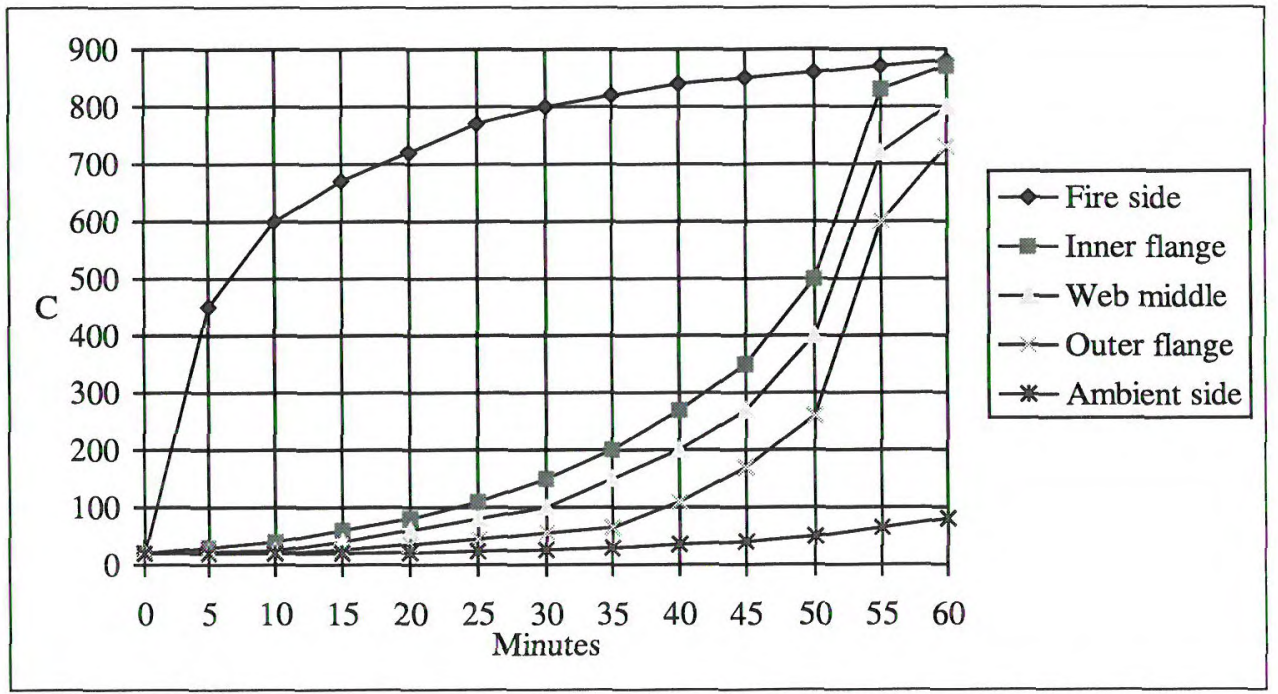

Figure A.7 Temperature development in a C-section, $b_{w}=150 \mathrm{~mm}, b_{\mathrm{f}}=40 \mathrm{~mm}$, $b_{c}=15 \mathrm{~mm}, t=0,6 \mathrm{~mm}$ protected by $2 \times 12,5 \mathrm{~mm}$ gypsum boards on both sides and without insulation.

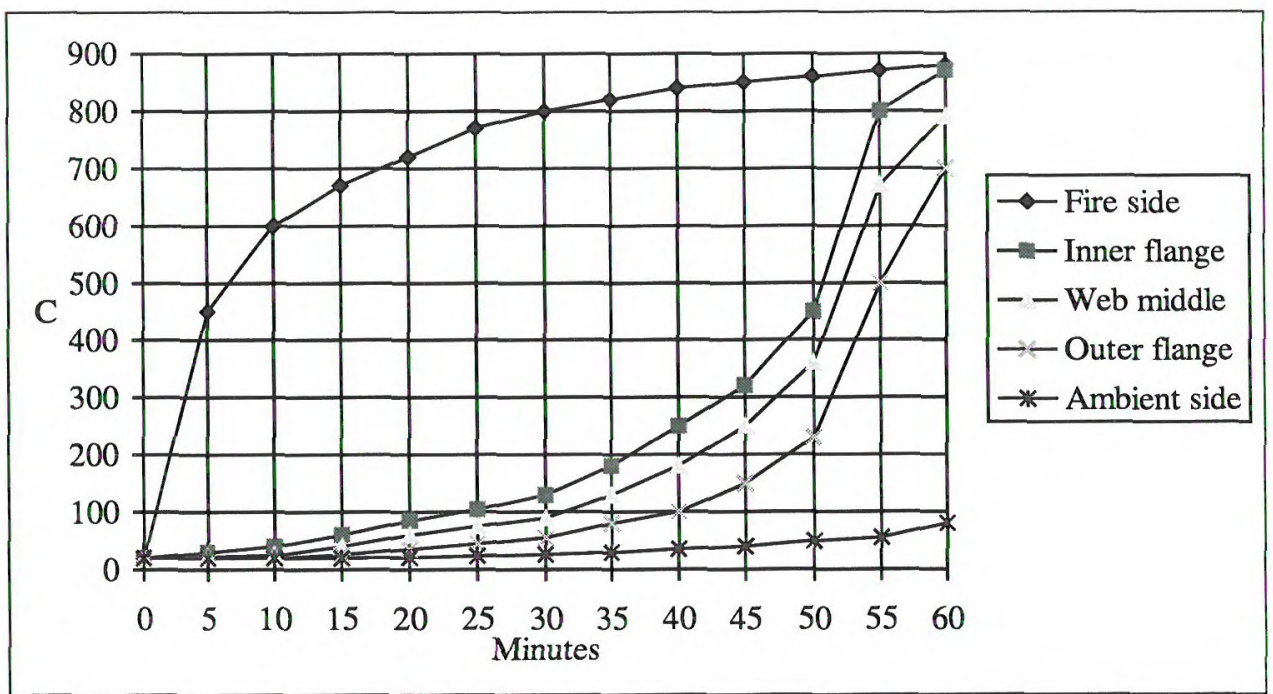

Figure A.8 Temperature development in a C-section, $b_{w}=150 \mathrm{~mm}, b_{f}=40 \mathrm{~mm}$, $b_{c}=15 \mathrm{~mm}, t=1,0 \mathrm{~mm}$ protected by $2 \times 12,5 \mathrm{~mm}$ gypsum boards on both sides and without insulation. 


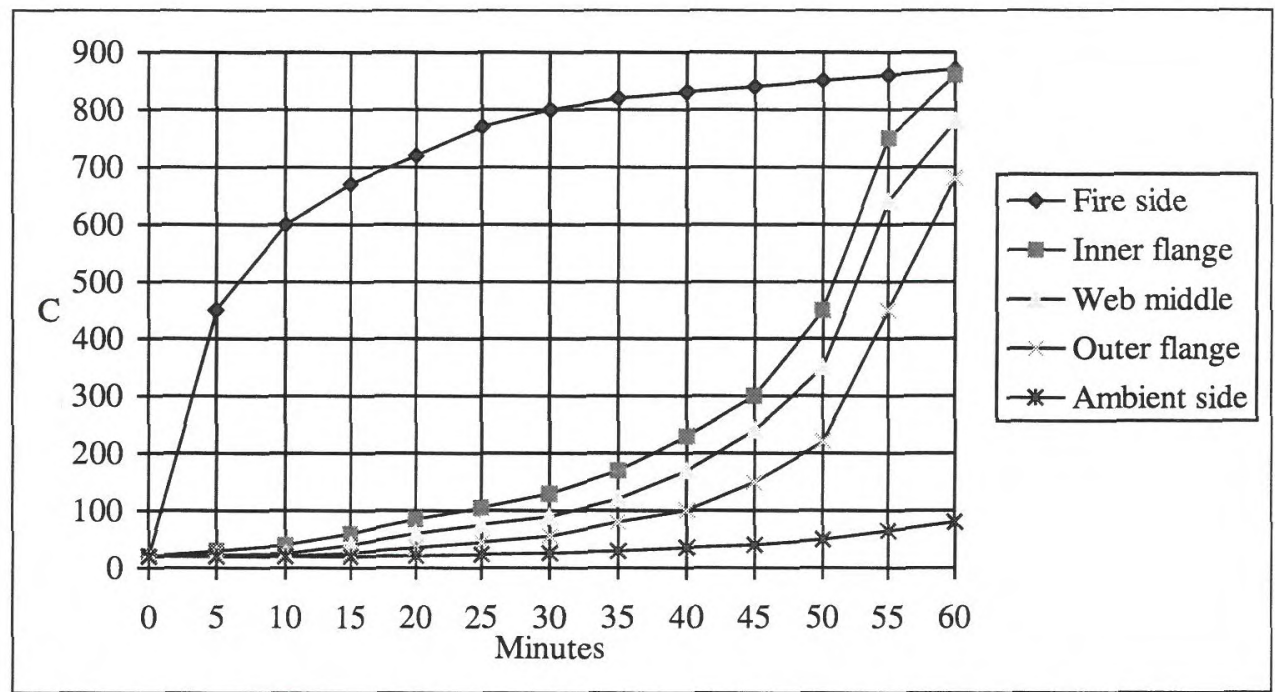

Figure A.9 Temperature development in a C-section, $b_{w}=150 \mathrm{~mm}, b_{f}=40 \mathrm{~mm}$, $\mathrm{b}_{\mathrm{c}}=15 \mathrm{~mm}, \mathrm{t}=1,2 \mathrm{~mm}$ protected by $2 \times 12,5 \mathrm{~mm}$ gypsum boards on both sides and without insulation.

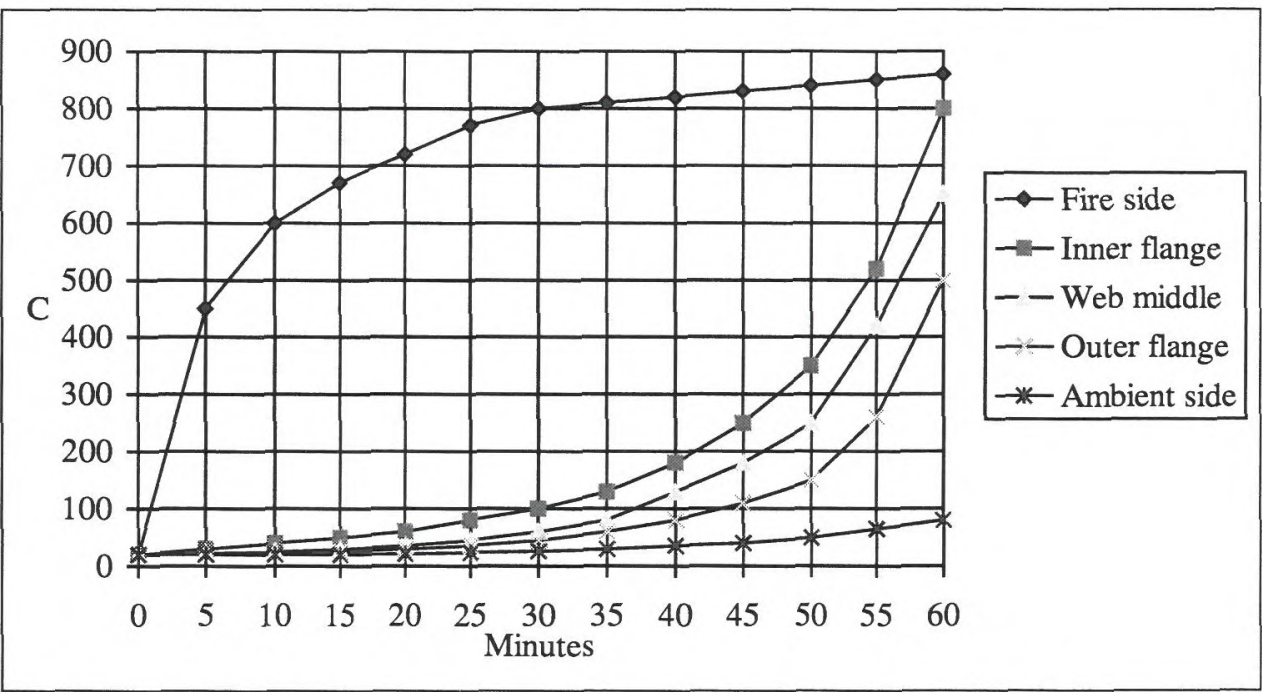

Figure A.10 Temperature development in a C-section, $b_{w}=150 \mathrm{~mm}, b_{f}=40 \mathrm{~mm}$, $\mathrm{b}_{\mathrm{c}}=15 \mathrm{~mm}, \mathrm{t}=3,0 \mathrm{~mm}$ protected by $2 \times 12,5 \mathrm{~mm}$ gypsum boards on both sides and without insulation. 


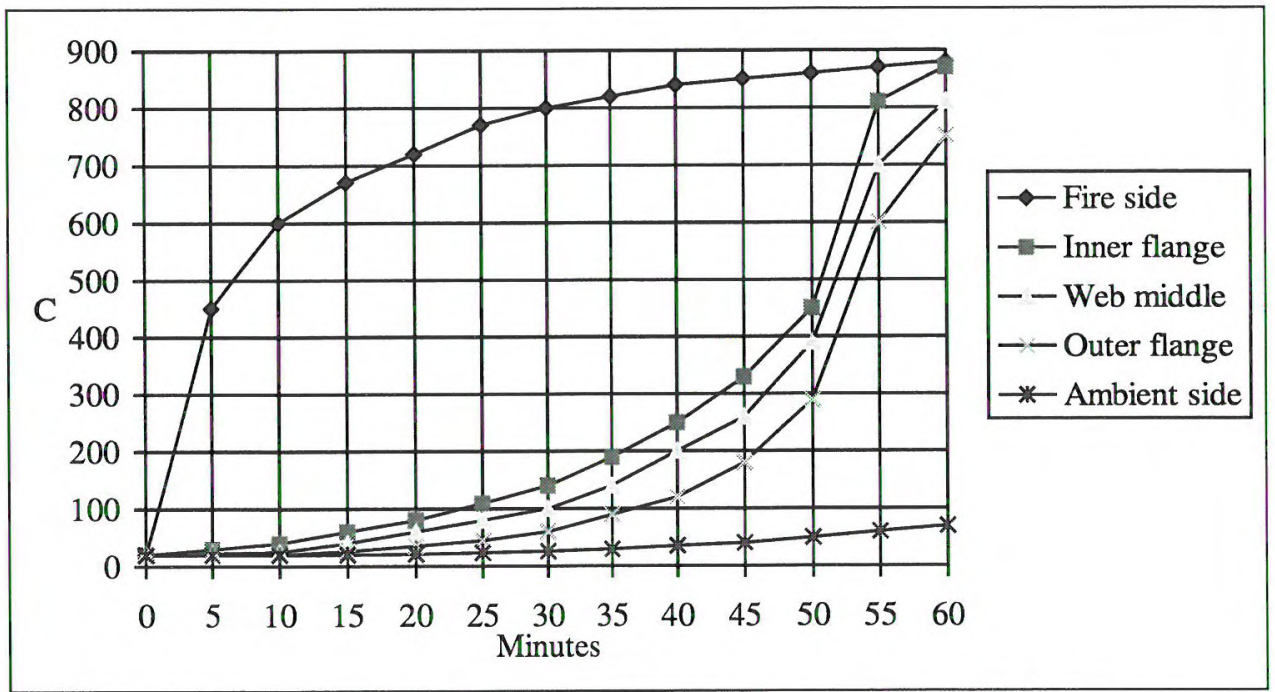

Figure A.11 Temperature development in a C-section, $b_{w}=100 \mathrm{~mm}, b_{f}=40 \mathrm{~mm}$, $b_{c}=15 \mathrm{~mm}, \mathrm{t}=0,8 \mathrm{~mm}$ protected by $2 \times 12,5 \mathrm{~mm}$ gypsum boards on both sides and without insulation.

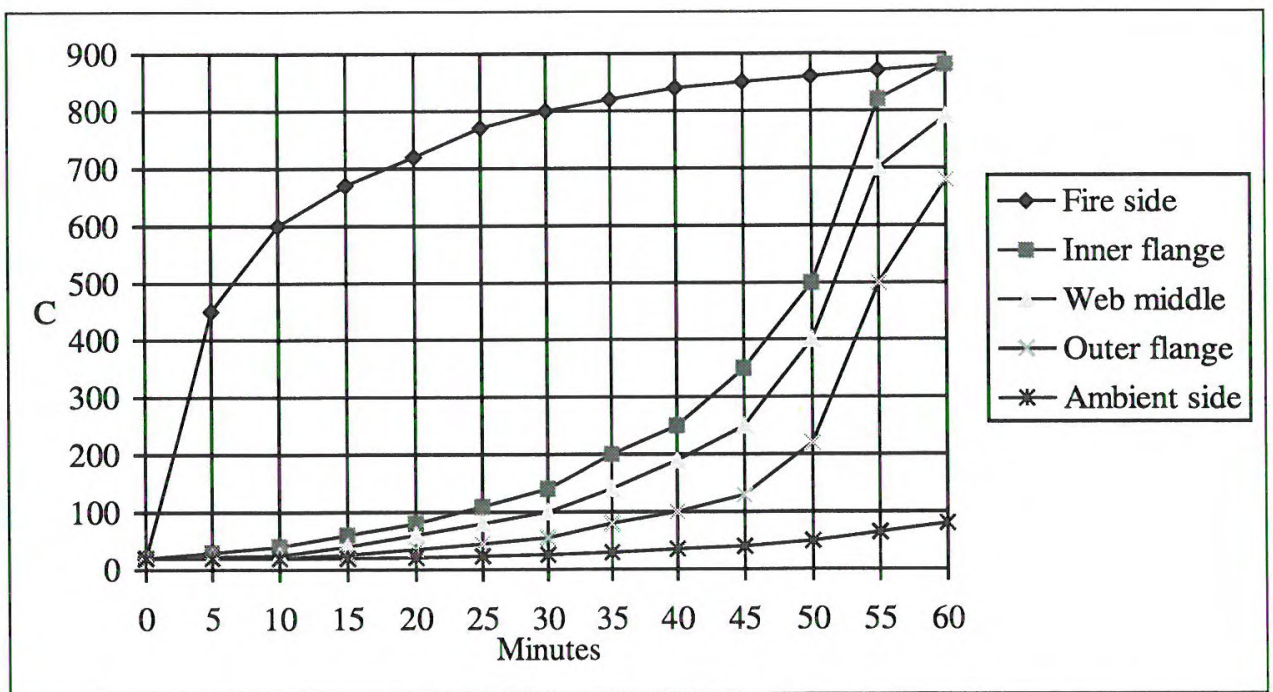

Figure A.12 Temperature development in a C-section, $b_{w}=200 \mathrm{~mm}, b_{f}=40 \mathrm{~mm}$, $b_{c}=15 \mathrm{~mm}, \mathrm{t}=0,8 \mathrm{~mm}$ protected by $2 \times 12,5 \mathrm{~mm}$ gypsum boards on both sides and without insulation. 


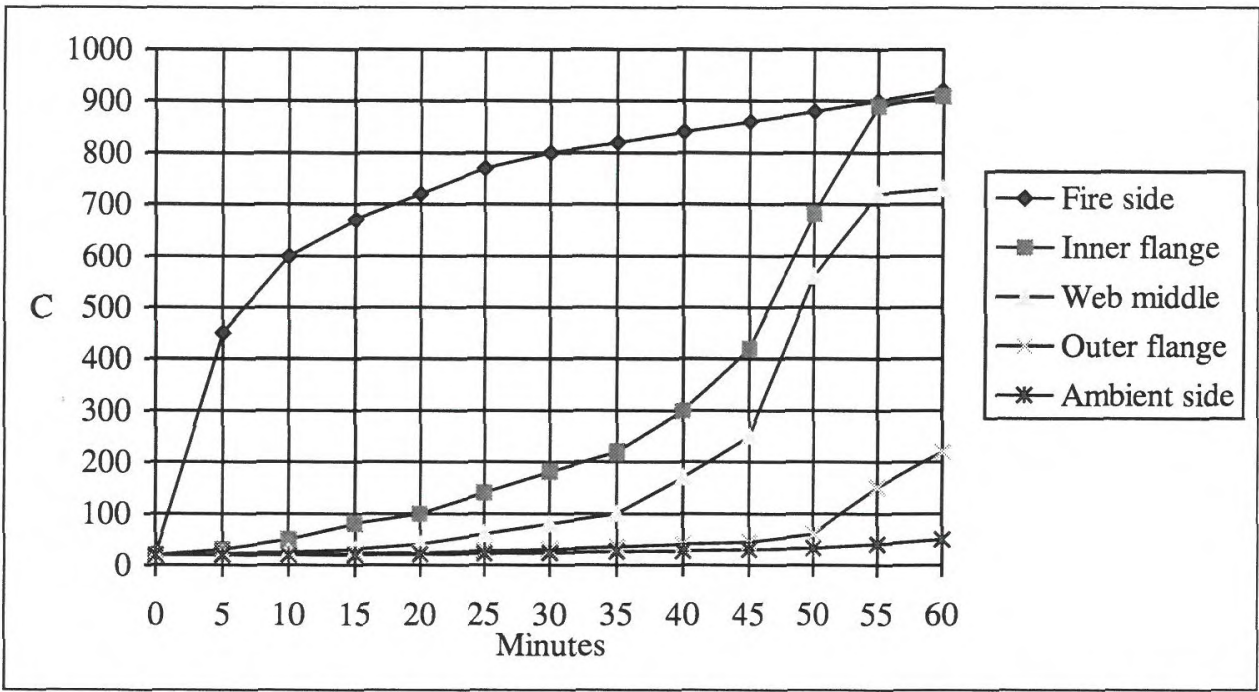

Figure A.13 Temperature development in a slotted C-section, $b_{w}=150 \mathrm{~mm}, b_{f}=40 \mathrm{~mm}$, $\mathrm{b}_{\mathrm{c}}=15 \mathrm{~mm}, \mathrm{t}=1,0 \mathrm{~mm}$ protected by $2 \times 12,5 \mathrm{~mm}$ gypsum boards on both sides and insulated with glass fibre wool, $\rho=15 \mathrm{~kg} / \mathrm{m}^{3}$.

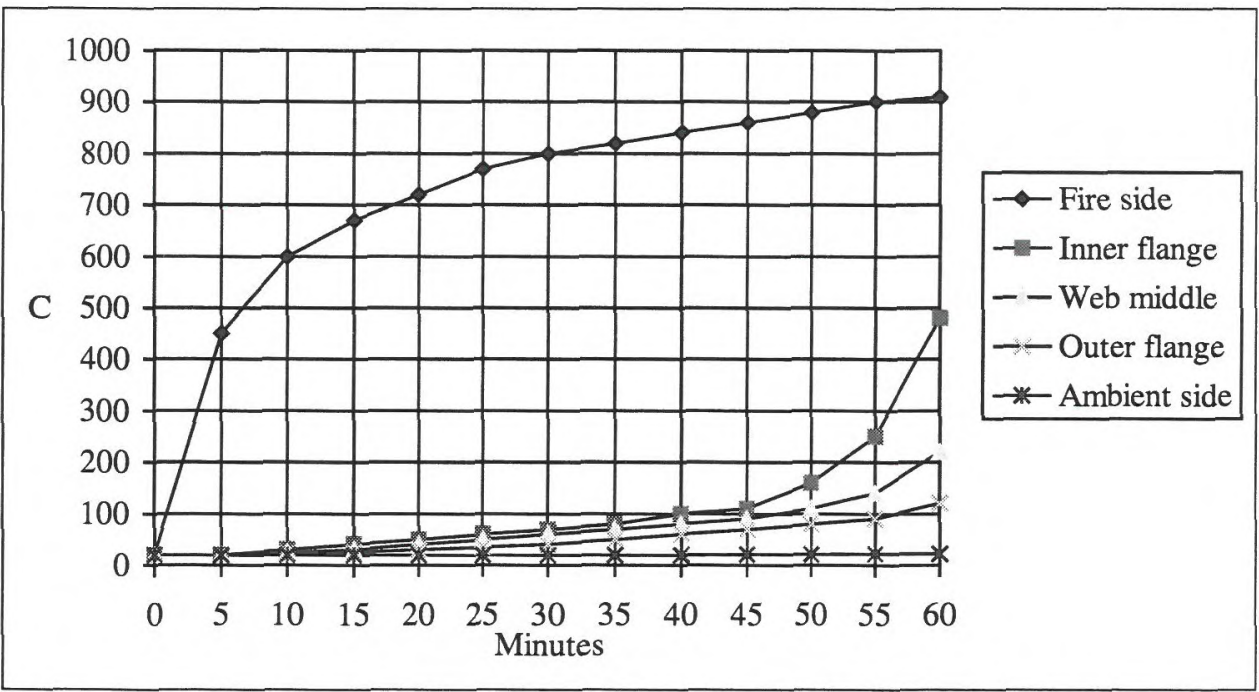

Figure A.14 Temperature development in a C-section, $b_{w}=100 \mathrm{~mm}, b_{f}=50 \mathrm{~mm}$, $\mathrm{b}_{\mathrm{c}}=15 \mathrm{~mm}, \mathrm{t}=3,0 \mathrm{~mm}$ protected by $2 \times 15 \mathrm{~mm}$ gypsum boards on both sides and insulated with rock fibre wool, $\rho=50 \mathrm{~kg} / \mathrm{m}^{3}$. 


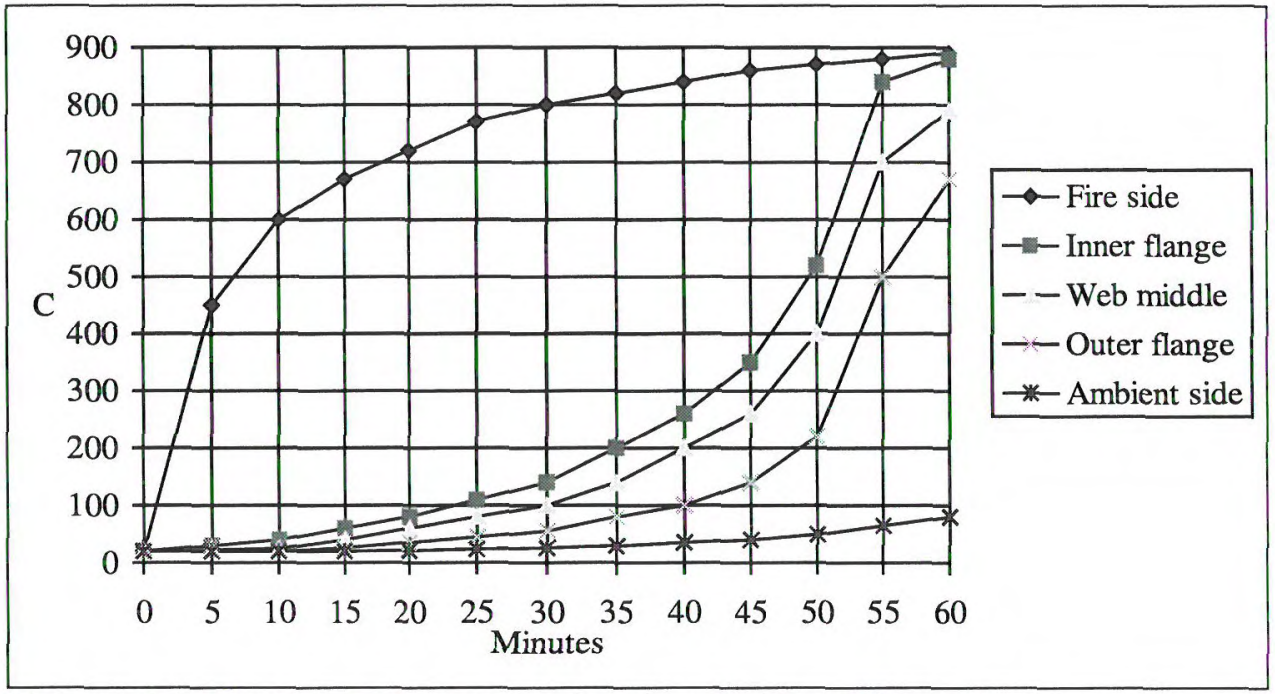

Figure A.15 Temperature development in a C-section, $b_{w}=200 \mathrm{~mm}, b_{f}=30 \mathrm{~mm}$, $\mathrm{b}_{\mathrm{c}}=15 \mathrm{~mm}, \mathrm{t}=0,8 \mathrm{~mm}$ protected by $2 \times 12,5 \mathrm{~mm}$ gypsum boards on both sides and without insulation.

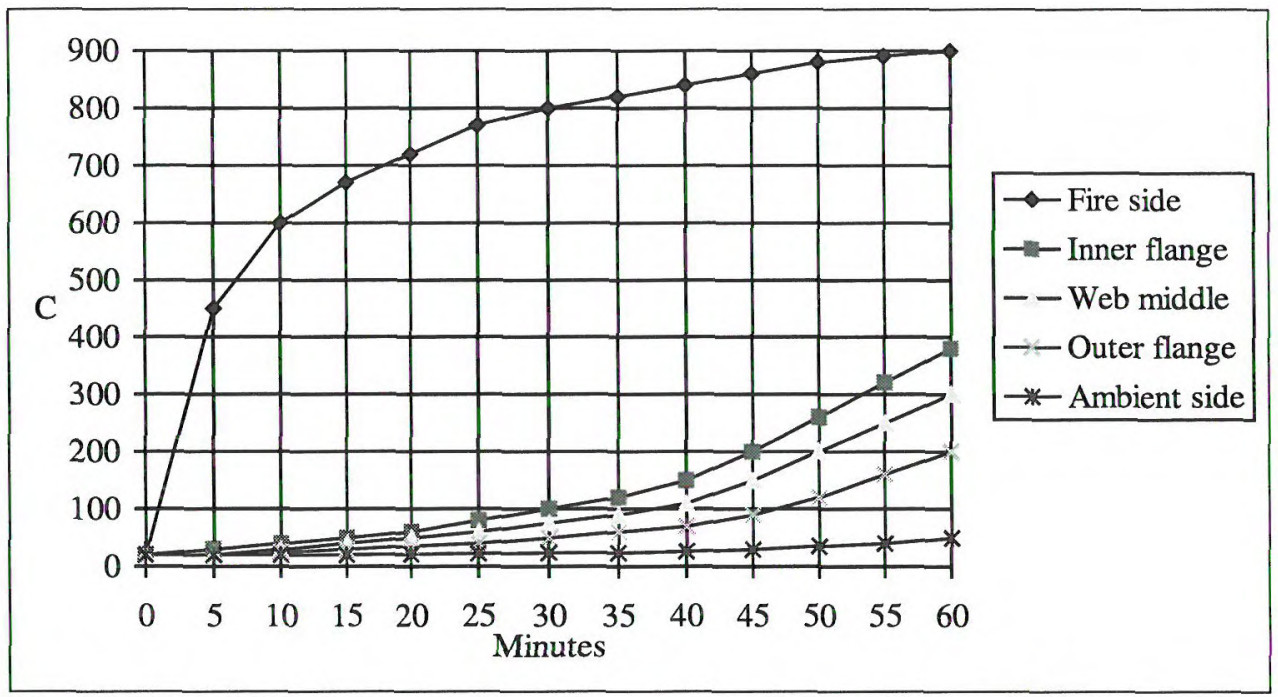

Figure A.16 Temperature development in a C-section, $b_{w}=150 \mathrm{~mm}, b_{f}=40 \mathrm{~mm}$, $\mathrm{b}_{\mathrm{c}}=15 \mathrm{~mm}, \mathrm{t}=0,8 \mathrm{~mm}$ protected by $1 \times 12,5 \mathrm{~mm}$ gypsum board + $1 \times 15,0 \mathrm{~mm}$ fire resistance gypsum board on both sides and without insulation. 


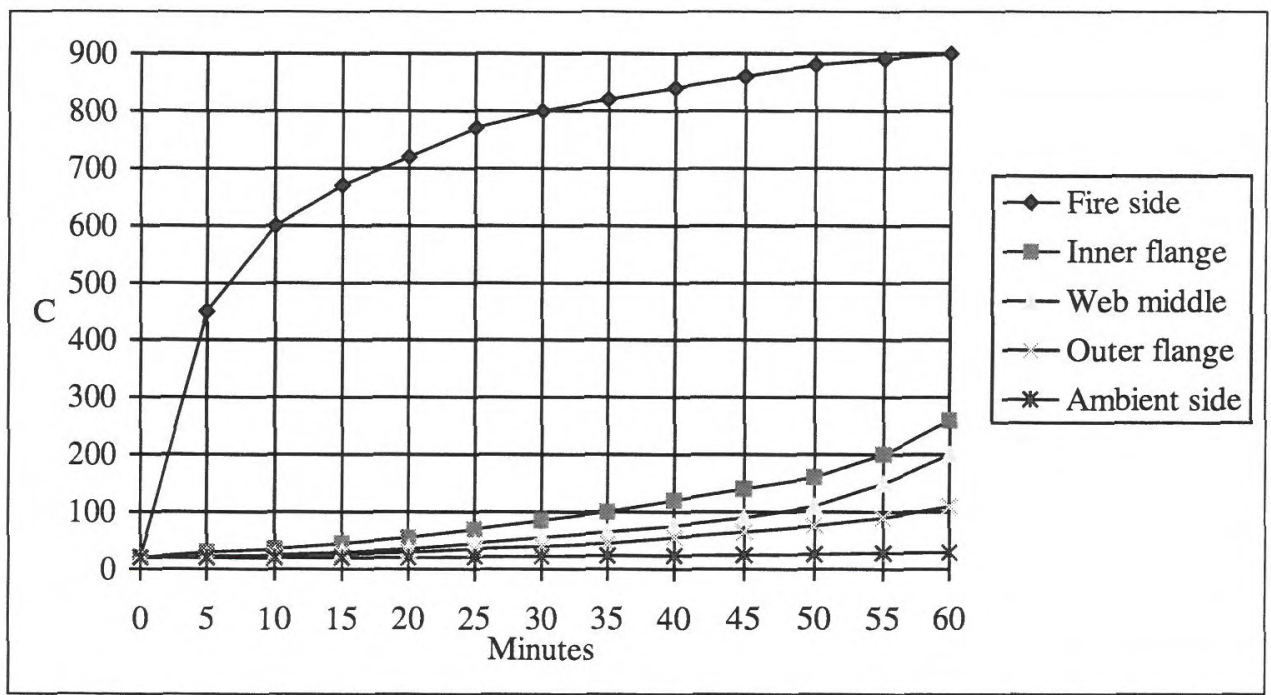

Figure A.17 Temperature development in a C-section, $b_{w}=150 \mathrm{~mm}, b_{f}=40 \mathrm{~mm}$, $b_{c}=15 \mathrm{~mm}, \mathrm{t}=0,8 \mathrm{~mm}$ protected by $2 \times 15,0 \mathrm{~mm}$ fire resistance gypsum boards on both sides and without insulation. 


\section{APPENDIX B}

\section{Relationship of load - axial deformation due to local buckling.}

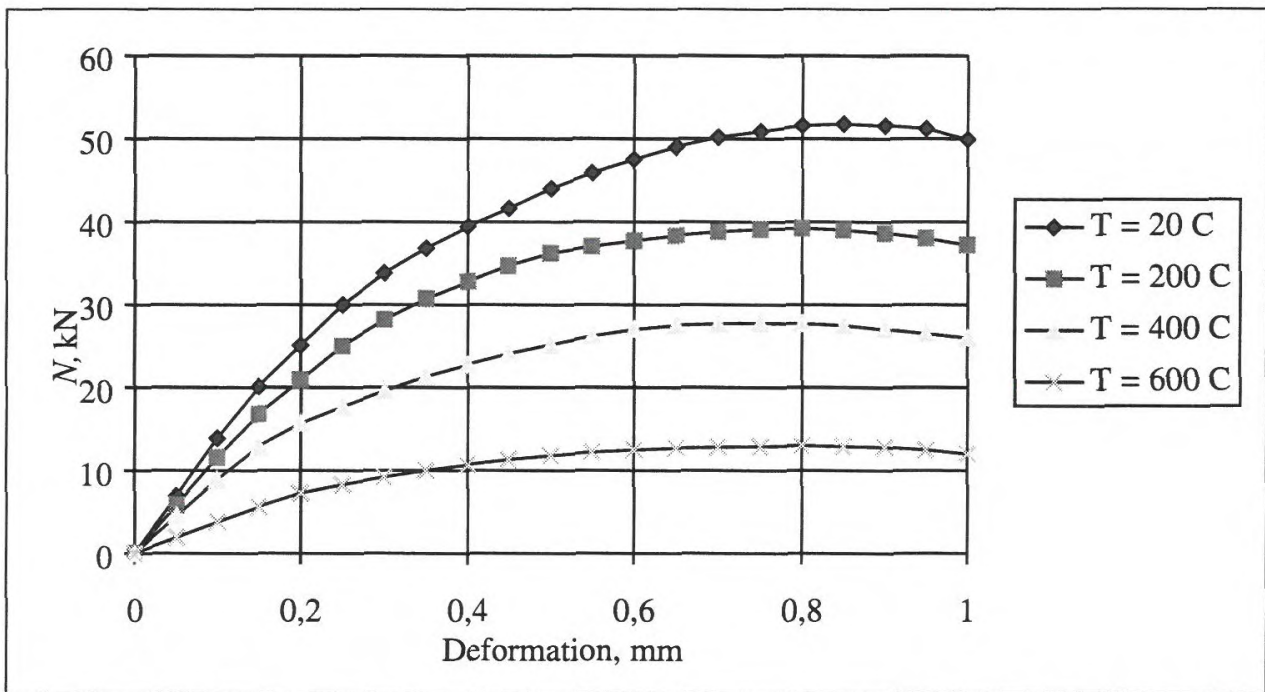

Figure B.1 Load - axial deformation relationship due to local buckling of the C-section, $\mathrm{b}_{\mathrm{w}}=100 \mathrm{~mm}, \mathrm{~b}_{\mathrm{f}}=40 \mathrm{~mm}, \mathrm{~b}_{\mathrm{c}}=15 \mathrm{~mm}$ and $\mathrm{t}=1,0 \mathrm{~mm}$, by FEM.

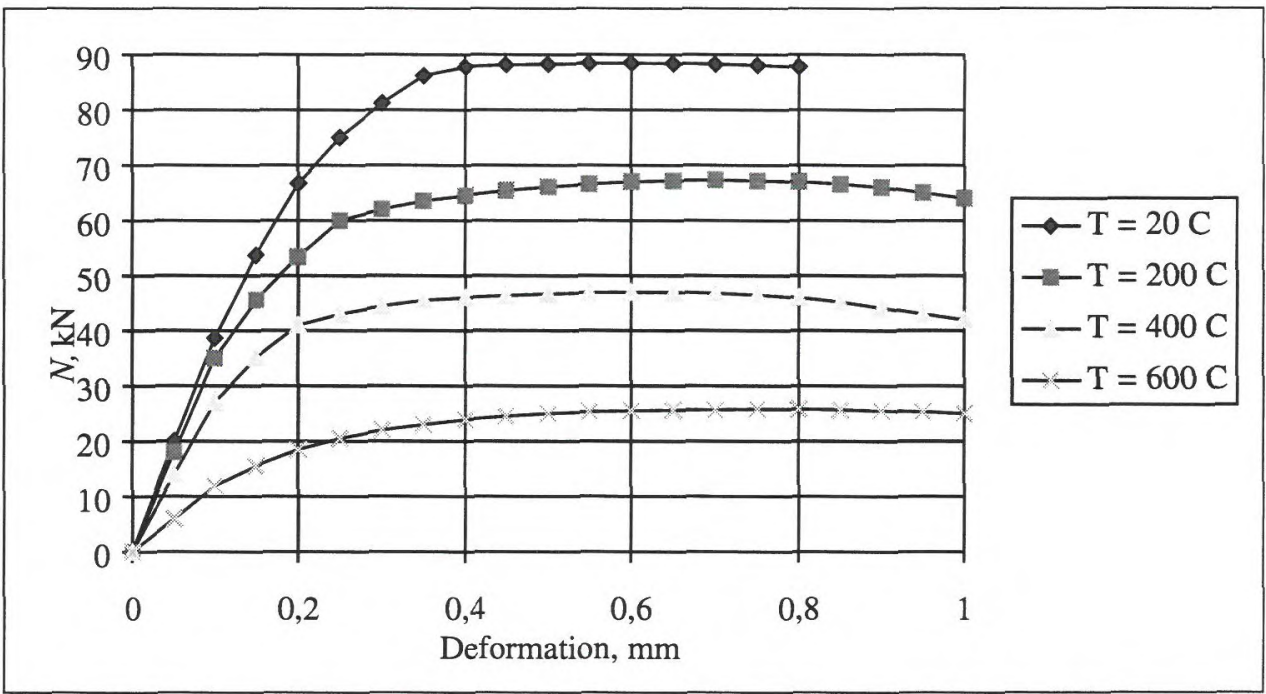

Figure B.2 Load - deformation relationship due to local buckling of the C-section, $\mathrm{b}_{\mathrm{w}}=100 \mathrm{~mm}, \mathrm{~b}_{\mathrm{f}}=40 \mathrm{~mm}, \mathrm{~b}_{\mathrm{c}}=15 \mathrm{~mm}$ and $\mathrm{t}=1,5 \mathrm{~mm}$, by FEM. 


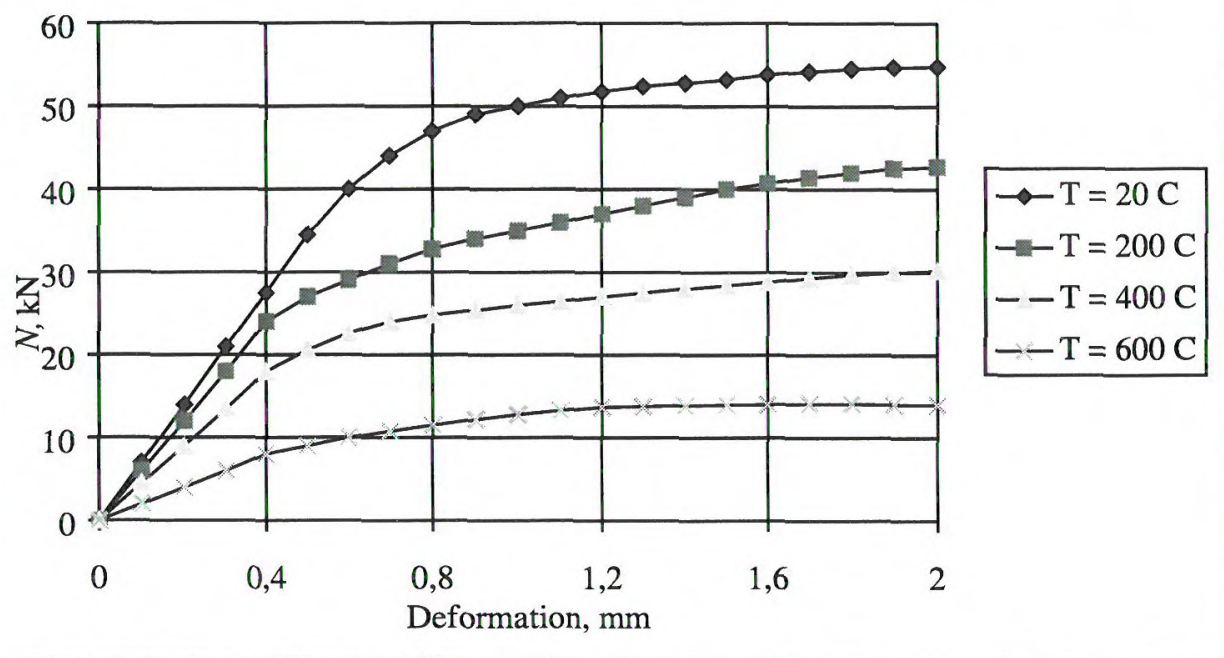

Figure B.3 Load - axial deformation relationship due to local buckling of the C-section, $b_{w}=200 \mathrm{~mm}, b_{f}=40 \mathrm{~mm}, b_{c}=15 \mathrm{~mm}$ and $t=1,0 \mathrm{~mm}$, by FEM.

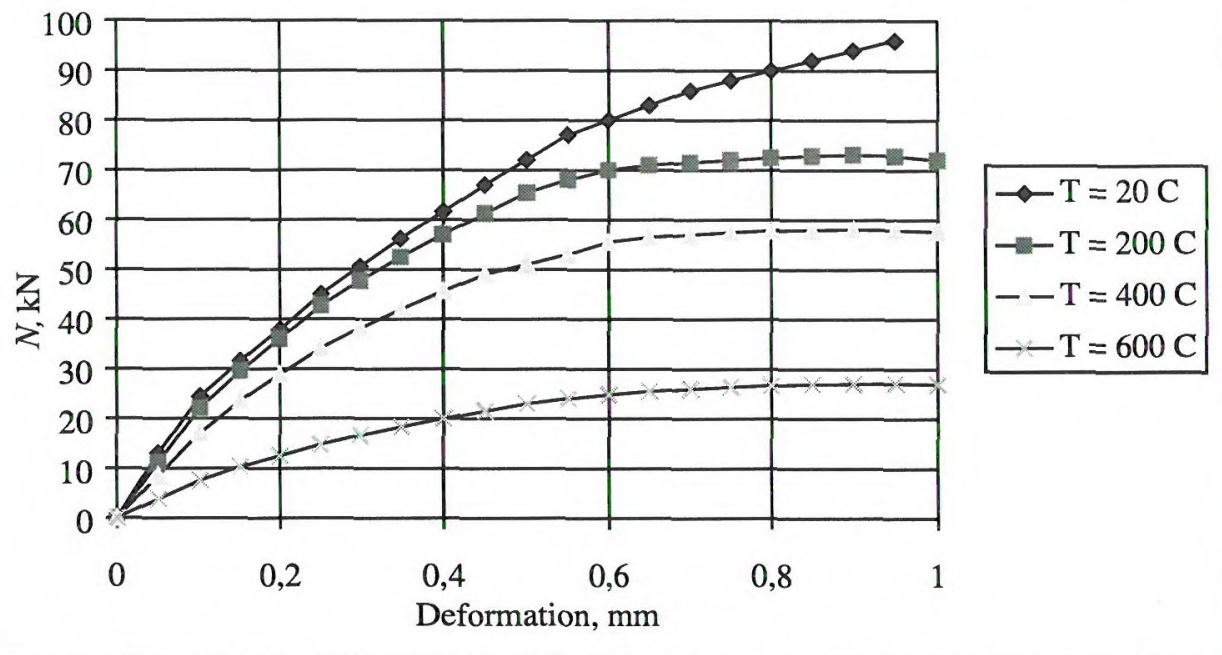

Figure B.4 Load - deformation relationship due to local buckling of the C-section, $b_{w}=200 \mathrm{~mm}, b_{f}=40 \mathrm{~mm}, b_{c}=15 \mathrm{~mm}$ and $t=1,5 \mathrm{~mm}$, by FEM. 


\section{Relationship of ultimate load - temperature due to local buckling.}

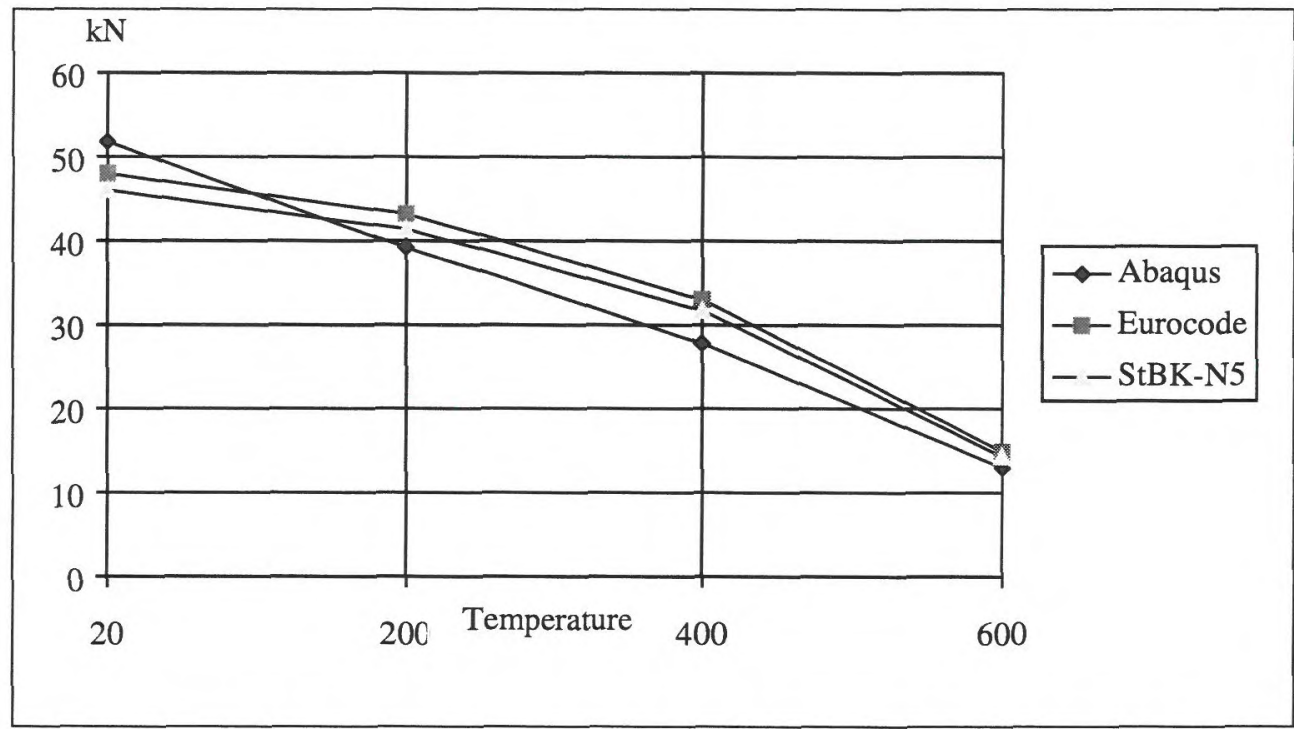

Figure B.5 Ultimate load - temperature relationship due to local buckling of the Csection, $b_{w}=100 \mathrm{~mm}, b_{f}=40 \mathrm{~mm}, b_{c}=15 \mathrm{~mm}$ and $t=1,0 \mathrm{~mm}$.

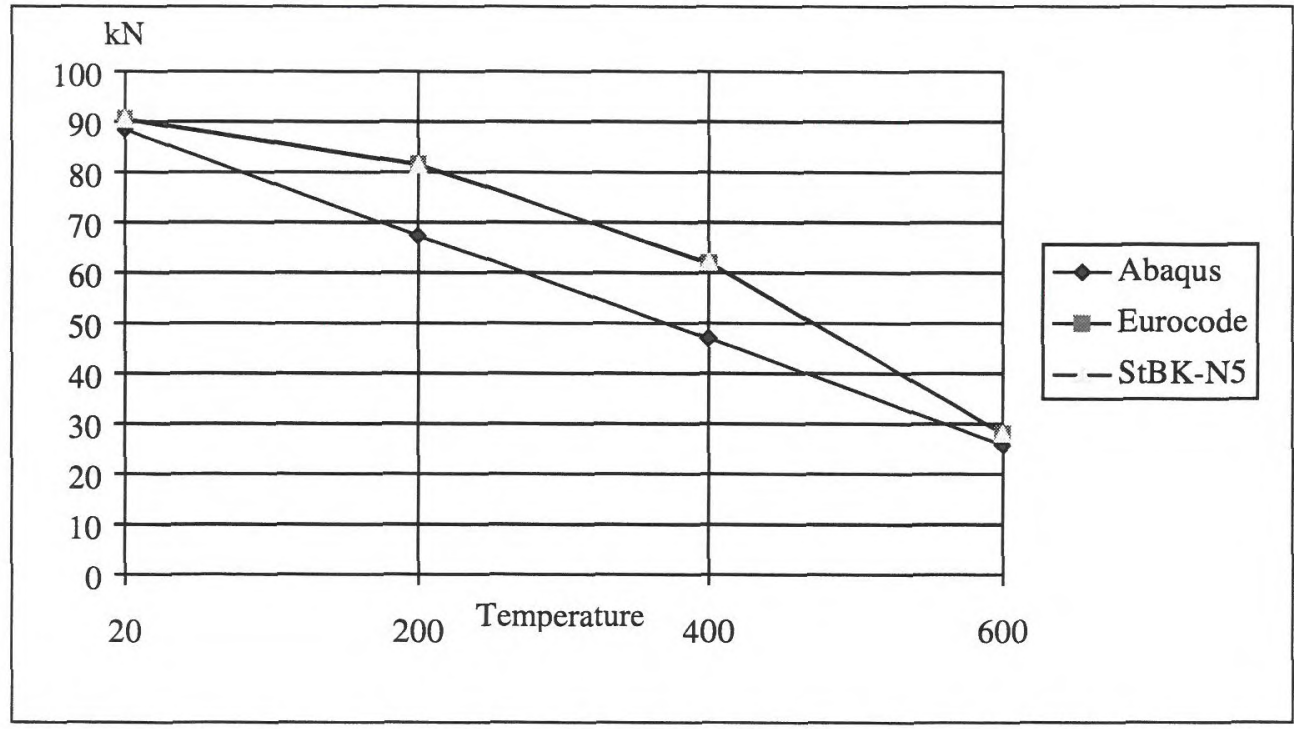

Figure B.6 Ultimate load - temperature relationship due to local buckling of the Csection, $b_{w}=100 \mathrm{~mm}, b_{\mathrm{f}}=40 \mathrm{~mm}, b_{c}=15 \mathrm{~mm}$ and $\mathrm{t}=1,5 \mathrm{~mm}$. 


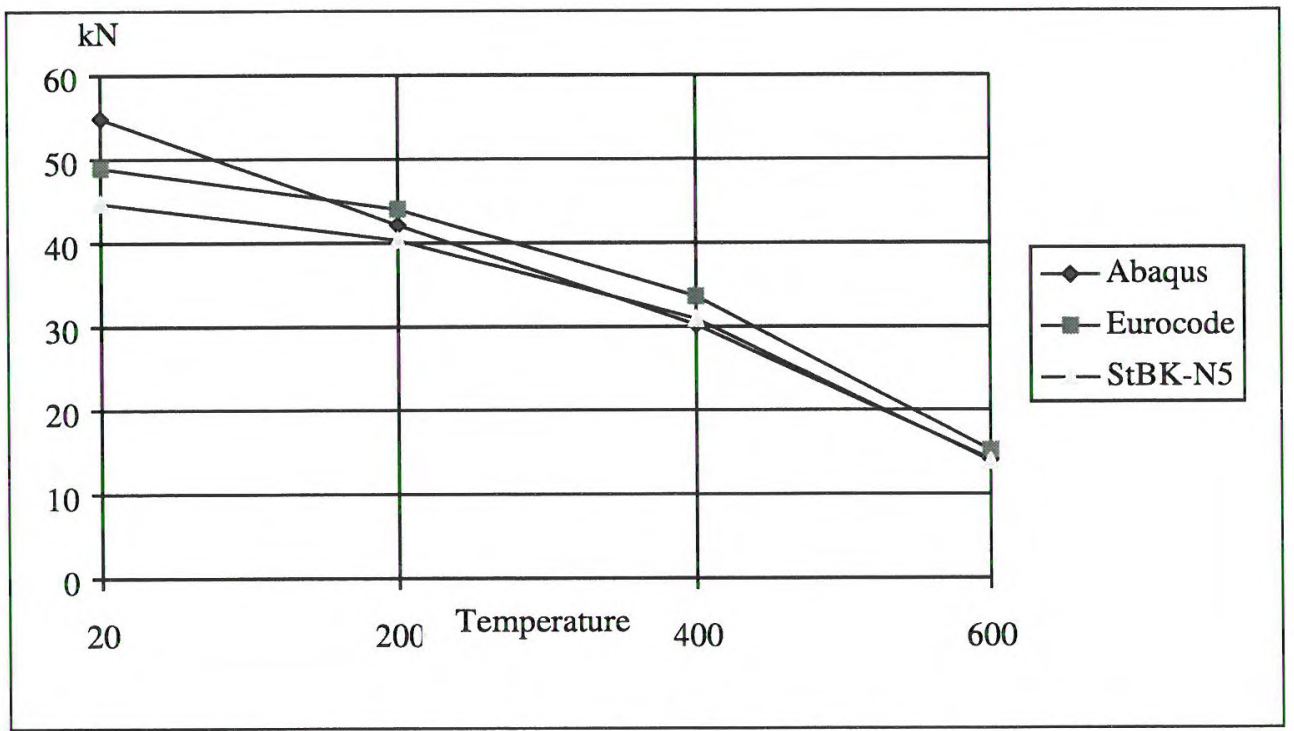

Figure B.7 Ultimate load - temperature relationship due to local buckling of the Csection, $b_{w}=200 \mathrm{~mm}, b_{f}=40 \mathrm{~mm}, b_{c}=15 \mathrm{~mm}$ and $t=1,0 \mathrm{~mm}$.

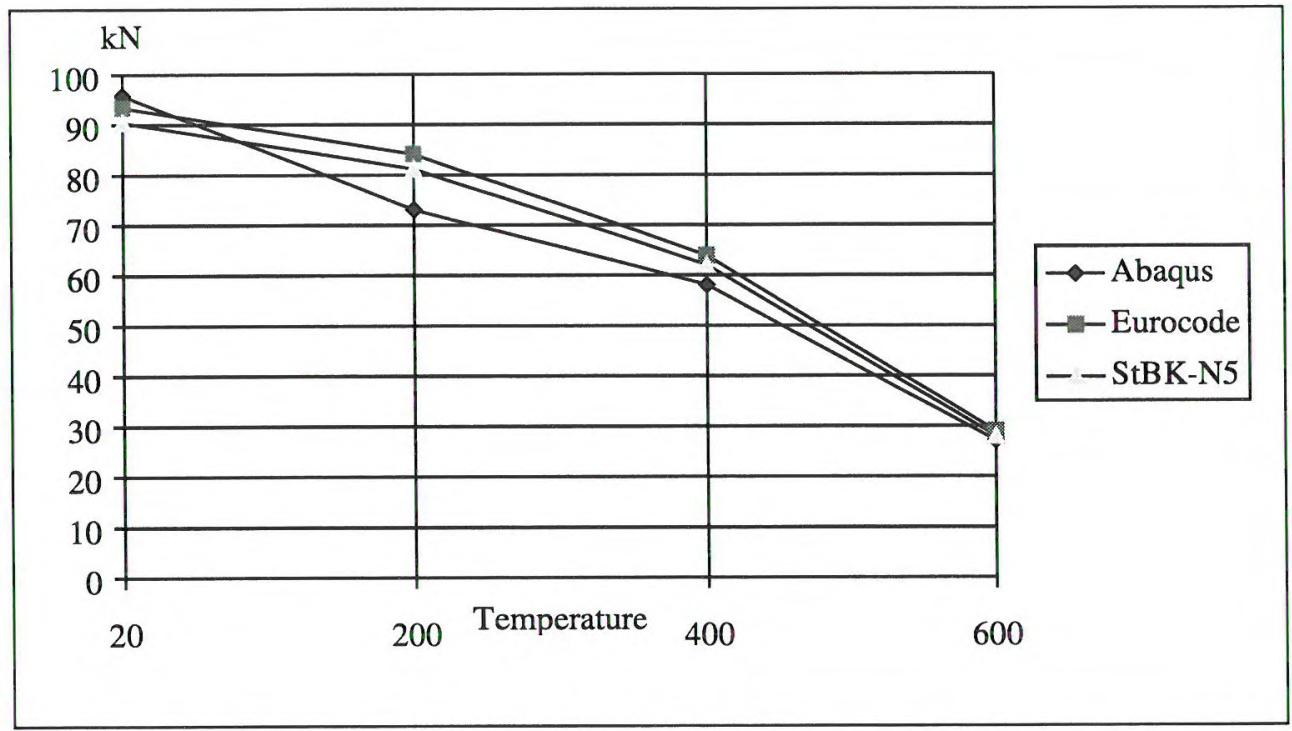

Figure B.8 Ultimate load - temperature relationship due to local buckling of the Csection, $b_{w}=200 \mathrm{~mm}, b_{f}=40 \mathrm{~mm}, b_{c}=15 \mathrm{~mm}$ and $t=1,5 \mathrm{~mm}$. 


\section{APPENDIX C}

\section{Relationship of load - axial deformation due to flexural buckling.}

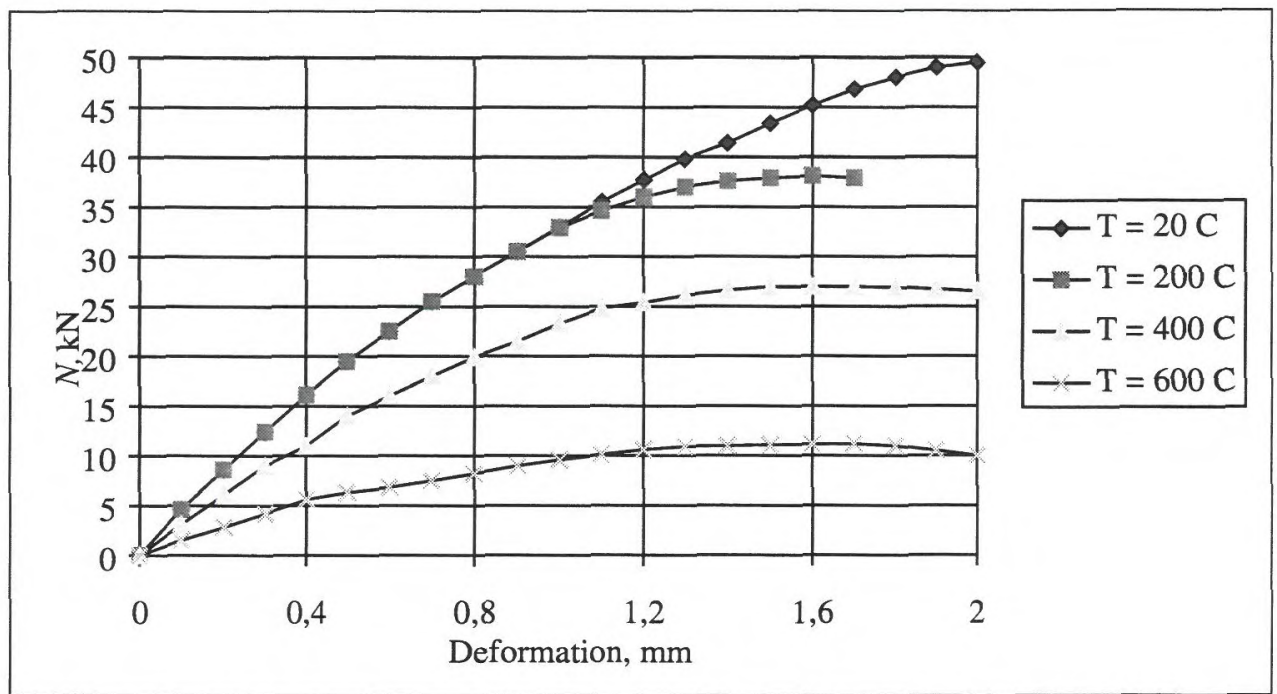

Figure C.1 Load - axial deformation relationship due to flexural buckling of the C-section, $b_{w}=100 \mathrm{~mm}, b_{f}=40 \mathrm{~mm}, b_{c}=15 \mathrm{~mm}$ and $t=1,0 \mathrm{~mm}$, by FEM.

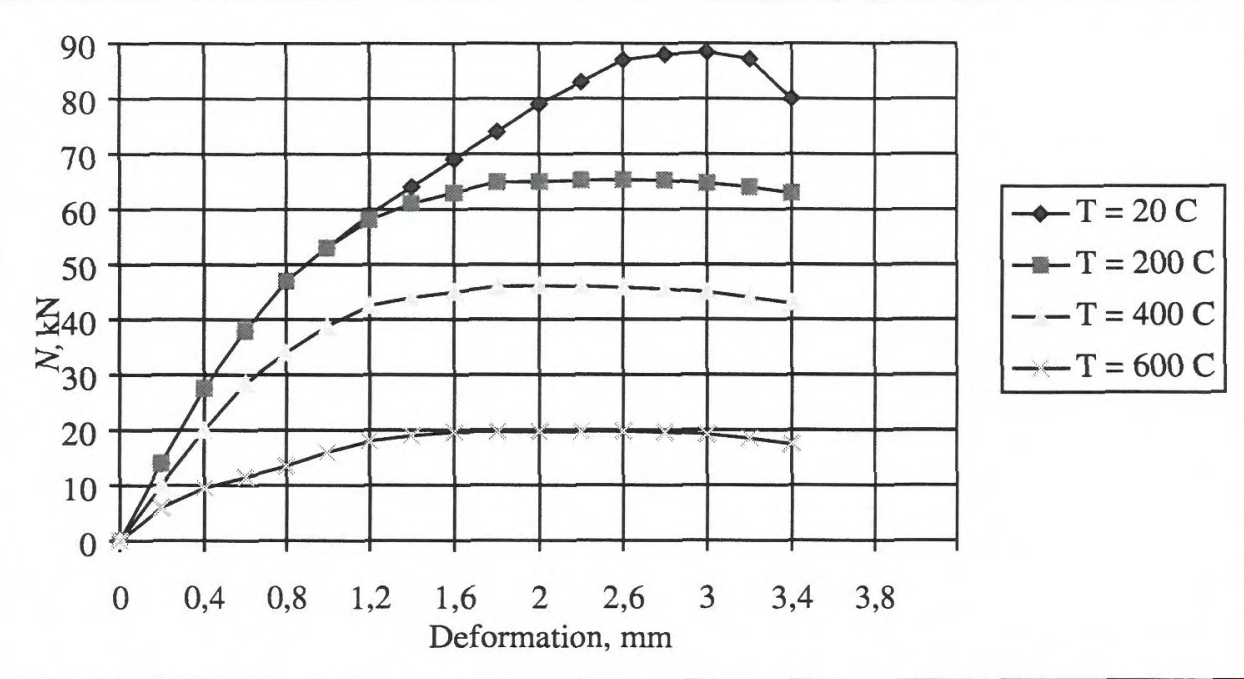

Figure C.2 Load - axial deformation relationship due to flexural buckling of the C-section, $b_{w}=100 \mathrm{~mm}, b_{f}=40 \mathrm{~mm}, b_{c}=15 \mathrm{~mm}$ and $t=1,5 \mathrm{~mm}$, by FEM. 


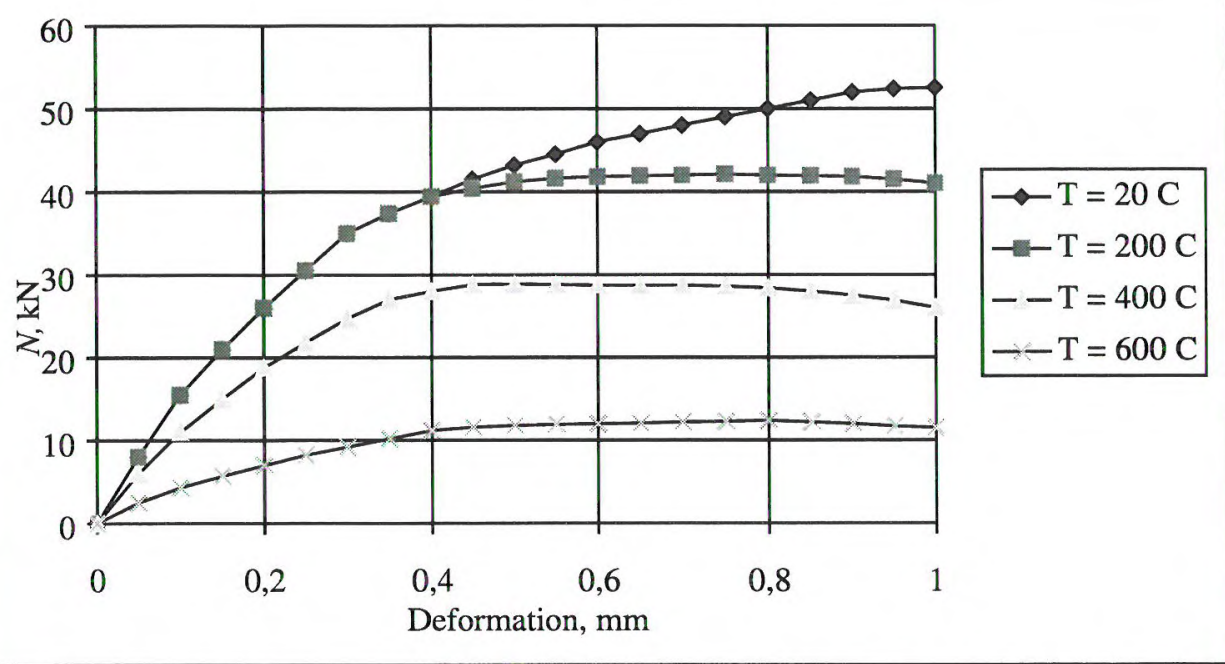

Figure C.3 Load - axial deformation relationship due to flexural buckling of the C-section, $b_{\mathrm{w}}=200 \mathrm{~mm}, \mathrm{~b}_{\mathrm{f}}=40 \mathrm{~mm}, \mathrm{~b}_{\mathrm{c}}=15 \mathrm{~mm}$ and $\mathrm{t}=1,0 \mathrm{~mm}$, by FEM.

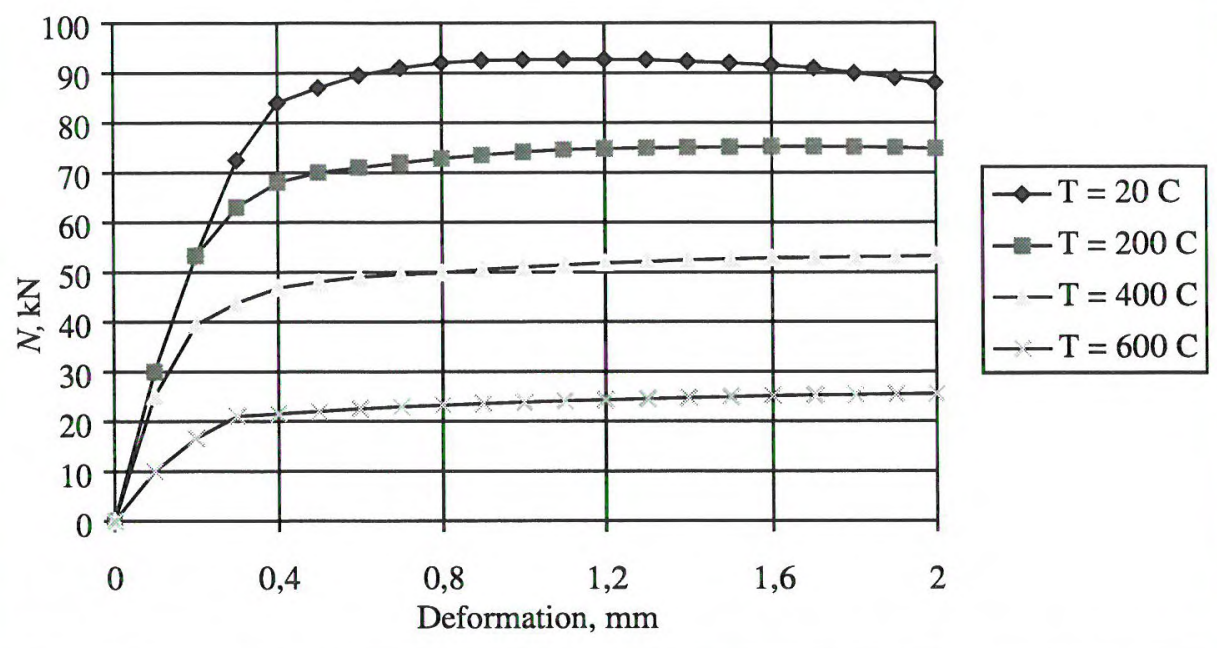

Figure C.4 Load - deformation relationship due to flexural buckling of the C-section, $b_{w}=200 \mathrm{~mm}, b_{f}=40 \mathrm{~mm}, b_{c}=15 \mathrm{~mm}$ and $t=1,5 \mathrm{~mm}$, by FEM. 


\section{Relationship of ultimate load - temperature due to flexural buckling.}

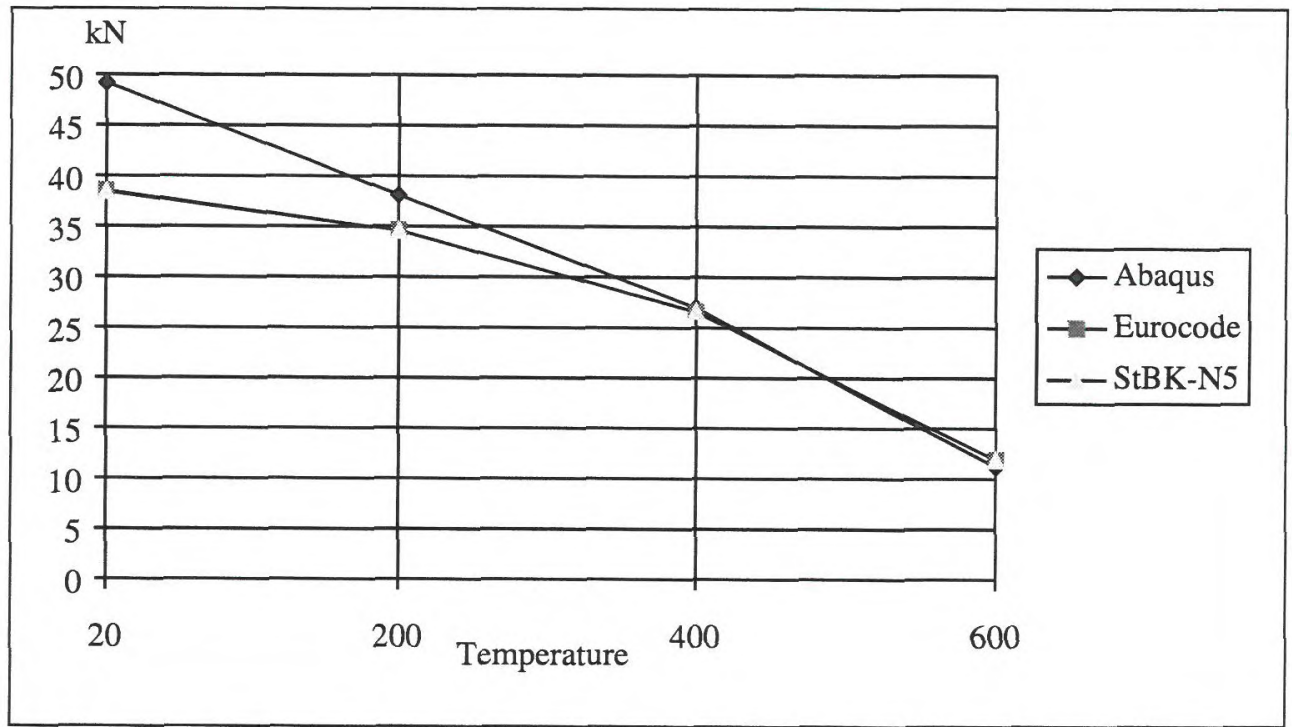

Figure C.5 Ultimate load - temperature relationship due to flexural buckling of the Csection, $b_{w}=100 \mathrm{~mm}, b_{f}=40 \mathrm{~mm}, b_{c}=15 \mathrm{~mm}$ and $\mathrm{t}=1,0 \mathrm{~mm}$.

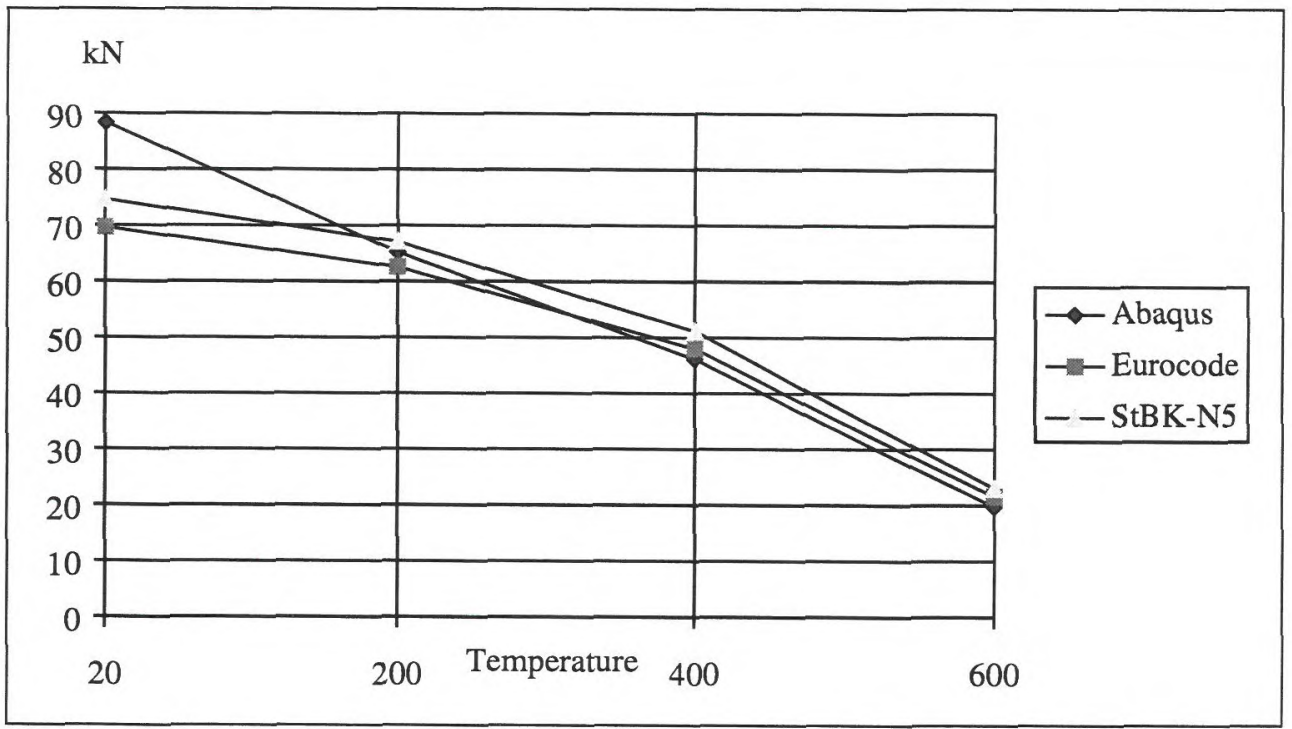

Figure C.6 Ultimate load - temperature relationship due to flexural buckling of the Csection, $b_{w}=100 \mathrm{~mm}, b_{f}=40 \mathrm{~mm}, b_{c}=15 \mathrm{~mm}$ and $t=1,5 \mathrm{~mm}$. 


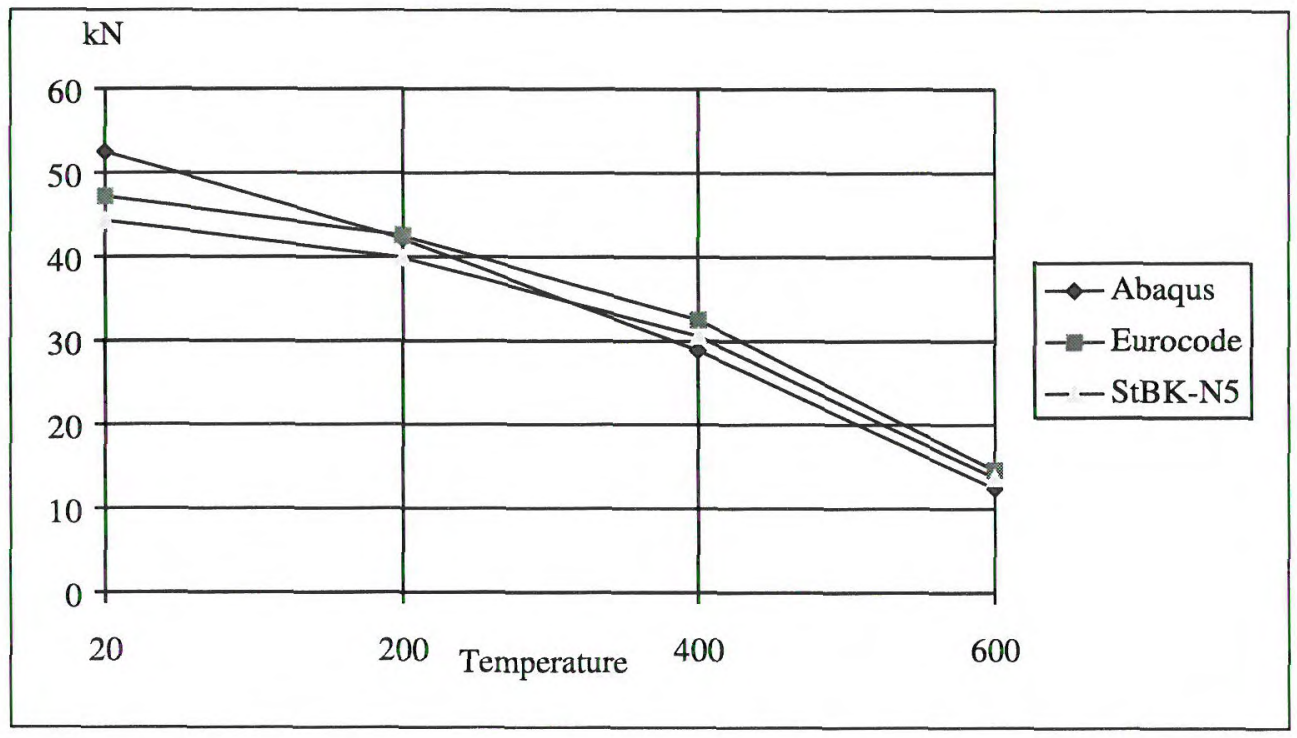

Figure C.7 Ultimate load - temperature relationship due to flexural buckling of the Csection, $b_{w}=200 \mathrm{~mm}, b_{f}=40 \mathrm{~mm}, b_{c}=15 \mathrm{~mm}$ and $t=1,0 \mathrm{~mm}$.

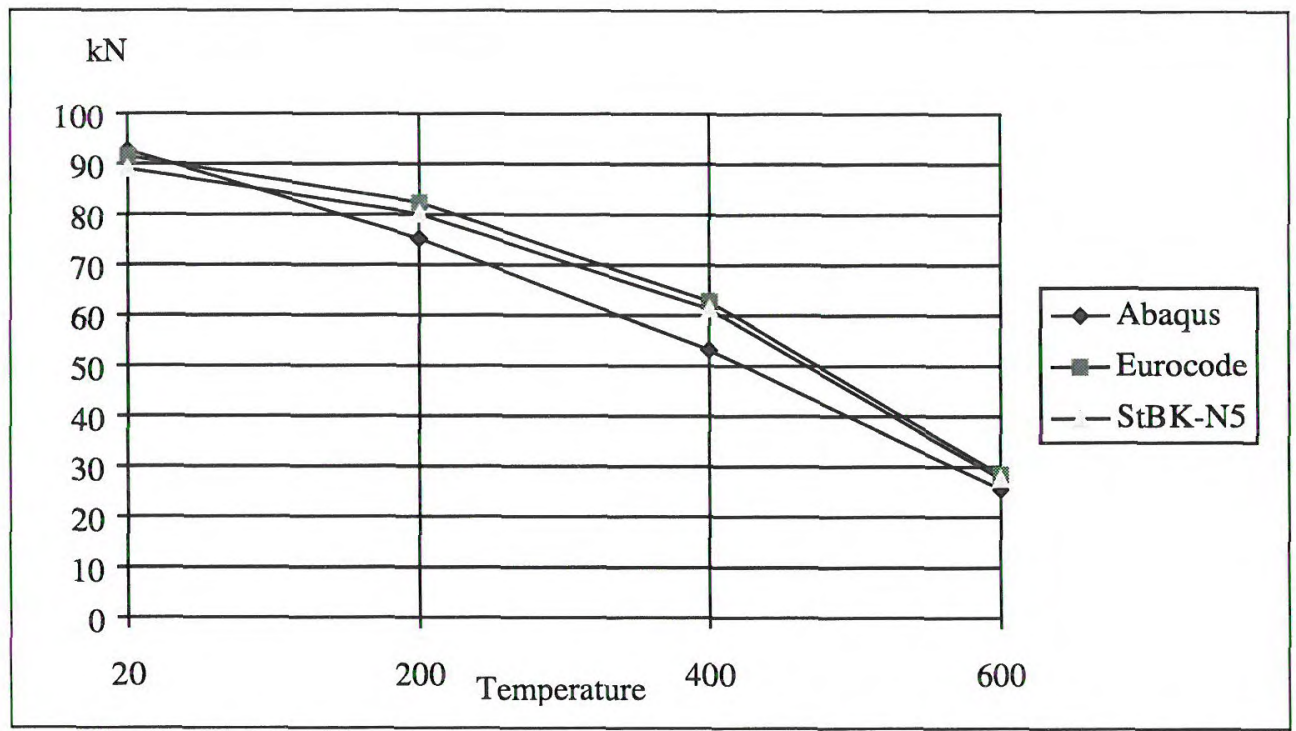

Figure C.8 Ultimate load - temperature relationship due to flexural buckling of the Csection, $b_{w}=200 \mathrm{~mm}, b_{f}=40 \mathrm{~mm}, b_{c}=15 \mathrm{~mm}$ and $t=1,5 \mathrm{~mm}$. 


\section{APPENDIX D}

\section{Relationship of ultimate load - temperature due to torsional- flexural buckling.}

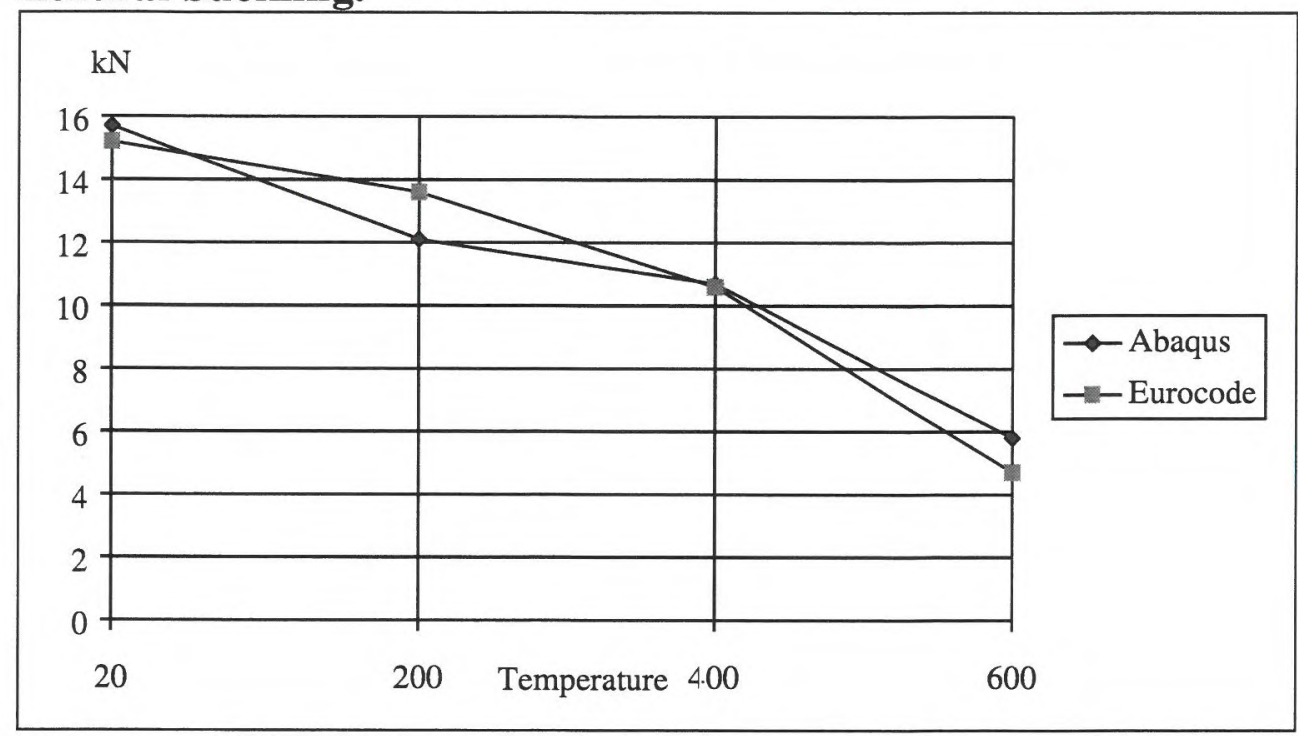

Figure D.1 Ultimate load - temperature relationship due to torsional-flexural buckling of the C-section, $b_{w}=100 \mathrm{~mm}, b_{\mathrm{f}}=40 \mathrm{~mm}, b_{c}=15 \mathrm{~mm}$ and $\mathrm{t}=1,0 \mathrm{~mm}$.

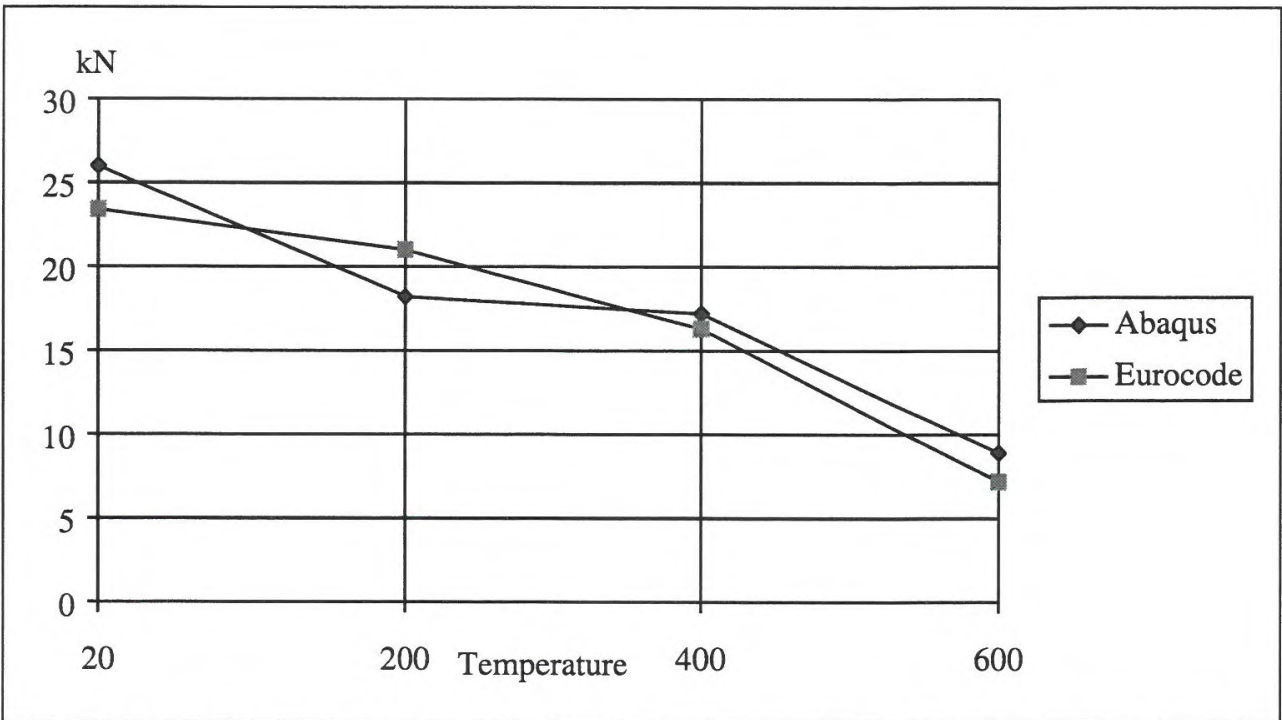

Figure D.2 Ultimate load - temperature relationship due to torsional-flexural buckling of the C-section, $b_{w}=100 \mathrm{~mm}, b_{f}=40 \mathrm{~mm}, b_{c}=15 \mathrm{~mm}$ and $\mathrm{t}=1,5 \mathrm{~mm}$. 


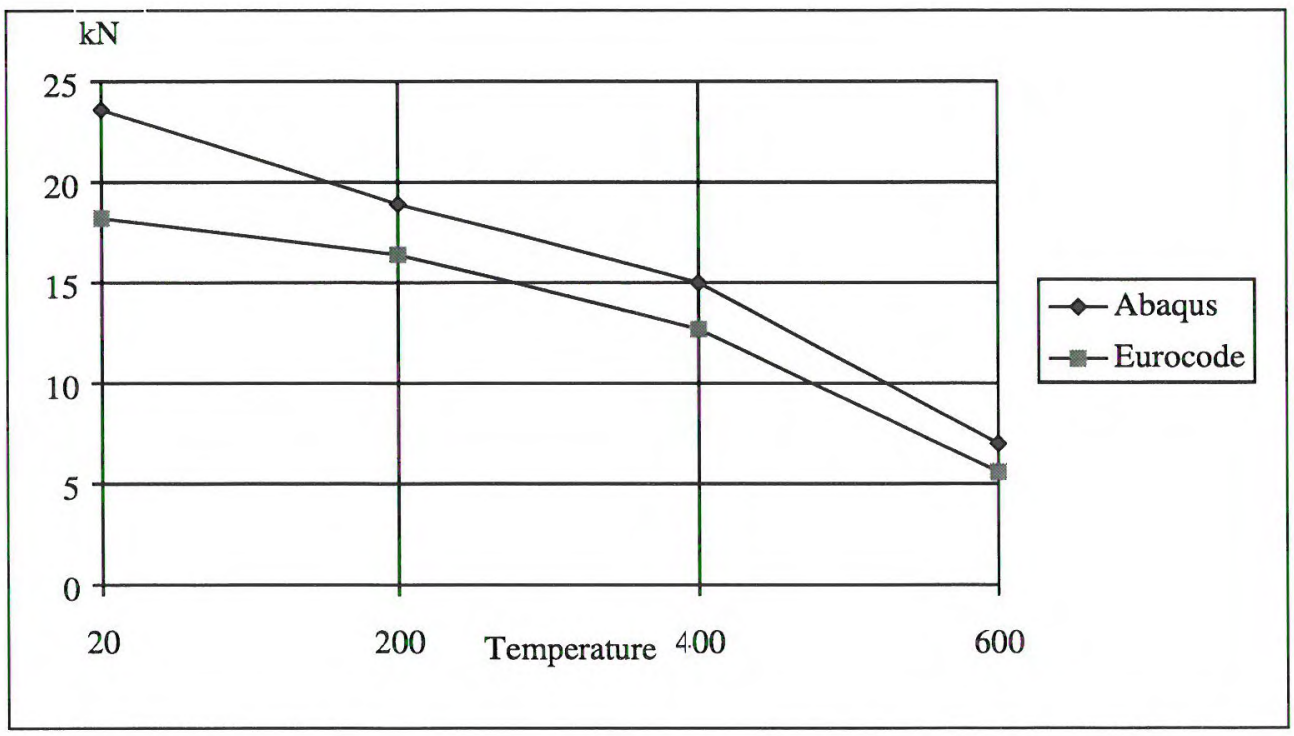

Figure D.3 Ultimate load - temperature relationship due to torsional-flexural buckling of the C-section, $b_{w}=200 \mathrm{~mm}, b_{\mathrm{f}}=40 \mathrm{~mm}, b_{c}=15 \mathrm{~mm}$ and $\mathrm{t}=1,0 \mathrm{~mm}$.

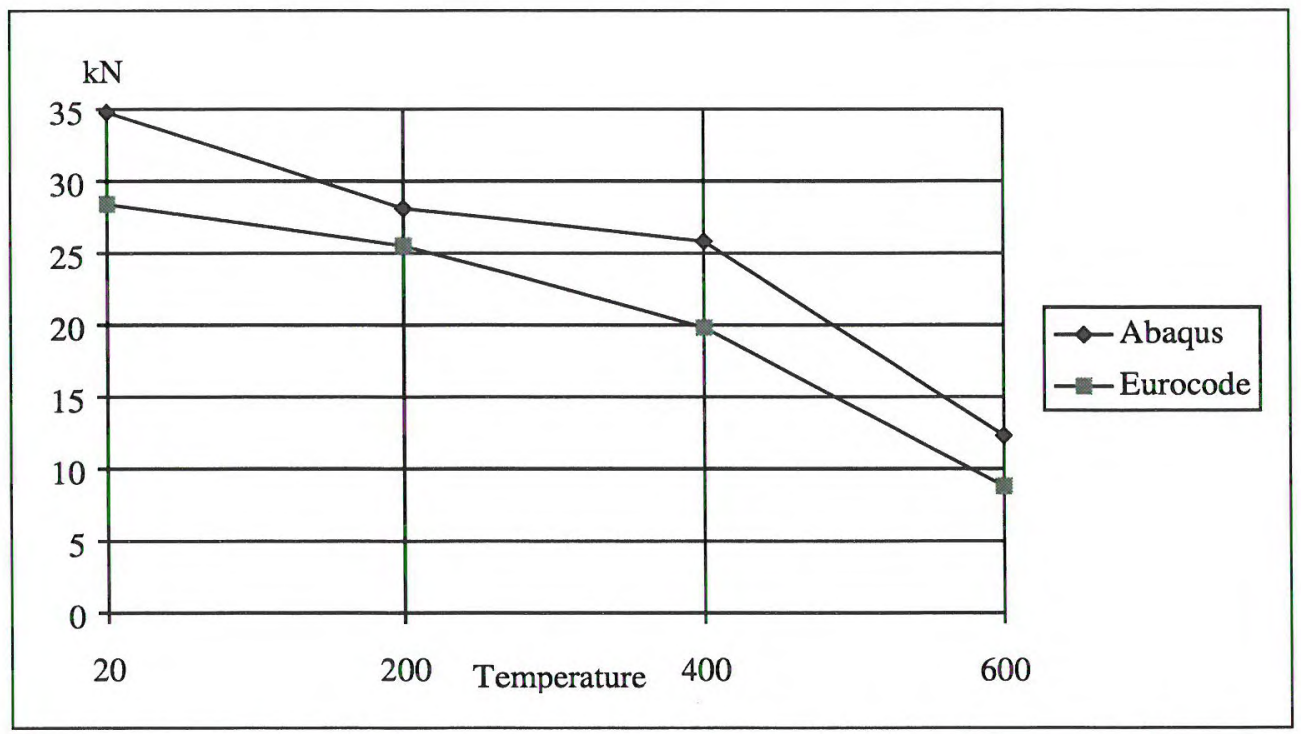

Figure D.4 Ultimate load - temperature relationship due to torsional-flexural buckling of the C-section, $b_{w}=200 \mathrm{~mm}, b_{f}=40 \mathrm{~mm}, b_{c}=15 \mathrm{~mm}$ and $\mathrm{t}=1,5 \mathrm{~mm}$. 


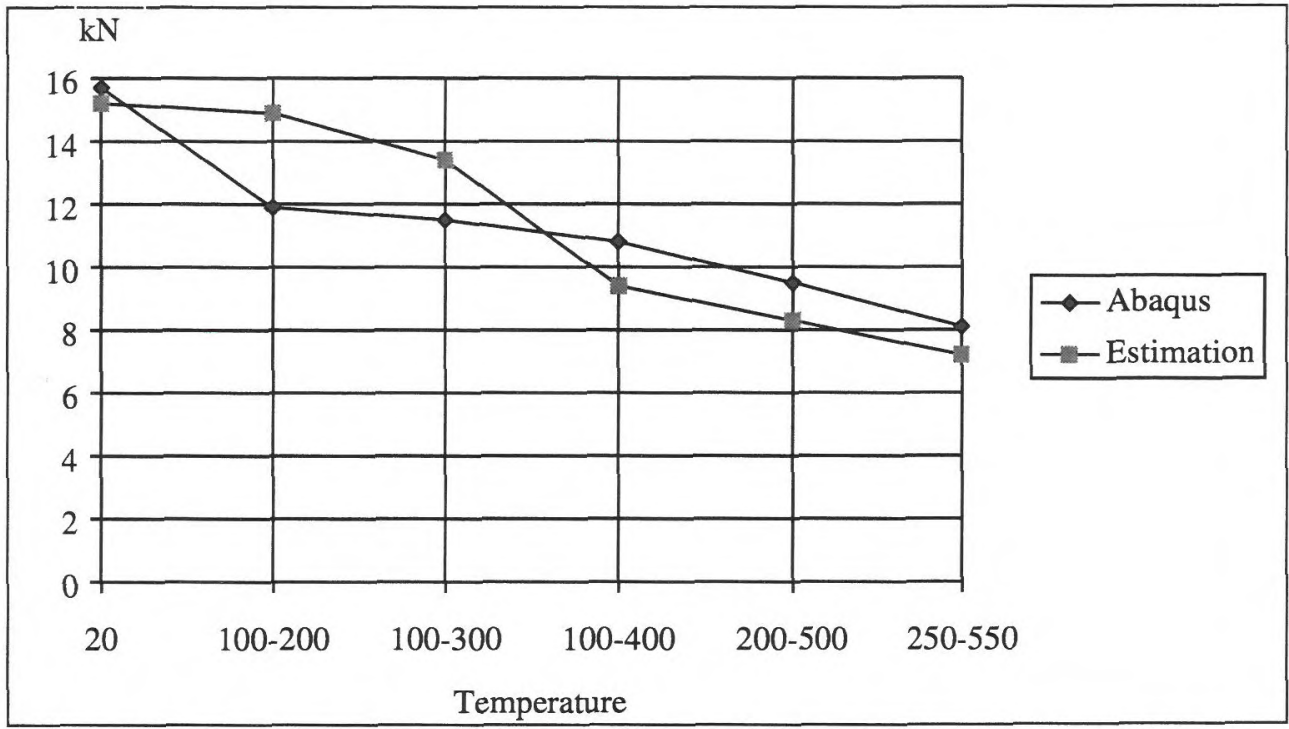

Figure D.5 Ultimate load - temperature relationship due to torsional-flexural buckling of the C-section, $b_{w}=100 \mathrm{~mm}, b_{f}=40 \mathrm{~mm}, b_{c}=15 \mathrm{~mm}$ and $t=1,0 \mathrm{~mm}$.

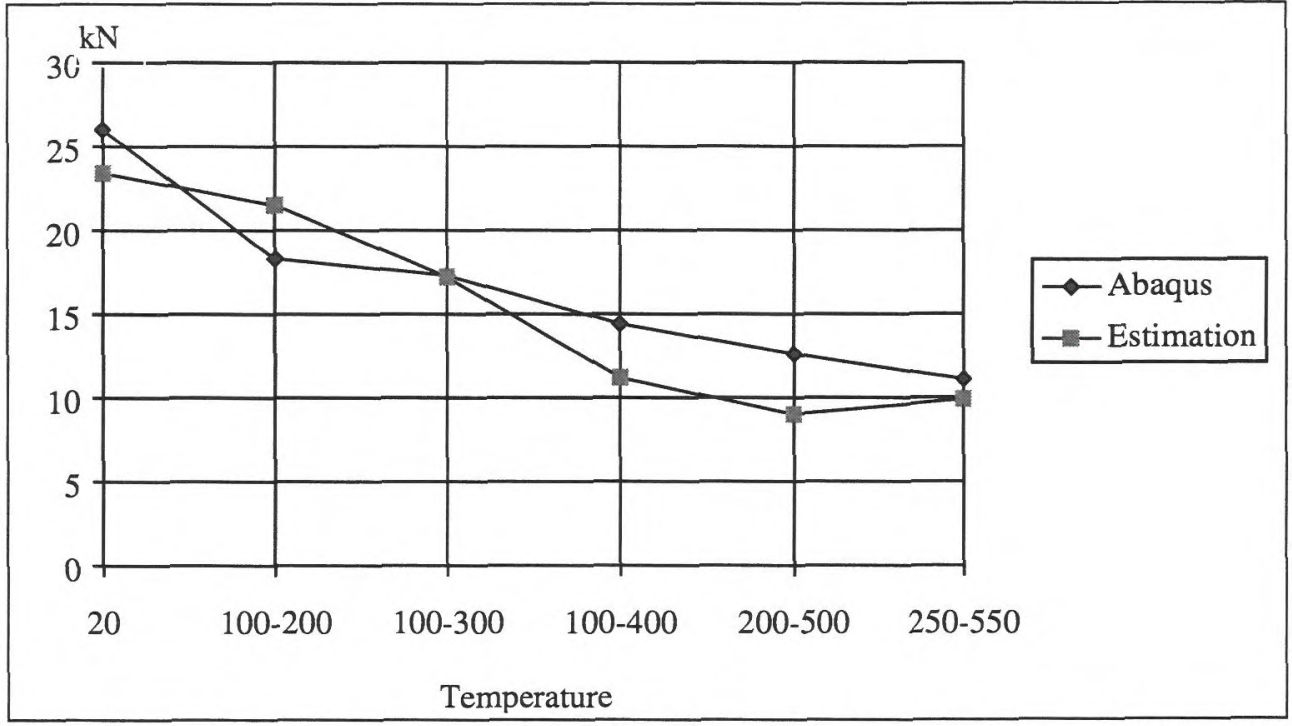

Figure D.6 Ultimate load - temperature relationship due to torsional-flexural buckling of the C-section, $b_{w}=100 \mathrm{~mm}, b_{f}=40 \mathrm{~mm}, b_{c}=15 \mathrm{~mm}$ and $\mathrm{t}=1,5 \mathrm{~mm}$. 


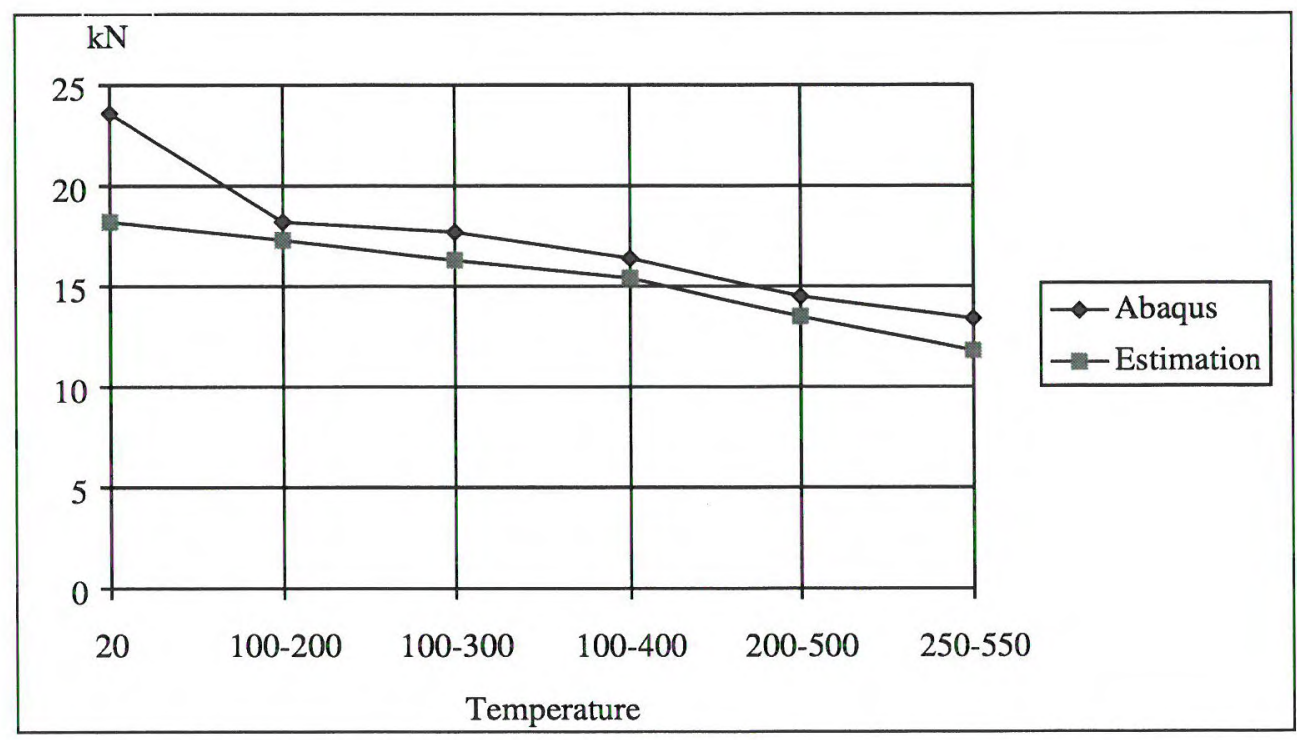

Figure D.7 Ultimate load - temperature relationship due to torsional-flexural buckling of the C-section, $b_{w}=200 \mathrm{~mm}, b_{f}=40 \mathrm{~mm}, b_{c}=15 \mathrm{~mm}$ and $t=1,0 \mathrm{~mm}$.

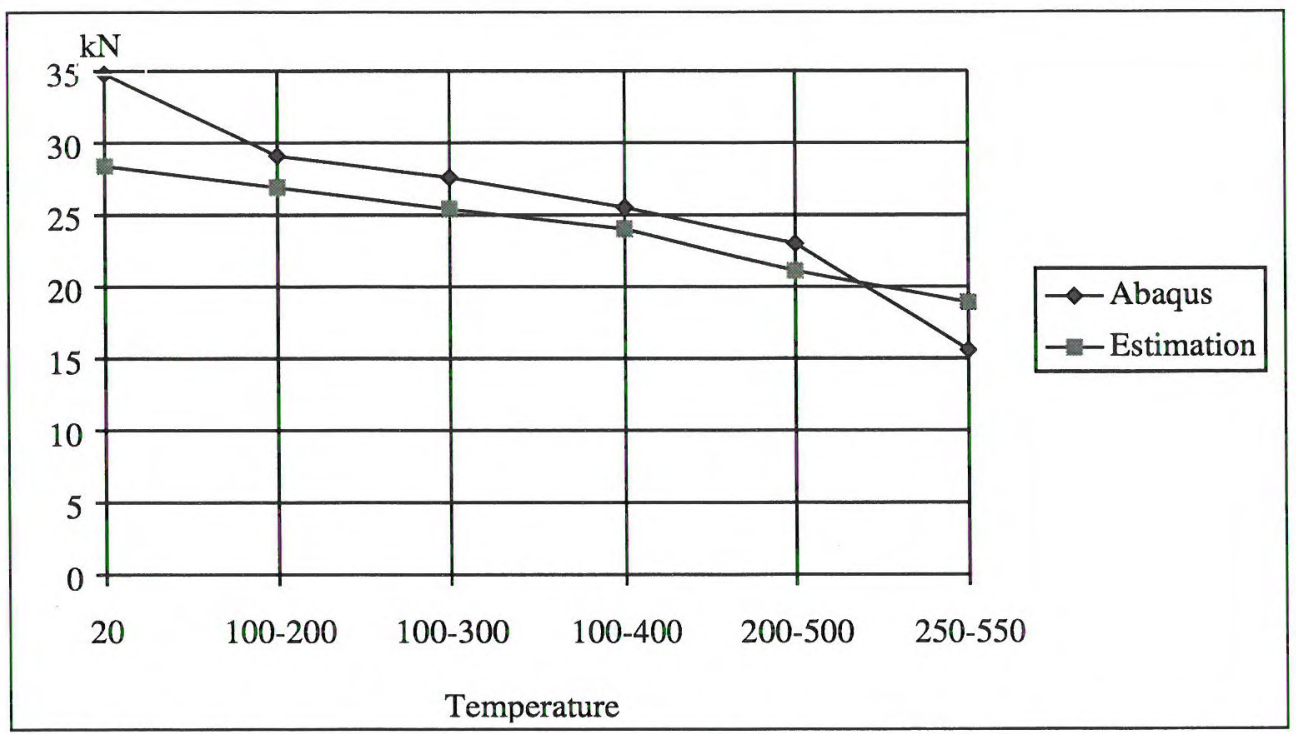

Figure D.8 Ultimate load - temperature relationship due to torsional-flexural buckling of the C-section, $b_{w}=200 \mathrm{~mm}, b_{f}=40 \mathrm{~mm}, b_{c}=15 \mathrm{~mm}$ and $\mathrm{t}=1,5 \mathrm{~mm}$. 


\section{APPENDIX E}

\section{Relationship of ultimate load - temperature due to flexural buckling by different design models.}

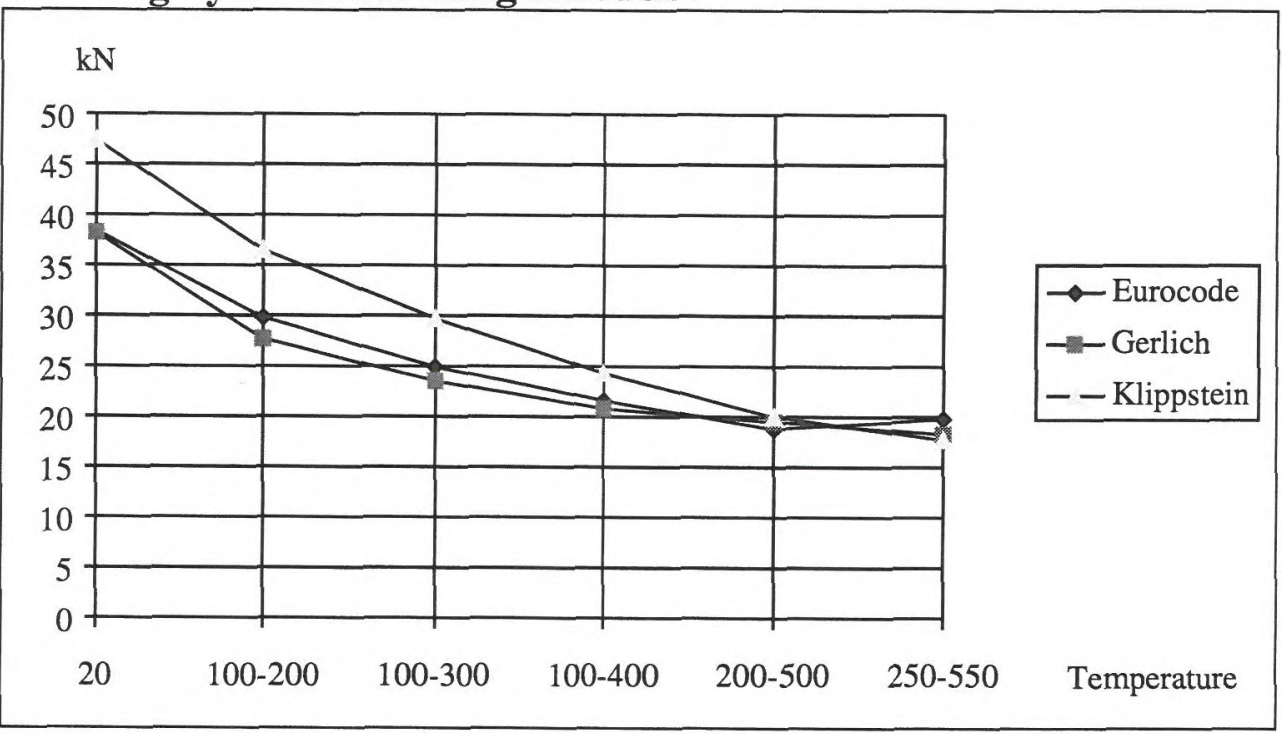

Figure E.1 Ultimate load - temperature relationship due to flexural buckling by different design models, C-section, $b_{w}=100 \mathrm{~mm}, b_{f}=40 \mathrm{~mm}, b_{c}=15 \mathrm{~mm}$ and $t=1,0 \mathrm{~mm}$.

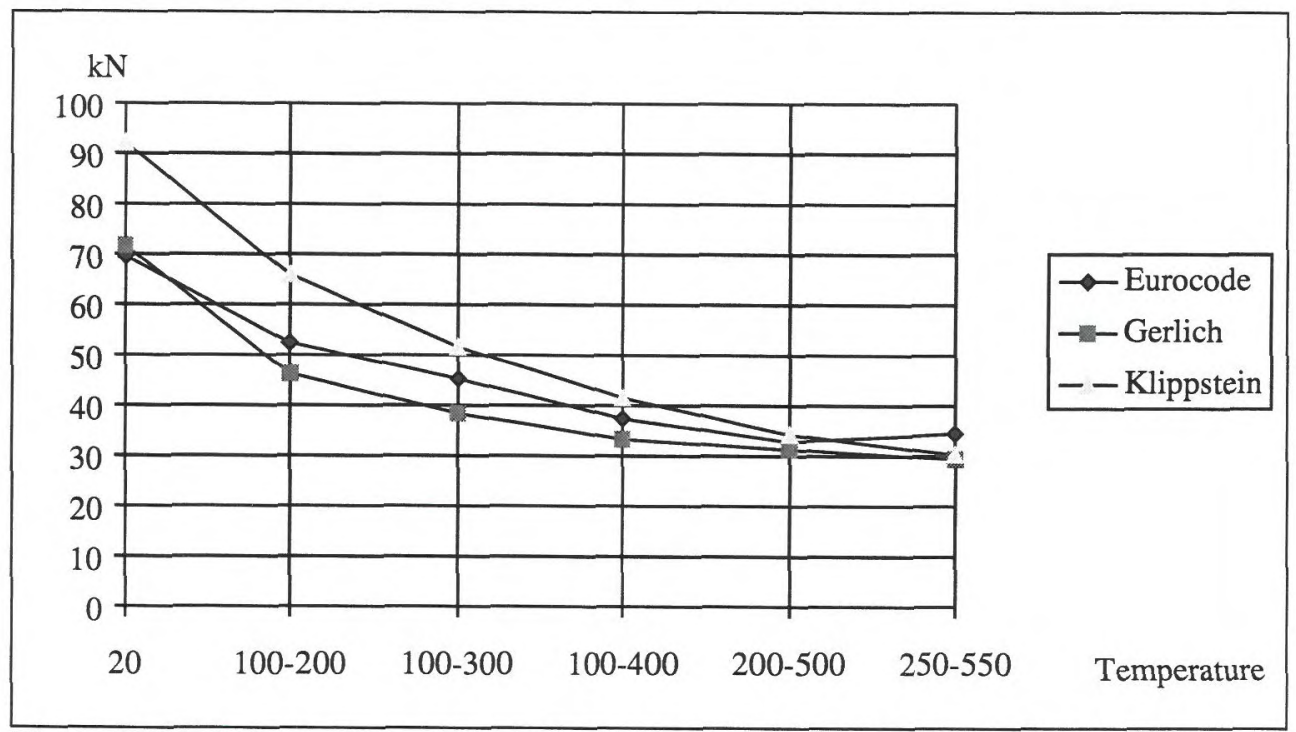

Figure E.2 Ultimate load - temperature relationship due to flexural buckling by different design models, C-section, $b_{w}=100 \mathrm{~mm}, b_{f}=40 \mathrm{~mm}, b_{c}=15 \mathrm{~mm}$ and $t=1,5 \mathrm{~mm}$. 


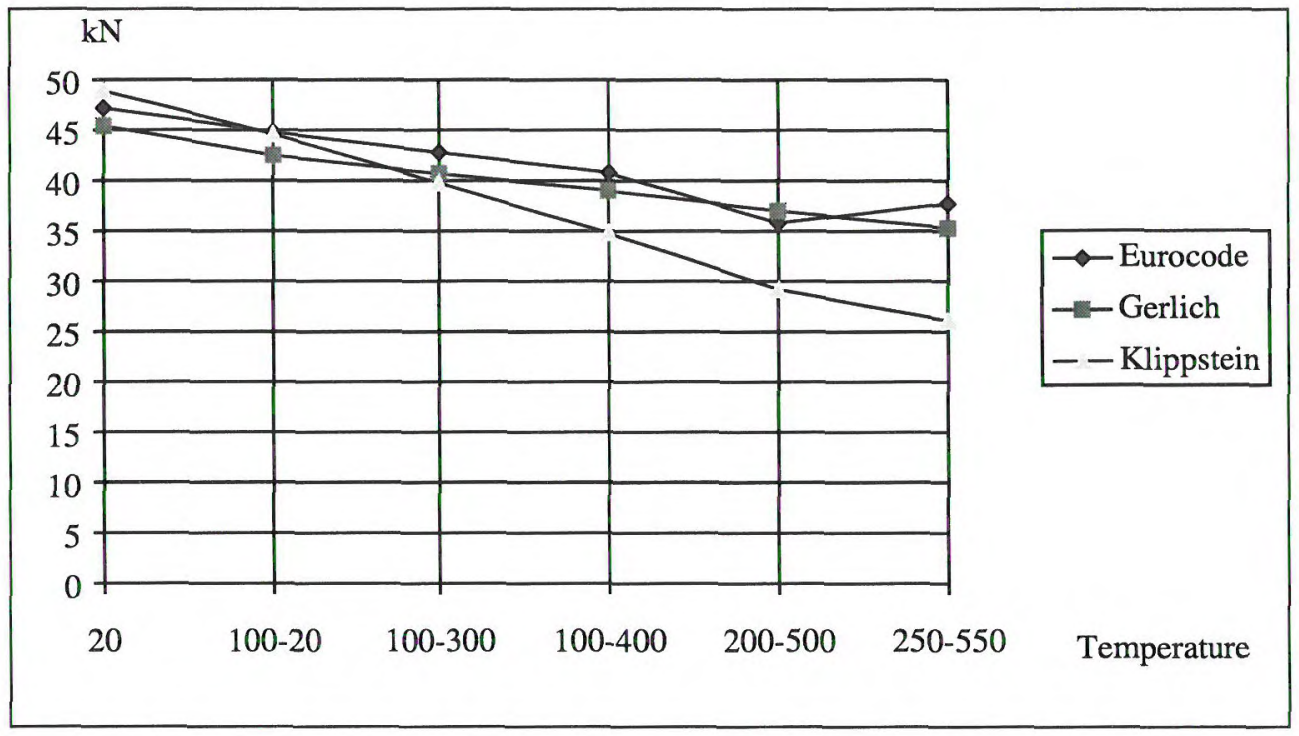

Figure E.3 Ultimate load - temperature relationship due to flexural buckling by different design models, C-section, $b_{w}=200 \mathrm{~mm}, b_{f}=40 \mathrm{~mm}, b_{c}=15 \mathrm{~mm}$ and $t=1,0 \mathrm{~mm}$.

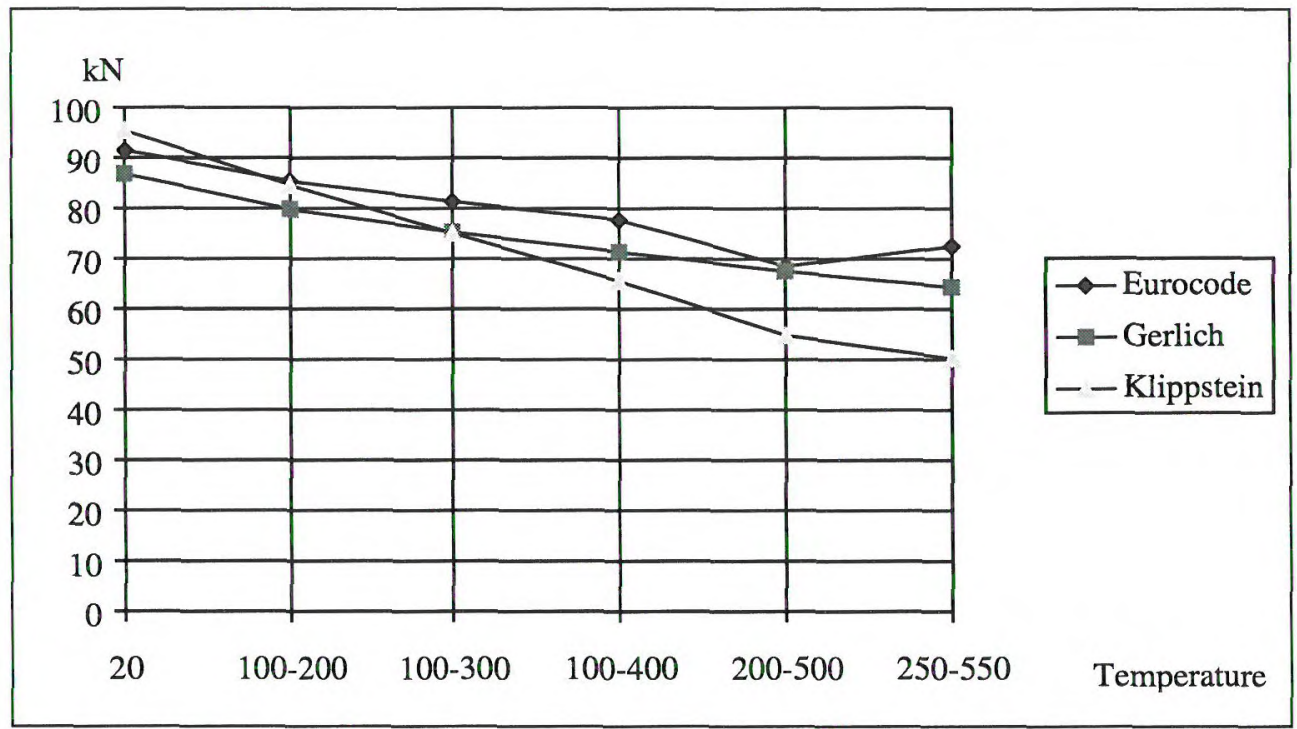

Figure E.4 Ultimate load - temperature relationship due to flexural buckling by different design models, C-section, $b_{w}=200 \mathrm{~mm}, b_{f}=40 \mathrm{~mm}, b_{c}=15 \mathrm{~mm}$ and $t=1,5 \mathrm{~mm}$. 


\section{APPENDIX F}

Input files used in non-linear analysis with Abaqus version 5.6 to version $5.8,(5)$.

\begin{tabular}{|c|c|c|c|c|}
\hline Directory & File name & Supplementary files & $\begin{array}{l}\text { Failure } \\
\text { mode }\end{array}$ & Chap \\
\hline$/ \mathrm{CD} / \mathrm{t}=0,8 /$ non & pr-1-1gl.inp & $\begin{array}{l}\quad \text { pr-1-1.fil } \\
\text { Fig-pr-3-1gl-1.gif } \\
\text { Fig-pr-3-1gl-2.gif } \\
\text { Fig-pr-3-1gl-3.gif }\end{array}$ & $\begin{array}{c}\text { local } \\
\text { buckling }\end{array}$ & 3 \\
\hline$/ \mathrm{CD} /=2.5 / \mathrm{non}$ & pr-1-1lg2.inp & $\begin{array}{c}\text { profill-gimp2.data } \\
\text { pr-1-1.fil }\end{array}$ & $\begin{array}{l}\text { flexural } \\
\text { buckling }\end{array}$ & 4 \\
\hline $\begin{array}{c}\text { CD/ } /=2.5-\mathrm{ltb} / \\
\text { non-var }\end{array}$ & $\begin{array}{l}\mathrm{pr}-2 \mathrm{n}-1 \mathrm{~mm}- \\
40 \mathrm{~min} . \mathrm{inp}\end{array}$ & $\begin{array}{l}\text { IMP-10-tot-plbuck-fin.nodes } \\
\text { MAT-T100.data } \\
\text { MAT-T150.data supp1.nodes } \\
\text { MAT-T200.data supp2.nodes }\end{array}$ & $\begin{array}{l}\text { torsional- } \\
\text { flexural } \\
\text { buckling }\end{array}$ & 5 \\
\hline /CD/slit/provA & $\begin{array}{l}\text { Comp-imp- } \\
\text { glvloc-gips.inp }\end{array}$ & $\begin{array}{l}\text { Fig-Comp-imp-glvloc-gips-2.gif nodes-extra } \\
\text { Fig-Comp-imp-glvloc-gips-3.gif nodes-glv-imp } \\
\text { Fig-Comp-imp-glvloc-gips-1.gif buck1.fil }\end{array}$ & $\begin{array}{c}\text { local } \\
\text { buckling }\end{array}$ & 4 \\
\hline /CD/slit/provC & $\begin{array}{l}\text { comp-imp- } \\
\text { glvloc-led.imp }\end{array}$ & $\begin{array}{l}\text { kant-smal kant-bred kant-glvloc-led.fil } \\
\text { fig-com-imp-glvloc-led-1.gif nodes } 45 \\
\text { fig-com-imp-glvloc-led-3.gif nodes-extra } \\
\text { fig-com-imp-glvloc-led-s.gif }\end{array}$ & $\begin{array}{l}\text { torsional- } \\
\text { flexural } \\
\text { buckling }\end{array}$ & 5 \\
\hline
\end{tabular}




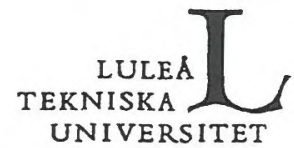

Institution/Department

\begin{tabular}{r|l|} 
NR & $1999: 05$ \\
& $1402-1757$ \\
& $\angle \pi 2-\angle 1 C--99 / 5-5 E$ \\
\cline { 2 - 3 }
\end{tabular}

Väg- och Vattenbyggnad/Civil and Mining Engineering

Avdelning/Division

Upplaga/Number of copies

Stålbyggnad/Steel Structures

150

Datum/Date

1999-01-15

Titel/Title

Structural Fire Design of Thin Walled Steel Sections

Författare/Author(s)

Anders Ranby

Uppdragsgivare/Commissioned by

Stålbyggnadsinstitutet

Styrelsen för Svensk Brandforskning

$S S A B$ Tunnplåt $A B$

Plannja $A B$

Gasell Profil $A B$

Lindab Profil AB

Gyproc Group AB

Knauf Danogips A/S
Typ/Type

0 Doktorsavhandling/PhD thesis

(x) Licentiatuppsats/Licentiate thesis

0 Forskningsrapport/Research report

0 Teknisk rapport/Technical report

0 Examensarbete/Final project report

0 Övrig rapport/Other report

Språk/Language

0 Svenska/Swedish (x) Engelska/English 0

Sammanfattning, högst 150 ord/Abstract, $\max 150$ words

The aim of the thesis is to study the structural fire behaviour of thin walled steel sections; to find the actual steel temperature; how it varies across the steel sections and the phenomena of local buckling at elevated steel temperatures. The flexural buckling and torsional-flexural buckling load bearing resistance has also been studied. With this information a method to design thin walled steel columns at elevated temperature has been developed.

The proposed model presented in the thesis is the result of an analysis of the different phenomena, deciding the load bearing resistance of thin walled steel columns at elevated temperature verified by numerical $\mathrm{FE}$ analysis.

The conclusion is that the yield point can be taken as the conventional 0,2 per cent proof stress, and empirical expressions in codes can be used, when designing the load resistance of thin walled steel columns in case of fire.

Nyckelord, högst $8 /$ Keywords, max 8

Structural fire design, thin walled steel section, class 4 cross section, initial deflection, local buckling, flexural buckling, lateral-flexural buckling, torsional-flexural buckling

Underskriff av gpanskare/handledare / Signature of examinator/supervisor 


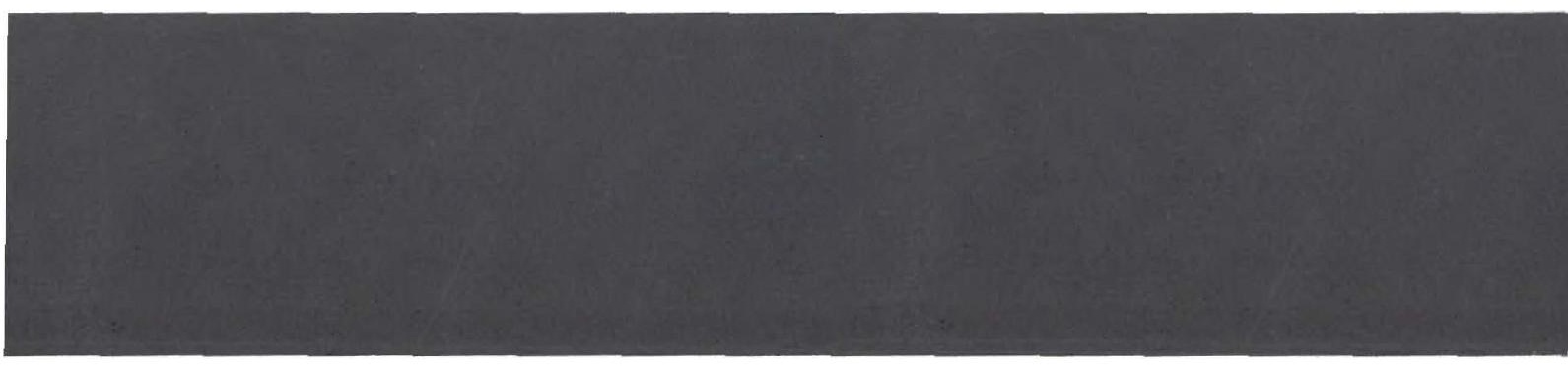

Universitctseryckeriet. Luleá 